\title{
Untersuchungen über Chlorophyll;
}

von Richard Willstätter.

[Mitteilung ans dem chemischen Laboratorium des Schweizerischen Polytechnikums in Zürich.]

\section{XII. Über Phytol I;}

von Richard Willstätter, Erwin W. Mayer und Ernst Ilüni.

(Eingelaufen am 10. Oktober 1910.)

\section{Theoretischer Teil.}

Das Phytol ist als eine alkoholische Komponente des Phäophytins vor einigen Jahren aufgefunden worden. Nach den mitgeteilten Untersuchungen enthält das Chlorophyll stets das Phytol und der Gehalt beträgt konstant fast $1 / 3$ des Moleküls. Über die Konstitution des Phytols hat die erste Beschreibung ${ }^{1}$ ) soviel ergeben, daß es der Zusammensetzung $\mathrm{C}_{20} \mathrm{H}_{40} \mathrm{O}$ entspricht und daß es ein ungesättigter primärer Alkohol der Fettreihe mit verzweigter Kohlenstoff kette ist.

Die Spaltung des Phytols am Ort der Doppelbindung haben wir nach zwei verschiedenen Methoden mit dem gleichen Ergebnisse ansgeführt. Durch die Einwirkung von Chromsäure wie von Ozon wird Phytol abgebaut zu einem Keton $\mathrm{C}_{15} \mathrm{H}_{30} \mathrm{O}$, destilliertes Phytol aber zu einem Keton $\mathrm{C}_{13} \mathrm{H}_{26} \mathrm{O}$. Somit unterscheiden sich rohes und destilliertes, die als $\alpha$ - und $\beta$-Phytol bezeichnet werden sollen, durch den Ort der Äthylenbindung, er liegt zwischen dem 5. und 6. Kohlenstoffatom

$$
\left(\mathrm{C}_{: 4} \mathrm{H}_{30}\right) \mathrm{C}=\mathrm{C}\left(\mathrm{C}_{3} \mathrm{H}_{7}\right) \mathrm{CH}_{2} \mathrm{OH}
$$

beim natürlichen Phytol, zwischen dem 7. und 8.

$$
\left(\mathrm{C}_{12} \mathrm{H}_{96}\right) \mathrm{C}=\mathrm{C}\left(\mathrm{C}_{5} \mathrm{H}_{11}\right) \mathrm{CH}_{2} \mathrm{OH}
$$

nach der Umlagerung durch die Destillation.

1) R. Willstätter und F. Hocheder, diese Annalen 354, 205 (1907). 


\section{Abbau mit Chromsäure.}

Leicht und glatt wird der ungesättigte Alkohol an der Stelle der Doppelbindung von Chromsäure angegriffen. Von verschiedenen Anwendungsformen des Oxydationsmittels haben wir namentlich zwei Verfahren in vielen Fällen vorteilhaft gefunden: Die Behandlung mit Chromtrioxyd unter Zusatz von konz. Schwefelsäure in Fisessig, oder mit Chromtrioxyd in Eisessig bei Gegenwart von Kaliumbisulfat. Die letztere Methode gibt uns die einfachsten Resultate und die reinsten Oxydationsprodukte.

Das Hauptprodukt der Oxydation von $\alpha$-Phytol ist das Methylketon $\mathrm{C}_{15} \mathrm{H}_{30} \mathrm{O}$, das in einer Ausbeute von über $3 / 4$ der Theorie auftritt; dabei verbrauchen die abgespaltenen fünf Kohlenstoffatome viel Sauerstoff. Untergeordnet entsteht durch die Oxydation der Carbinolgruppe zum Carboxyl die dem Phytol entsprechende Säure $\mathrm{C}_{20} \mathrm{H}_{38} \mathrm{O}_{2}$, Phytensäure, und zwar nach dem Chromtrioxyd-Bisulfatverfahren in reinem Zustande. Die meisten anderen Bedingungen der Oxydation führen zu einem größeren Anteil an Säure, aber zu einem Gemisch von Phytensäure und einer gesättigten Säure von niederer Kohlenstoffatomzahl.

An anderer Stelle wird die durch viele tertiäre Kohlenstoffatome empfindliche Kette gespalten, wenn man zuerst durch Vermittelung des Dibromids Hydroxyle an Phytol addiert und dann Chromsäure anwendet. So entsteht ein Methylketon $\mathrm{C}_{11} \mathrm{H}_{22} \mathrm{O}$, das dem ersten Keton sehr ähnlich ist und die Säure $\mathrm{C}_{14} \mathrm{H}_{28} \mathrm{O}_{2}$, welche auch aus dem Keton $\mathrm{C}_{15} \mathrm{H}_{30} \mathrm{O}$ anf dem Wege über das Olefin $\mathrm{C}_{15} \mathrm{H}_{30}$ und sein Glykol hervorgeht. Die Säure $\mathrm{C}_{14} \mathrm{H}_{28} \mathrm{O}_{2}$ liefert dann mit Chromsäure noch ein gleichartiges Methylketon $\mathrm{C}_{13} \mathrm{H}_{26} \mathrm{O}$ und wieder eine Säure $\mathrm{C}_{12} \mathrm{H}_{24} \mathrm{O}_{2}$. Dieses Keton $\mathrm{C}_{13} \mathrm{H}_{28} \mathrm{O}$ tritt auch zugleich mit einer Säure $\mathrm{C}_{10} \mathrm{H}_{20} \mathrm{O}_{2}$ bei der Oxydation des Methylketons $\mathrm{C}_{15} \mathrm{H}_{30} \mathrm{O}$ mit Chromsäure auf. Auch ist es mit dem $\mathrm{Ab}$ bauprodukt identisch, das aus $\beta$-Phytol mit Chromsäure 
gebildet wird. Die folgende Tabelle stellt diese Ergebnisse der Oxydation zusammen.

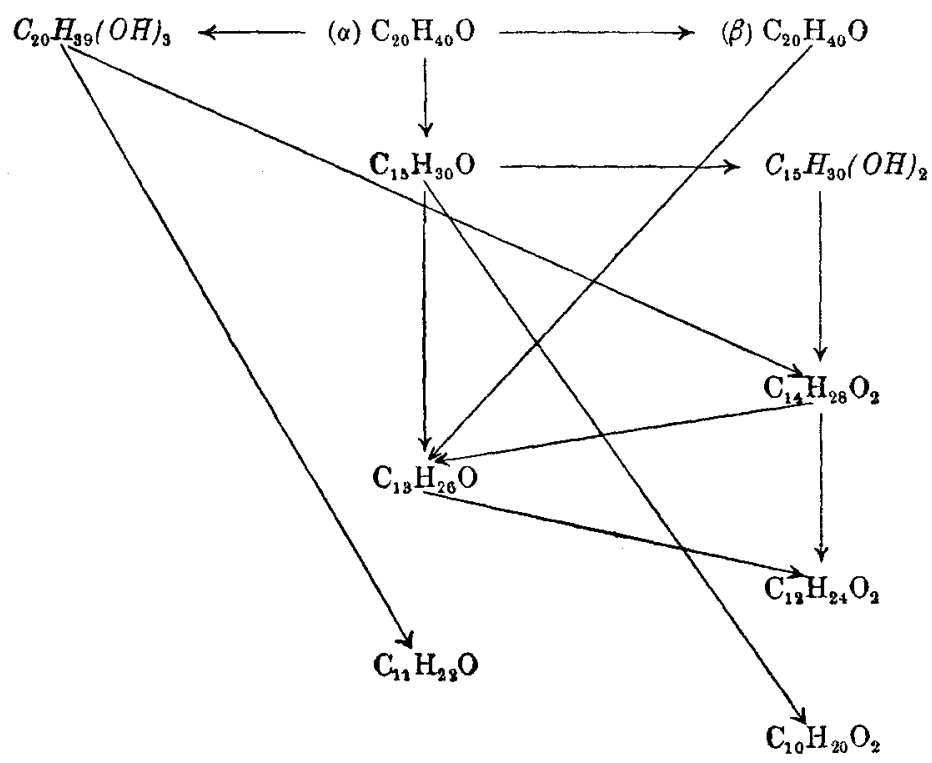

Abbau mit Ozon.

Die Methode der Ozonidspaltung von C. Harries ${ }^{1}$ ) hat die Möglichkeiten der Oxydation ungesättigter Verbindungen wesentlich bereichert. Die Methode war uns für die Oxydation der Phytole wertvoll, um auf mehr als einem Wege den Ort ihrer Doppelbindungen festzustellen. Außerdem haben wir die Ozonmethode auch für den Abbau des Methylketons $\mathrm{C}_{15} \mathrm{H}_{30} \mathrm{O}$ angewandt, indessen nicht mit so einfachen Resultaten, wie sie ein ungesättigtes Ausgangsmaterial gibt.

Die Phytolozonide

$$
\begin{aligned}
& \mathrm{C}_{20} \mathrm{H}_{40} \mathrm{O} . \mathrm{O}_{4}, \\
& \mathrm{C}_{20} \mathrm{H}_{40} \mathrm{O} . \mathrm{O}_{3}, \\
& \mathrm{C}_{20} \mathrm{H}_{40} \mathrm{O} . \mathrm{O}_{2}
\end{aligned}
$$

zeigen Bemerkenswertes, so genan auch das Bild der

1) Diese Annalen 343, 311 (1905) und 374, 288 (1910). 
Ozonide bereits in den schönen Arbeiten von Harries gezuichnet worden ist.

Das Rohozonid weist bei nicht $z$ langem $0 z o n i s i e r e n$ die Znsammensetzung $\mathrm{O}_{20} \mathrm{H}_{40} \mathrm{O}_{4}$ auf, aber es ist nicht einheitlich. Ein großer Teil ist leicht löslich in $\mathrm{Hol}$ \%geist, der kleinere darin unlöslich. Las lösliche Oronid ist sauerstoffreicher, gehört also zu den Oxozoniden, die von Harries ${ }^{1}$ ) und seinen Mitarbeitern und ron 0 . Diels ${ }^{2}$ ) bei Olefinen und Cycloolefinen beobachtet worden sind. Es ist interessant, dab das Oxozonid bei monatelangem Stehen im Vakuumexsiccator ein Atom Sauerstoff verliert, so daß die Verbindung im Zustand der Gewichtskonstanz der Formel mit drei Atomen addierten Samerstoffs entspricht.

Eine neue Erscheinung bei der Einwirkung von Ozon ist die Bildung des Moloxydes $\mathrm{C}_{20} \mathrm{H}_{40} \mathrm{O} 0 . \mathrm{O}_{z}$, das im holzgeistunlöslichen Teil des Rohozonids vorliegt. Im Verhalten and im Zerfall beim Verkochen unterscheidet es sich nicht von den anderen Sauerstoffverbindungen.

Die Ozonide von $\alpha$-Phytol liefern beim Verkochen das Keton $\mathrm{C}_{15} \mathrm{H}_{30} \mathrm{O}$ and in untergeordneter Menge die Säure $\mathrm{C}_{14} \mathrm{H}_{28} \mathrm{O}_{2}$, ans destilliertem Phytol entsteht anf gleiche Weise das Keton $\mathrm{C}_{13} \mathrm{H}_{26} \mathrm{O}$. Das erste Keton wird durch Einwirkung von Ozon and Hydrolyse der gebildeten Peroxyde je nach der Arbeitsweise abgebaut zu den Nethylketonen $\mathrm{C}_{13} \mathrm{H}_{26} \mathrm{O}, \mathrm{C}_{11} \mathrm{H}_{22} \mathrm{O}$ and $\mathrm{C}_{9} \mathrm{H}_{18} \mathrm{O}$, neben welchen die Säure $\mathrm{C}_{12} \mathrm{H}_{24} \mathrm{O}_{2}$ auftritt. Die Sänre $\mathrm{C}_{14} \mathrm{H}_{28} \mathrm{O}_{2}$ entsteht mit Ozon zwar nicht direkt aus dem Keton $\mathrm{C}_{15} \mathrm{H}_{30} \mathrm{O}$, aber aus dem durch Reduktion zum sekundären

1) C. Harries und H. Neresheimer, Ber. d. d. chem. Ges. 39, 2846 (1906) und 11, 38 (1908); C. Harries und A. Himmelmann, ebenda 41, 2198 (1908); C. Harries und H. r. SplawaNeymann, cbenda 41, 350̃2 (1908); C. Harries und K. Häffner, ebonda 41, 3098 (1905); diese Annalen 374, 331 (1910); C. Harries und R. Koetsehau, Ber. d. d. chem. Ges. 42, 3305 (1909); K. Langheld, ebenda 41, 1023 (1908).

2) Ber. d. d. chem. Ges. 41, 2596 (1908). 
Alkohol and Wasserabspaltung erhaltenen Olefin $\mathrm{C}_{15} \mathrm{H}_{30}$. Sie wird bei dieser Bildnng von der Säure $\mathrm{C}_{10} \mathrm{H}_{20} \mathrm{O}_{2}$ begleitet.

(a)

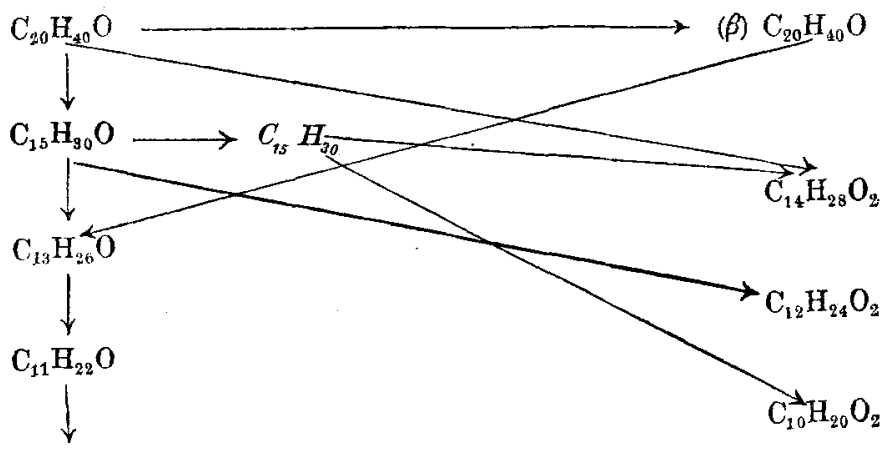

$\mathrm{C}_{9} \mathrm{H}_{18} \mathrm{O}$

Außer den normalen Spaltungsproduktedern Ozonide und Peroxyde begegnen wir eigentümlichen Nebenprodukten.

Der Zerfall der $\alpha$-Phytolozonide läbt immer in kleiner Menge einen gesättigten Kohlenwasserstoff, $\mathrm{C}_{15} \mathrm{H}_{32}$, entstehen. Die Hydrolyse hat an das größere Spaltungsstück des Phytols zwei Atome Wasserstoff gefügt, und der addierte Sauerstoff ist entweder gänzlich vom kleineren Bruchstück verbraucht oder z. T. entbunden worden, sei es molekular oder in Form von Hydroperoxyd:

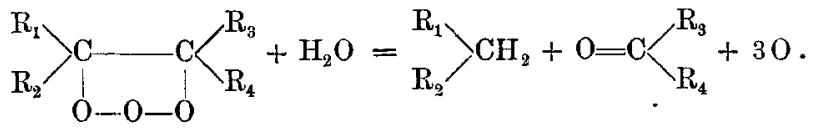

Das Olefin $\mathrm{C}_{15} \mathrm{H}_{30}$, dessen Doppelbindung gemäß der Oxydation seines Glykols zur Säure $\mathrm{C}_{14} \mathrm{H}_{28} \mathrm{O}_{2}$ am Ende der Kette steht, zerfällt beim Verkochen des Ozonides nur zum kleineren Teil (Schema I) zwischen den mit Sauerstoff beladenen Kohlenstoffatomen, überwiegend aber an einer gesättigten Stelle (Schema II).

I. $\begin{aligned} \mathrm{C}_{13} \mathrm{H}_{27}-\underset{\mathrm{I}}{\mathrm{CH}}-\mathrm{CH}_{2} \rightarrow \mathrm{C}_{13} \mathrm{H}_{27}-\mathrm{CO}_{2} \mathrm{H} \\ \mathrm{O}-\mathrm{O}-\mathrm{O}\end{aligned}$ 
II. $\mathrm{C}_{9} \mathrm{H}_{19}-\mathrm{CH}-\mathrm{CH}-\mathrm{CH}-\mathrm{CH}_{2} \rightarrow \mathrm{C}_{9} \mathrm{H}_{19}-\mathrm{CO}_{2} \mathrm{H}$

Dabei tritt die Säure $\mathrm{C}_{10} \mathrm{H}_{20} \mathrm{O}_{2}$ in eigentümlicher Form auf, nämlich mit dem entsprechenden primären Alkohol verestert.

Diesen Alkohol $\mathrm{C}_{10} \mathrm{H}_{21} \mathrm{OH}$ beobachtet man auch in der Form seines $\ddot{A}$ thers bei vielen Spaltungen in kleiner Menge, so bei der Einwirkung von Ozon auf das Keton $\mathrm{C}_{15} \mathrm{H}_{30} \mathrm{O}$ und auch bei dessen Oxydation mit Chromsäure.

\section{Die Oxydationsprodukte.}

Die wichtigsten Abbauprodukte des Phytols, indifferente und sauere, gehören zwei homologen Reihen an. Eine Reihe umfaßt die Ketone; von ihnen sind die Glieder mit 15 und 13 Kohlenstoffatomen rein erhalten und genau untersucht worden, die Verbindungen mit 11 und 9 Kohlenstoffatomen schwerer zugänglich geblieben und nicht ebenso sicher bearbeitet. Die Ketone entstehen nach folgenden Methoden:

$\mathrm{C}_{15} \mathrm{H}_{30} \mathrm{O}$ aus $a$-Phytol mit Chromsäure oder durch die Ozonictspaltung,

$\mathrm{C}_{13} \mathrm{H}_{28} \mathrm{O}$ ans $\beta$-Phytol mit Chromsäure oder durch die Ozonidspaltung, aus dem Keton $\mathrm{C}_{15} \mathrm{H}_{30} \mathrm{O}$ mit Chromsäure oder Ozon, aus der Säure $\mathrm{C}_{14} \mathrm{H}_{28} \mathrm{O}_{2}$ mit Chromsüure,

$\mathrm{C}_{11} \mathrm{H}_{22} \mathrm{O}$ aus Trioxyphytan mit Chromsäure und aus den Ketonen $\mathrm{C}_{15} \mathrm{H}_{30} \mathrm{O}$ und $\mathrm{C}_{13} \mathrm{H}_{28} \mathrm{O}$ mit Ozon, $\mathrm{C}_{9} \mathrm{H}_{18} \mathrm{O}$ aus den drei ersten Ketonen mit Ozon.

Diese Verbindungen sind Methylketone. Obwohl mit Hypobromit nur eine Spur Bromoform und durch Beckmannsche Umlagerung nur wenig Methylamin entsteht, wird die Acetylgruppe im Keton $\mathrm{C}_{15} \mathrm{H}_{30} \mathrm{O}$ ladurch bewiesen, daß es sich auf dem Wege über den Alkohol, das Olefin und dessen Glykol mit Chromsäure zur Säure $\mathrm{C}_{14} \mathrm{H}_{28} \mathrm{O}_{2}$ abbauen läßt nach folgenden Formeln:

$$
\begin{aligned}
& \mathrm{C}_{13} \mathrm{H}_{27} \mathrm{COCH}_{3} \rightarrow \mathrm{C}_{13} \mathrm{H}_{27} \mathrm{CH}(\mathrm{OH}) \mathrm{CH}_{3} \rightarrow \mathrm{C}_{13} \mathrm{H}_{27} \mathrm{CH}=\mathrm{CH}_{2} \rightarrow \\
& \mathrm{C}_{13} \mathrm{H}_{27} \mathrm{CH}(\mathrm{OH})-\mathrm{CH}_{2}(\mathrm{OH}) \rightarrow \mathrm{C}_{18} \mathrm{H}_{27} \mathrm{CO}_{2} \mathrm{H} \text {. }
\end{aligned}
$$

Die vier Ketone sind einander im Verhalten und in den physikalischen Eigenschaften überraschend ähnlich. 
Nach der Destillation bilden sie hellgelbgrünliche Öle, deren Farbe erst bei längerem Stehen verschwindet. Ihre Siedepunkte liegen sehr nahe beieinander, $\mathrm{C}_{11} \mathrm{H}_{22} \mathrm{O}$ siedet sogar eine Spur höher als $\mathrm{C}_{13} \mathrm{H}_{28} \mathrm{O}, \mathrm{C}_{9} \mathrm{H}_{18} \mathrm{O}$ kaum tiefer.

Daher erscheinen die Siedepunkte, namentlich der Ketone mit 9 und 11 Kohlenstoffatomen, obwohl sie viele Verzweigungen enthalten, weitaus zu hoch im Vergleich mit den normalen Methylketonen und mit niedrigeren verzweigten Methylketonen z. B. $\mathrm{CH}_{3}-\mathrm{CO}-\mathrm{CH}\left(\mathrm{CH}_{3}\right)-$ $\mathrm{CH}\left(\mathrm{CH}_{3}\right)_{2}$ vom Siedep. 135-140". Die Anomalie reiht sich an wenige Fälle der Literatur an, in denen homologe Reihen fallenden Siedepunkt aufweisen, z. B. die aliphatischen Säureamide und die $a$-Glykole.

Diese rätselhaft hohen Siedepunkte ${ }^{1}$ ), welche die Tabelle zusammenstellt, scheinen uns nur mit der experimentell zu prüfenden Annahme erklärlich, daß die Ketone nicht als Carbonylverbindungen, sondern als Enole vorliegen:

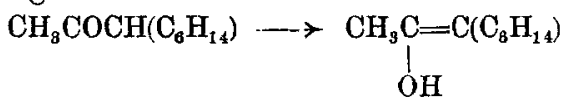

\begin{tabular}{|c|c|c|c|c|c|}
\hline Keton & $\begin{array}{l}\text { Siedepunkt im } \\
\text { Vakuum }\end{array}$ & $\begin{array}{l}\text { Siedep. } \\
\text { bei } \\
720 \mathrm{~mm}\end{array}$ & $d_{i}^{0}$ & $\begin{array}{l}\text { Sehmelzp. } \\
\text { des } \\
\text { Semicarb- } \\
\text { azons }\end{array}$ & $\begin{array}{l}\text { Siedep. } \\
\text { des entspr. } \\
\text { norm. } \\
\text { Methyl- } \\
\text { ketons }\end{array}$ \\
\hline $\mathrm{C}_{15} \mathrm{H}_{30} \mathrm{O}$ & $173-174^{\circ}(9 \mathrm{~mm})$ & $292^{\circ}$ & 0,853 & $64,5^{0}$ & $294^{\circ}$ \\
\hline $\mathrm{C}_{13} \mathrm{H}_{20} \mathrm{O}$ & $168-170 \quad(10 \mathrm{~mm})$ & $288-289^{\circ}$ & 0,865 & $62^{\circ}$ & $263^{\circ}$ \\
\hline $\mathrm{C}_{11} \mathrm{H}_{22} \mathrm{O}$ & $168-170 \quad(8 \mathrm{~mm})$ & - & - & $68-72^{\circ}$ & $232^{\circ}$ \\
\hline $\mathrm{C}_{9} \mathrm{H}_{18} \mathrm{O}$ & $168 \quad(10 \mathrm{~mm})$ & $282^{0}$ & 0,836 & $75^{\circ}$ & $195^{\circ}$ \\
\hline
\end{tabular}

Die zweite Reihe von Abbauprodukten der Phytole besteht aus gesättigten Fettsäuren, nämlich:

1) Auch bei einigen anderen Abbauprodukten des Phytols beobachten wir ungewöhnlich hohe Siedepunkte. Der Kohlenwasserstoff $\mathrm{C}_{15} \mathrm{H}_{82}$ z. B., der viele Methylgruppen entbält, siedet (261 bis $\left.263^{\circ}\right)$ nur $8^{\circ}$ niederer als sein normales Isomeres, und das Olefin $\mathrm{C}_{15} \mathrm{H}_{30}$ siedet $\left(290^{\circ}\right.$ ) sogar um fast $30^{\circ}$ höher als der gesättigte Kohlen w asserstoff. 
$\mathrm{C}_{14} \mathrm{H}_{28} \mathrm{O}_{2}$ aus $a$ - Phytol mit Ozon, aus Trioxyphytan mit Chromsäure und ans dem Olefin $\mathrm{C}_{15} \mathrm{H}_{80}$ nach der Ozonmethode oder über das Glykol mit Chromsäure;

$\mathrm{C}_{12} \mathrm{H}_{24} \mathrm{O}_{2}$ ans dem Keton $\mathrm{C}_{15} \mathrm{H}_{30} \mathrm{O}$ mit Ozon, aus $\mathrm{C}_{13} \mathrm{H}_{28} \mathrm{O}$ durch Chromsäure, aus der ersten Säure mit Chromsäure;

$\mathrm{C}_{10} \mathrm{H}_{20} \mathrm{O}_{2}$ aus dem Keton $\mathrm{C}_{15} \mathrm{H}_{30} \mathrm{O}$ mit Chromsäure, aus dem Ozonid des Olefins $\mathrm{C}_{15} \mathrm{H}_{30}$.

Keine von diesen Säuren krystallisiert, sie erinnern im Habitus noch an Phytol. Obwohl gegen Brom gesättigt, sind sie gegen Permanganat nur kurze Zeit beständig.

\section{Struktur des Phytols.}

Zwischen dem Carbinolrest und dem doppelt gebundenen Kohlenstoff des $\alpha$-Phytols liegen drei Kohlenstoffatome. Die dem Phytol entsprechende Phytensäure ist gemäß ihrer Umwandlung in das isomere $\gamma$-Lacton eine $\Delta^{2}$-Säure. Demnach stehen für die ersten fünf Kohlenstoffatome des Phytols nur drei Möglichkeiten zur Wahl:

I.<smiles>CCCCCC(C)C(C)C(C)CO</smiles>

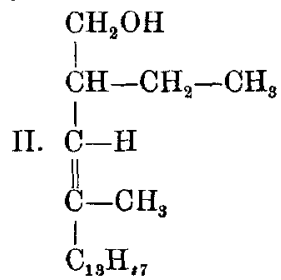

III.<smiles>CCC(CCO)=C(C)c1ccccc1</smiles>

Von diesen drei Formeln erscheint die mit Methylgruppen (I) als die wahrscheinlichste, weil anch die Kohlenstoffatome 7, 9, 11 und 13

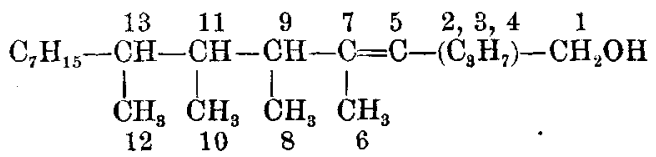

Methylgruppen tragen, die durch das Auftreten der Methylketone und der um je ein Kohlenstoffatom ärmeren Carbonsäuren nachgewiesen sind.

Mit dieser einen Wahrscheinlichkeitsannahme sind die Strukturformeln der beiden Phytole, die sich durch den Ort der Doppelbindung unterscheiden, folgendermaßen bestimmt: 


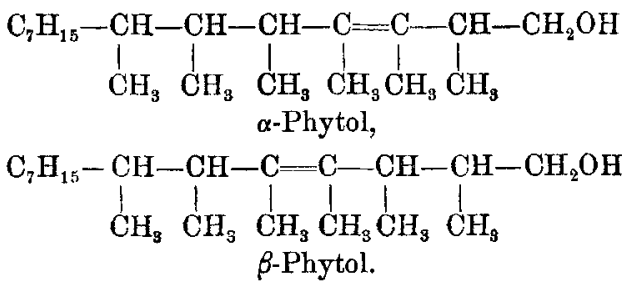

Soweit reichen für die sichere Kenntnis der Struktur die bisherigen Abbauversuche. Aber die niedrigsten Oxydationsprodukte erlauben noch Vermutangen über die Struktur des in diesen Formeln nicht aufgelösten Alphyls $\mathrm{C}_{7} \mathrm{H}_{15}$. Die Säure $\mathrm{C}_{9} \mathrm{H}_{19} \mathrm{CO}_{2} \mathrm{H}$ und das Keton $\mathrm{C}_{7} \mathrm{H}_{15} \mathrm{CO} . \mathrm{CH}_{3}$ sind in ihren Eigenschaften den höheren Homologen merkwürdig ähnlich und von den normalen Isomeren gan $z$ verschieden. Es ist daher wahrscheinlich, daß die Gruppe $\mathrm{C}_{7} \mathrm{H}_{15}$ viele Verzweigungen und zwar Methyle enthält. Und es erscheint uns als eine für die weitere Untersuchung des Phytols wegleitende Vermutung, daß dieses Alphyl dem Teile des Molekïls von bekannter Struktur ähnlich konstituiert ist, also noch vier Methyle enthält, gemäß folgender hypothetischer Formel für $\alpha$-Phytol:<smiles>CC(C)C(C)C(C)C(C)C(C)C(C)C(C)(C)C(C)C(C)C(C)CO</smiles>

Nach dieser Annahme denken wir uns das Phytol aus den gleichen Bausteinen zusammengesetzt wie aliphatische und cyclische Terpene and Kautschuk. Nämlich wie Geraniol und Limonen aus 2 Mol. Isopren aufgebaut sind, so erscheinen $4 \mathrm{Mol}$. Isopren kondensiert

$$
{ }_{4} \mathrm{C}_{5} \mathrm{H}_{8}+\mathrm{H}_{2} \mathrm{O}+3 \mathrm{H}_{2}=\mathrm{C}_{20} \mathrm{H}_{40} \mathrm{O}
$$

zum Phytol, vielleicht 8 Mol. zum Carotin ${ }^{1}$ von der Formel $\mathrm{C}_{40} \mathrm{H}_{56}$.

Wenn man allerdings aus Isoprensystemen das Gerüst des Phytols zusammensetzt, so lassen sich Widersprüche zu dem sicheren Inhalt unserer Phytolformel

1) R. Willstätter und W. Mieg, diese Annalen 3วō, 1 (1907). 
nur mit der Annahme einer Strukturverschiebung vermeiden, am einfachsten so, wie sie die folgende Skizze andentet:

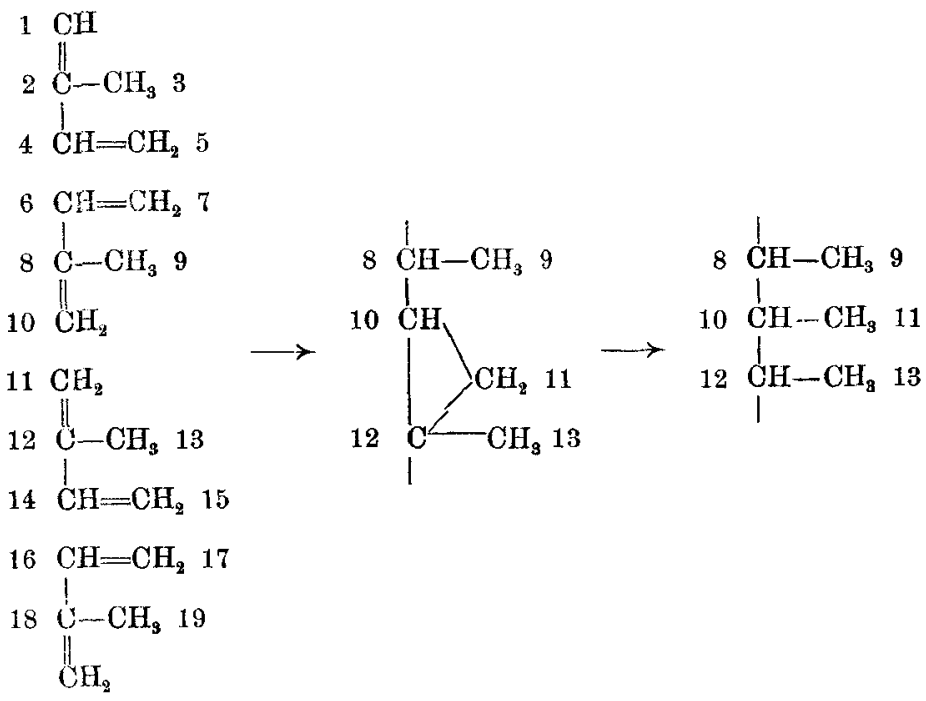

\section{Experimenteller Teil.}

I. Kapitel. Phytol und seine Derivate.

$\alpha$ - und $\beta$-Phytol.

Das Ausgangsmaterial für unsere Arbeit, $860 \mathrm{~g}$ Phytol, gewannen wir durch die Hydrolyse von $3 \mathrm{~kg}$ Phäophytin hauptsächlich aus Brennesseln, Gras und Holunder, nämlich aus ungefähr $1000 \mathrm{~kg}$ trockner Blätter. Wir führten die Verseifung nach dem Verfahren von Willstätter und Hocheder aus, mit den Abänderungen, die für die Bestimmung der Phytolzahl ${ }^{1}$ ) erprobt worden sind. Das Phytol wird nach der Verseifung mit siedender methylalkoholischer Kalilauge ohne Verdünnen mit Wasser durch Ausschütteln mit $̈$ ther und Dekantieren extrahiert; die ätherische Lösung wird zweimal mit sehr

1) R. Willstätter in Abderhaldens Handbuch der bio(heminehen Arbeitsmethoden, Bd. II, S. 705 und R. Willstätter, F. H 1. d.r and E. Hug, diese Annalen 371, 18 (1909). 
verdünnter Lauge und noch oftmals mit Wasser (nicht mit konz. Salzsäure) gewaschen, mit Natriumsulfat getrocknet und mit Tierkohle entfärbt.

Rohes und destilliertes Phytol enthalten die Doppelbindung an verschiedenem Ort und zeigen charakteristische Unterschiede; sie sollen als $\alpha$ - und $\beta$-Phytol bezeichnet werden. ${ }^{1}$ )

Die Destillation des Phytols haben Willstätter und Hocheder unter äußerst niedrigem Drucke ausgeführt. Im Vakuum der Wasserstrahlpumpe war es nicht gelungen, Phytol ohne Zersetzung zu destillieren, gewib weil Destillationskolben mit Wurtzschen Kugeln angewandt wurden, die ein Überhitzen der Substanz notwendig machten. Es hat sich gezeigt, daB Phytol aus Claisenkolben sogar in Portionen von $10-30 \mathrm{~g}$ bei 8-12 mm Druck ganz ohne Zersetzung und ohne Bildung erheblichen Rückstandes destilliert werden kann. Es siedet unter 9-10 mm Druck konstant bei $203-204^{\circ}$ (Quecksilber im Dampf). Das Destillat zeigte sich in der Zusammensetzung ${ }^{2}$ ) und in der Mischbarkeit mit Holzgeist, Petroläther and Eisessig unverändert.

I. $0,1716 \mathrm{~g}$ gaben $0,5092 \mathrm{CO}_{2}$ und $0,2086 \mathrm{H}_{2} \mathrm{O}$.

II. $0,1580 \mathrm{~g} \quad, \quad 0,4712 \mathrm{CO}_{\mathrm{g}} \quad, \quad 0,1904 \mathrm{H}_{2} \mathrm{O}$.

III. $0,1403 \mathrm{~g} \quad, \quad 0,4168 \mathrm{CO}_{\mathrm{s}}, \quad 0,1732 \mathrm{H}_{2} \mathrm{O}$.

\begin{tabular}{lcccc} 
& Ber. für & \multicolumn{3}{c}{ Gef. } \\
& $\mathrm{C}_{20} \mathrm{H}_{40} \mathrm{O}$ & I & II & III \\
$\mathrm{C}$ & 80,99 & 80,95 & 81,33 & 81,02 \\
$\mathrm{H}$ & 13,61 & 13,52 & 13,48 & 13,80
\end{tabular}

Zur Beschreibung tühren wir noch den Brechungsindex an, der bei $\alpha$ - und $\beta$-Phytol ziem]ich übereinstimmt.

$\alpha$-Phytol: $\mathrm{d}_{4}^{20}=0,856 ; \mathbf{n}_{\mathrm{D}}^{20}=1,46364 ;$

Mol.-Refr. (nach der Formel: $\frac{\mathrm{n}^{2}-1}{\mathrm{n}^{2}+2} \frac{\mathrm{M}}{\mathrm{d}}$ ) gef. 96,05, ber. 95,29.

$\beta$-Phytol: $\quad d_{4}^{20}=0,852 ; \mathbf{n}_{\mathbf{D}}^{20}=1,46380 ;$

Mol.-Ref. gef. 95,95, ber. 95,29.

1) Unter Phytol schlechtweg ist das nicht destillierte $(\alpha)$ zu verstehen.

2) Die Analysen sind mit drei verschiedenen Präparaten ausgeführt worden. 
Die Angabe von Willstätter und Hocheder für

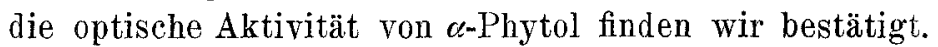

Die Jodzahl der beiden Phytole nach von $\mathrm{H} \ddot{u} \mathrm{bls}{ }^{1}$ ) Methode stimmt mit der Addition von Brom scharf überein, die mit der Aufnahme von 1,05 Mol. beendigt ist. ${ }^{2}$ )

$\alpha$-Phytol: $0,2183 \mathrm{~g}$ erforderten entsprechend $15,56 \mathrm{ccm}{ }^{n} / 10$-Thiosulfat $0,1976 \mathrm{~g}$ Jod, d. i. $1,05 \mathrm{Mol}$. Jodzahl gef. 90,5 , ber. 85,5.

$\beta$-Pliytol: $0,4316 \mathrm{~g}$ erforderten entsprechend $30,92 \mathrm{ccm}{ }^{n} / 10^{-T h i o-~}$ sulfut $0,3973 \mathrm{~g}$ Jod, d. i. 1,05 Mol. Jodzahl gef. 91,2, ber. 85,5.

Eine zum Nachweis des Phytols z. B. in Phäophytinpräparaten brauchbare Reaktion ist die Bildung eines beständigen farblosen Öles beim Kochen mit konz. Salpetersäure. Wenn man Phytol mit reiner Salpetersäure erhitıt, so tritt eine lebhafte Reaktion ein. Verdünnt man nach einigen Minnten, so wird ein zu Boden sinkendes dickes Öl vollständig gefällt, das in ätherischer Lösung durch Einleiten von Ammoniak von einer kleinen Menge Säure befreit wird. Das Öl hat den Stickstoffgehalt eines Nitrosites; nur ist es zweifelhaft, ob es das Molekïl des Phytols intakt enthält.

$0,1277 \mathrm{~g}$ gaben $8,80 \mathrm{ccm}$ Stiekgas bei $18^{\circ}$ und $723 \mathrm{~mm}$ Druck.

$$
\begin{array}{ccc} 
& \text { Ber. für } \mathrm{C}_{20} \mathrm{H}_{40} \mathrm{O}_{4} \mathrm{~N}_{2} & \text { Gef. } \\
\mathrm{N} & 7,53 & 7,51
\end{array}
$$

Bei längerem Kochen mit der Salpetersäure entsteht eine stickstoffhaltige Säure, deren alkalische Lösung intensiv gelb ist.

\section{Autoxydation des Phytols.}

In der ersten Beschreibung des Phytols ist eine Eigenschaft noch nicht erwähnt worden, die zwar nicht an allen, aber: an zahlreichen Präparaten von Phytol, und zwar in recht verschiedenem Maße, bei längerem Stehen bemerkbar wurde. Viele Phytolpräparate, rohe

1) Dingl. Polyt. Journ. 25\%3, 281 (1884).

2) Diese Annalen 354, 248 (1907). 
wie destillierte, veränderten sich nämlich bei mehrmonatlichem Stehen in mit Kork verschlossenen Gefäßen; die Stopfen wurden hell gebleicht, das öl nahm einen scharfen, stechenden Geruch an und die Atmosphäre über der Flüssigkeit rötete befeuchtetes Lackmuspapier stark. Dabei wurde das Phytol allmählich ganz zähflüssig und seine alkoholische Lösung verbrauchte dann erhebliche Mengen Alkali zur Neutralisation.

Phytol ist also autoxydabel in der Art wie ungesättigte Kohlenwasserstoffe nach den Untersuchungen von C. Engler und J. Weißberg, ${ }^{1}$ ) z. B. Terpentinöl und Amylen. Es ist also nicht nur Autoxydator, sondern zugleich Acceptor, indem es den Sanerstoff des nachweislich entstehenden Moloxyds zum großen Teil selbst verbraucht. Nebenher geht beim Phytol immer die Zerstörung des Korkes. Das Auftreten eines Peroxydes läßt sich nach den Angaben von Engler nachweisen: Versetzt man Titansulfat mit ein wenig Phytol, so tritt oft schon nach einer Stunde Gelbfärbung ein, die sich bei weiterem Stehen stark vertieft, während uns Oleinund Erucylalkohol die Reaktion nicht, Geraniol und Nerol nur langsam zeigen. Die Chromsüurereaktion des Hydroperoxyds bleibt dabei ans. Aus nentraler Jodkaliumlösung setzt das autoxydierte Phytol Jod in Freiheit. Den Oxydationsverlauf bei verschiedenen Präparaten haben wir durch die Titration der gebildeten Säure verglichen. Es war wohl denkbar, daß von der entstandenen Säure ein Teil durch Esterbildung mit noch vorhandenem Phytol verbraucht würde, dab also die freie Säure nicht den ganzen Betrag an saurem Oxydationsprodukt darstellt. Wir haben aber durch die Verseifungsprobe gefunden, daß diese Esterifizierung nicht eintrat; die Säurezahl war gleich der Verseifungszahl.

Die Bildung von Säure ging bei beliebig langem

${ }^{1)}$ Ber. d. d. chem. Ges. 31, 3046 (1898); C. Engler, ebenda 33, 1090 (1900); C. Engler a. J.Weißberg, Kritische Studien über die Vorgänge der Autoxydation (Braunschweig 1904). 
Stehen nicht über etwa 32 Proz. des Phytols hmaus. Wir rechnen durchgehends mit der Annahme, daß 1 Mol. Phytol 1. Mol. Säure bilde.

\begin{tabular}{|c|c|c|c|}
\hline Präparat & $\begin{array}{l}\text { cem } " / 10^{-A l k a l i} \\
\text { für } 1 \mathrm{~g} \text { Substanz }\end{array}$ & $\begin{array}{l}\text { Säure } \\
\text { Proż. }\end{array}$ & Zeit \\
\hline$\beta$-Phytol & 10,60 & 31,2 & 6 Monate \\
\hline Dasselbe & 10,64 & 31,5 & 29 \\
\hline
\end{tabular}

Die Geschwindigkeit der Autoxydation ist sehr ungleich bei Phytolpräparaten aus verschiedenen Pflanzen, und auch bei mehreren Darstellungen aus der nämlichen Pflanze; während manche sich mehr als ein Jahr ohne merkliche Änderung halten, beginnt bei anderen die Oxydation schon in den ersten Monaten.

\begin{tabular}{|c|c|c|c|c|c|}
\hline Phytol aus & & $\begin{array}{l}\operatorname{ccm} \mathrm{n} / 10-\text { Alkali } \\
\text { für. } 1 \mathrm{~g} \text { Substanz }\end{array}$ & $\begin{array}{l}\text { Säure } \\
\text { Proz. }\end{array}$ & \multicolumn{2}{|c|}{ Zeit } \\
\hline Brennesseln a & . & 0,847 & $2, \check{5}$ & \multicolumn{2}{|c|}{28 Monate } \\
\hline Dasselbe $\quad b$ & & 6,58 & 18,9 & 14 & " \\
\hline Dasselbe & . & $10, \tilde{5} 8$ & 31,3 & 39 & $n$ \\
\hline Gras . . & & 10,84 & 32,1 & 49 & $"$ \\
\hline Platane. & & 4,45 & 13,1 & 13 & $"$ \\
\hline Weichsel. & & 10,27 & 30,4 & 16 & , \\
\hline Alchemilla . & . & 8,84 & 26,2 & 13 &. \\
\hline Frauenhaar. & - & 1,64 & 4,9 & $1 \overline{5}$ & $"$ \\
\hline Seuna. . & $\cdot$ & 1,27 & 3,8 & 17 & 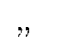 \\
\hline Pärenklau & . & 1,32 & 3,9 & 13 & $"$ \\
\hline
\end{tabular}

Hiernach ist es sehr wahrscheinlich, dab die Autoxydation katalytisch beschleunigt wird durch eine noch nicht zu definierende, ungleichmäßig anftretende, spurenweise Beimischung, die übrigens auch im destilliertem Phytol anzunehmen ist.

Aus einigen wiederholt titrierten Proben ergibt sich, daß die Bildung von Säure durch die Autoxydation zuert mit sich steigernder Geschwindigkeit erfolgt (bei A ist nämlich die Geschwindigkeit vom 14.-20. Monat gröBer als vorher). Dann nimmt die Geschwindigkeit ab (bei $\mathrm{B}$ ist sie vor dem 14. Monat größer als nachher), bis in 
gleichen Zeiten (bei B vom 14.--43. Monat) genau gleiche Mengen von Säure hinzukommen, solange als noch eine Vermehrung derselben eintritt.

\begin{tabular}{|c|c|c|c|}
\hline Phytol aus & $\begin{array}{l}\text { cem }{ }^{n / 10} \text { Alkali } \\
\text { für } 1 \mathrm{~g} \text { Substanz }\end{array}$ & $\begin{array}{l}\text { Säure } \\
\text { Proz. }\end{array}$ & Zeit \\
\hline A $\left\{\begin{array}{l}\text { Gras . } \\
\text { Dasselbe. }\end{array}\right.$ & $\begin{array}{r}6,07 \\
10,52\end{array}$ & $\begin{array}{l}17,8 \\
30,9\end{array}$ & $\begin{array}{l}14 \text { Monate } \\
20 "\end{array}$ \\
\hline B $\left\{\begin{array}{l}\text { Brennesseln. } \\
\text { Dasselbe } \\
\text { Dasselbe }\end{array}\right.$. & $\begin{array}{l}6,58 \\
6,86 \\
8,41\end{array}$ & $\begin{array}{l}18,9 \\
20,2 \\
24,9\end{array}$ & $\begin{array}{l}14 \\
20 \\
43\end{array}$ \\
\hline
\end{tabular}

Die bei der Autoxydation gebildete Sänre ist nicht einheitlich. Sie ist ungesättigt. Ihre Jodzahl (38) und die Elementaranalyse deuten darauf hin, dab ein Gemisch annähernd gleicher Gewichtsmengen von Phytensäure und einer gesättigten Carbonsäure mit ungefähr 10 Kohlenstoffatomen vorliegt.

0,1239 g erforderten entsprechend $3,89 \mathrm{ccm}^{\mathrm{n}} / 10^{-}$-Thiosulfat $0,0494 \mathrm{~J}$. $0,1510 \mathrm{~g}$ gaben $0,4076 \mathrm{CO}_{2}$ und $0,1620 \mathrm{H}_{2} \mathrm{O}$.

$$
\begin{array}{cr}
\multicolumn{2}{c}{\text { Gefunden }} \\
\text { C } & 73,62 \\
\text { H } & 12,00
\end{array}
$$

Phytolphthalestersäuren, $\mathrm{C}_{6} \mathrm{H}_{4}(\mathrm{COOH})\left(\mathrm{COOC}_{20} \mathrm{H}_{39}\right)$.

Willstätter and $\mathrm{Hocheder}{ }^{1}$ ) haben vergebens versucht, die Phytolphthalestersäure durch Erbitzen des Alkohols mit Phthalsäureanhydrid in Benzol darzustellen; sie beobachteten dabei die Umwandlung des Anhydrides in Phthalsäure. Es ist uns gelungen, nach derselben Methode die Phthalestersäure zu gewinnen, und eine überraschende Erklärung $z u$ finden für das negative Resultat von Willstätter und Hocheder.

Die Phthalestersäure zerfällt nämlich bei sehr geringem Überhitzen in Phytadien und Phthalsäure. Wenn man $\alpha$ - und $\beta$-Phytol oder Dihydrophytol in benzolischer Lösung mit Phthalsäureanhydrid auf dem Wasserbad am

1) Diese Annalen :i54, 249 (1907). 
Rückflußkühler kocht, so entstehen die drei Phthalestersäuren in guter Ansbeute. Erwärmt man dagegen im Baboschen Trichter aus Eisenblech, so trüben wich die Lösungen allmählich und scheiden schließlich quantitativ Phthalsäure aus. So entsteht Phytadien aus Phytol, Phyten aus Dihydrophytol.

Der Zerfall trat schneller beim destillierten Phytol ein, das auch unter den Bedingungen der Esterbildung nach Menschutkin ein viel stärkeres Sinkea der Esterausbeute bei längerem Erhitzen zeigt. Dieselbe Neigung zur Olefinbildung beim Überhitzen hat auch die Destillation des Phytols im Vakuum erschwert (s. S. 83).

Die Isolierung der Phytolphthalestersäuren gründet sich auf die ungewöhnlichen Iöslichkeitsverhältnisse ihrer Salze.

Wir erwärmen $\alpha$-Phytol mit dem gleichen Gewicht Phthalsäareanhydrid und dem vierfachen trocknen Benzols am Rückflußkühler 5 Stunden lang; die klare Lösung wird eingedampft und der Rückstand mit Äther aufgenommen. Um die Estersäure zu reinigen, kann man sie mittelst eines ätherlöslichen Salzes von etwas Phthalsäure befreien, mit Hilfe eines wasserlöslichen von tnhydrid und Phytol. Die ätherische Lösung wird mit etwa der berechneten Menge sehr verdünnter Kalilauge versetzt und zur Vermeidung von Fmulsionen nur gan\%

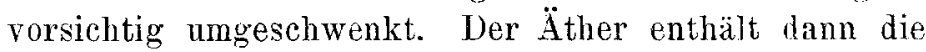
Kaliseife, er reagiert alkalisch. Mit N'atron, Soda oder Ammoniak kann man die Säure nicht aus dem $\ddot{A}$ ther in Wasser überführen, hingegen mit Piperidin, wenn man die ätherische Lösung mit dieser Base und dann vorsichtig mit Wasser versetzt. Aus der Lösung des Piperidinsalzes scheiden wir mit Kochsalz die schwerlösliche Natronseife $a b$, die beim Schütteln in Äther übergeht, und durch Ansäuren die freie Phytolphthalestersäure.

Einfacher wird diese aus der rohen ätherischen Lösung isoliert, indem man sie zuerst zasammen mit 
beigemischter Phthalsänre in sehr verdünnte wäßrige Piperidinlösung überführt. Dann bringt man sie durch Znfügen von reinem Kochsalz als Natronsalz in Äther. Die Lösung wird mit Schwefelsäure geschüttelt, gewaschen und nach dem Trocknen im Vakuum eingedampft. Die Estersäure hinterbleibt als Sirup in einer Ausbeute von etwa 84 Proz. der Theorie.

Die a-Phytolphthalestersäure ist leicht löslich in den Alkoholen, Eisessig, Benzol und Chloroform. Sie entfärbt in Eisessiglösung Permanganat wie Phytol und addiert 1 Mol. Brom; das Bromid ist ein leicht zersetzliches Öl. In alkoholischer Lösung läßt sich die. Estersäure unter Anwendung von Lackmus titrieren.

$0,2587 \mathrm{~g}$ erforderten $5,00 \mathrm{ccm} \mathrm{n}_{10}-\mathrm{NaOH}$, ber. für $\mathrm{C}_{28} \mathrm{H}_{44} \mathrm{O}_{4}$ $5,10 \mathrm{ecm}$.

Zur Kennzeichnung des Phytols eignet sich besonders das Silbersalz der $\alpha$-Phytolphthalestersäure, welches beim Vermischen der genau neutralisierten alkoholischen Lösung der Säure mit etwas weniger als der berechneten Menge alkoholischer Silbernitratlösung krystallinisch ausfällt. Es läßt sich durch Verdünnen der benzolischen Lösung mit Holzgeist umkrystallisieren und bildet dann mikroskopische flache Prismen vom konstanten Schmelzp. $119^{\circ}$. Das Silbersalz ist in $\ddot{A}$ ther, Benzol and heißem Alkohol leicht löslich, schwer in kaltem Alkohol, noch schwerer in Holzgeist; auch in heißem Ligroin löst es sich beträchtlich. Für die Analyse dienten Rohprodukt (Best. I) and umkrystallisiertes Salz (Best. II).

I. $0,1984 \mathrm{~g}$ gaben $0,0392 \mathrm{Ag}$.

II. $0,1449 \mathrm{~g}, 0,0285 \mathrm{Ag}$.

\begin{tabular}{cccc} 
& Ber. für & \multicolumn{2}{c}{ Gef. } \\
& $\mathrm{C}_{28} \mathrm{H}_{49} \mathrm{O}_{4} \mathrm{Ag}$ & I & II \\
$\mathrm{Ag}$ & 19,57 & 19,76 & 19,66
\end{tabular}

$\beta$-Phytolphthalestersäure. Destilliertes Phytol lieferte unter denselben Bedingungen wie rohes eine Phthalestersäure, aber die Ausbeute war geringer. Die Säure ist der $\alpha$-Verbindung sehr ähnlich, ein dickes ÖI, das 
in Alkohol, Äther und Eisessig leicht löslich ist, aber nicht in jedem Verhältnis damit mischbar.

$0,4702 \mathrm{~g}$ erforderten $1,05 \mathrm{ccm} \mathrm{n}-\mathrm{NaOH}$; ber. für $\mathrm{C}_{38} \mathrm{H}_{44} \mathrm{O}_{4}$ $1,04 \mathrm{cem}$.

Auch die Salze stimmen in den Löslichkeitsverhältnissen und anderen Eigenschaften mit den $\alpha$-Derivaten überein. Das Silbersalz läßt sich gut aus Alkohol umkrystallisieren, worin es sich leicht in der Hitze, schwer in der Kälte löst. In Äther, Chloroform und Benzol ist es sehr leicht löslich, in Petroläther fast unlöslich. Es bildet Prismen vom Schmelzp. $116^{\circ}$.

$0,2642 \mathrm{~g}$ gaben $0,0519 \mathrm{Ag}$.

$$
\begin{array}{ccc} 
& \text { Ber. für } \mathrm{C}_{28} \mathrm{H}_{49} \mathrm{O}_{4} \mathrm{Ag} & \text { Gef. } \\
\mathrm{Ag} & 19,57 & 19,64
\end{array}
$$

Zum Vergleich mit dem Phytolderivat stellten wir die Phthalestersäure eines normalen höheren Alkohols dar, des Cetylalkohols. Auch diese Säure bildet ätherlösliche, seifenähnliche Salze. Die Löslichkeitsverhältnisse weichen von den oben beschriebenen ab; das Natriumsalz ist in Wasser schwer, in Äther leicht löslich, das Kaliumsalz verhält sich umgekehrt, löst sich aber leicht in $\ddot{A} t h e r-$ Alkoholgemisch. Die Cetylphthalestersäure wird daher isoliert durch Überführen als Kaliumsalz in wäßrige und dann als Natriumsalz in ätherische Lösing. Die freie Säure ist paraffinartig and bildet nadeutliche Krystalle, die aus Benzol and aus Chloroform wiederholt umkrystallisiert bei $61-62^{\circ}$ selimelzen.

$0,3014 \mathrm{~g}$ erforderten $7,90 \mathrm{cem}{ }^{n} / 10-\mathrm{Ba}(\mathrm{OH})_{4}$; ber. für $\mathrm{C}_{24} \mathrm{H}_{38} \mathrm{O}_{4}$ $7,82 \mathrm{ccm}$.

Das cetylphthalestersaure Siller ist in Äther und Alkohol in der Kälte schwer, leichter in der Wärme löslich und krystallisiert aus den beim sieden erhaltenen Lösungen schön aus. Beim Ü̉bergießen mit Benzol, worin es sich schon kalt ziemlich leicht löst, wird das Salz schleimig; eigentümlicherweise krystallisiert es reichlich aus der heiß- wie auch aus der kaltgesättigten Benzollösung. 
I. $0,2065 \mathrm{~g}$ (Rohprodukt) gaben $0,0459 \mathrm{Ag}$.

Ii. $0,1979 \mathrm{~g}$ (umkrystallisiert) gaben $0,0432 \mathrm{Ag}$.

Ber. für

$\begin{array}{cccc} & \mathrm{C}_{24} \mathrm{H}_{37} \mathrm{O}_{4} \mathrm{Ag} & \mathrm{I} & \mathrm{II} \\ \mathrm{Ag} & 21,71 & 22,22 & 21,83\end{array}$

Phytyläther $\mathrm{C}_{20} \mathrm{H}_{39} \mathrm{OC}_{20} \mathrm{H}_{39}$.

Versetzt man die Eisessiglösung von Phytol mit konz. Schwefelsäure, so trübt sie sich und scheidet in einigen Minuten den Äther als dickliches Öl ab. Dieser ist im Gegensatz zum Phytol und Phytadien sehr schwer löslich in Eisessig und in Methylalkohol, mit $\ddot{\text { Ather und }}$ Petroläther ist er mischbar. Für die Analyse wurde das Öl im Vakuum bei $100^{\circ}$ vom Lösungsmittel befreit.

$0,1356 \mathrm{~g}$ gaben $0,4175 \mathrm{CO}_{2}$ und $0,1627 \mathrm{H}_{2} \mathrm{O}$.

$\begin{array}{ccc} & \text { Ber. für } \mathrm{C}_{40} \mathrm{H}_{78} \mathrm{O} & \text { Gef. } \\ \mathrm{C} & 83,53 & 83,97 \\ \mathrm{H} & 13,68 & 13,42\end{array}$

Der Phytyläther addiert Brom in Chloroformlösung anfangs schnell, gegen Ende langsam nnd unter geringer Entwickelung von Bromwasserstoff; er verbrauchte 2,12 Mol. Brom. Der Äther ist vielleicht identisch mit einem früher bei der Destillation des Phytols beobachteten Nebenprodukt, dessen Zusammensetzung und Molekulargewicht angegeben worden ist. ${ }^{1}$ )

\section{Phytanol (Dihydrophytol), $\mathrm{C}_{30} \mathrm{H}_{42} \mathrm{O}$. \\ Elektrolytische Reduktion von Phytol.}

Die Hydrierung des Phytols gelingt nicht mit Hilfe von Alkalimetail und Äthyl- oder Amylalkohol. Hingegen konnten wir sie auf elektrolytischem Wege ausführen, nämlich unter Anwendung von platinierten Platinelektroden $^{2}$ ) in alkoholisch-schwefelsaurer Lösung nach dem Verfahren, mit welchem C. F. Böhringer und Söhn $e^{3}$ )

1) Diese Annalen :354, 257 (1907).

2) Bei Anwendung von Bleielektroden verlief die Reduktion viel weniger günstig.

s) D. R. P. 187788; Chem. Centralbl. 1907, II, 1287 und 1908, I, 185 . 
die Reduktion ungesättigter Fettsäuren und ihrer Ester errielt haben.

Wir tauchten die platinierte Platinkathode in die, Lösung von $5 \mathrm{~g}$ Phytol in $200 \mathrm{ccm}$ absolntem Alkohol die nit $5 \mathrm{ccm}$ konz. Schwefelsäure versetzt war, und trennten diese Fliissigkeit mittelst eines Tondiaphragmas, das mit einer Mischung von Alkohol und Schwefelsäture beschickt war, vom Raume der ebenfalls platinierten Platinanode. Es erwies sich als vorteilhaft, während der Daner des Stromdurchganges die Phytollösung zu kühlen. \%ar Reduktion diente ein Strom von etwa $3 \mathrm{Amp}$. auf $1 \mathrm{qm}$ Elektrodenfläche und einer Spannung von 6 Volt. Wir verfolgten die Veränderung des Phytols durch Titration mit Brom und fanden das Produkt erst nach 8 Tagen gesättigt. Die Ausbente betrug $3,8 \mathrm{~g}$, den Verlust hatte Diffusion von Phytol durch das Diaphragma in den Anodenraum verursacht.

Das Reduktionsprodukt war ein Gemisch von Dihydrophytol und Phytan. Daher mischte es sich zwar mit wenig Holzgeist, trübte sich aber mit mehr Lösungsmittel. Schon bei einmaliger Fraktionierung im Vakuum ging unter $9,6 \mathrm{~mm}$ Druck zwischen 201,5-204,50 der Alkohol annähernd rein über nach Abtrennung des bei $170,5-170,7^{\circ}$ siedenden Kohlenwasserstoffs. Durch wiederholte Fraktionierung wurde das Dihydrophytol vollkommen gereinigt (Best. II). Die Menge des Kohlenwasserstoffs war nicht hinreichend, um ihn von sanerstoffhaltigen Verbindungen ganz za befreien, doch konnten wir das Phytan durch sein Verhalten gegen Lösungsmittel und gegen Brom identifizieren.

Das Phytanol stimmte in seinen Eigenschaften mit dem Produkt der folgenden Reduktionsmethode überein.

I. $0,1618 \mathrm{~g}$ gahen $0,4747 \mathrm{CO}_{2}$ und $0,2037 \mathrm{H}_{2} \mathrm{O}$.

II. $0,1953 \mathrm{~g},, \quad 0,5777 \mathrm{CO}_{2}, \quad 0,2481 \mathrm{H}_{2} \mathrm{O}$.

\begin{tabular}{cccc} 
& Ber. für & \multicolumn{2}{c}{ Gef. } \\
& $\mathrm{C}_{20} \mathrm{H}_{42} \mathrm{O}$ & I & II \\
$\mathrm{C}$ & 80,45 & 80,01 & 80,67 \\
$\mathrm{H}$ & 14,19 & 14,08 & $\mathbf{1 4 , 2 1}$
\end{tabular}




\section{Reduktion mit Platin und Wasserstoff.}

Die Methoden von Sabatier und Senderens sowie von Ipatiew waren für Phytol wegen seiner Nichtflüchtigkeit und seiner Zersetzlichkeit bei höherer Temperatur nicht anwendbar. Das Erfordernis, Phytol zu reduzieren, hat uns dazu geführt, eine von S. Fokin ${ }^{1}$ ) gegebene Anregung zu verfolgen und die Anwendung der Platinkatalyse zur Reduktion auszuarbeiten. Auf diese Weise ist es gelungen, den Effekt der SabatierSenderens-Methode an Olefinen, z. B. Phytol, Phyten, Cholesterin und anderen bei gewöhnlicher Temperatur zu erzielen. Da die Reduktionsmethode schon mitgeteilt worden ist ${ }^{2}$, haben wir hier nur ihre Anwendung zu beschreiben. Sie verdient wegen ihres glatteren Verlanfes den Vorzug gegenüber der elektrolytischen Reduktion.

Bei unseren ersten Versuchen mit der Platinmethode haben wir Wasserstoff in die ätherische Lösung der ungesättigten Verbindung eingeleitet. Wir versetzten die Mischung von $40 \mathrm{~g}$ Phytol und $200 \mathrm{~g}$ absolutem Äther mit $12 \mathrm{~g}$ Platinschwarz und unterhielten einen langsamen Wasserstoffstrom 3 Wochen lang, bis eine reichliche Probe der Substanz keine Spur Brom mehr entfärbte. Bei kleineren Portionen des Alkohols war die Reduktion je nach der Qualität des Platins in 6-9 Tagen beendigt. Später haben wir die Hydrierung viel rascher und bequemer ausgeführt, indem wir die Substanz mit dem Lösungsmittel verdünnt oder unverdünnt in einen

1) Journ. russ. phys.-chem. Ges. 39, 607 (1907); Chem. Centralbl. 1907, II, 1324. Die späteren Arbeiten von Fokin sind veröffentlicht worden in der Zeitsehr. f. angew. Chem. 22, 1496 (1909) und Zeitschr. f. analyt. Chem. 48, 337 (1909) und die fast gleichzeitigen Untersuchungen von $\mathrm{C}$. Paal und seinen Schülern über die Reduktion mit kolloidalen Platinmetallen in den Ber. d. d. chem. Ges. 38, 1406 (1905); 40, 2209 (1907); 41, 2273 und 2282 (1908); 42, $1541,1553,2239,3930$ (1909); 43, 243 (1910).

$\left.{ }^{2}\right)$ R. Willstätter und E. W. Mayer, Ber. d. d. chem. Ges. 41, 1475 und 2199 (1908); R. Willstätter und E. Wasex, Ber. d. d. chem. Ges. 43, 1176 (1910). 
sog. Einschlußkolben füllten, dessen langer, umgebogener Hals durch ein T-Stück mit dem Wasserstoffgasometer kommunizierte. Durch das T-Rohr wurde das GefäB vor Beginn der Reduktion luftfrei gepumpt. Den Wasserstoff ließen wir unter Druck einwirken und den Kolben schïttelten wir mit Hilfe eives Exzenters.

Die ätherische Lösung des Reduktionsproduktes hat oft etwas Platin als Organosol aufgenommen; durch wiederholtes Abdampfen der Lösung oder durch Schütteln mit Natriumsulfat läßt es sich ansfiocken.

Das Rohprodukt wies die Zusammensetzung des Dihydrophytols auf.

$0,2150 \mathrm{~g}$ gaben $0,6350 \mathrm{CO}_{2}$ und $0,2742 \mathrm{H}_{9} \mathrm{O}$.

$\begin{array}{ccc} & \text { Ber. für } \mathrm{C}_{20} \mathrm{H}_{\mathbf{4 2}} \mathrm{O} & \text { Gef. } \\ \mathrm{C} & 80,45 & 80,55 \\ \mathrm{H} & 14,19 & \mathbf{1 4 , 2 6}\end{array}$

Aber es war weniger rein, als die Analyse vermuten ließ. Denn auch bei dieser Art der Hydrierung war neben dem Phytanol etwas von dem gesättigten Kohlenwasserstoff entstanden. In einigen ähnlichen Fällen haben wir geprüft, ob die Paraffine durch weitere Reduktion der gesättigten Alkohole gebildet werden oder direkt aus den Olefinalkoholen. Tetrahydrogeraniol ${ }^{1}$ ) z. B., bei dessen Bildung sehr reichlich Dimethyloctan auftritt, liefert keine Spur dieses Kohlenwasserstoffes beim Behandeln mit Wasserstoff und Platin; ebenso erweist sich der normale Octadecylalkohol als beständig.

Durch wiederholte gründliche Fraktionierung ${ }^{2}$ ) im Vakuum und durch Ausfällen aus den Vorlänfen mit Holzgeist wurde das Phytan abgetrennt.

Das Dihydrophytol destillierte in reinem Zustand konstant bei $201,5-202^{\circ}$ (Quecksilber im Dampf) unter 9,5 mm Druck als farbloses und geruchloses, phytolähn-

1) R. Willstätter und E. W. Mayer, Ber. d. d. chem. Ges. 41, 1478 (1908).

2) Ausführlicheres enthält die Diss. von E. W. Mayer: Zur Kenntnis des Phytols, Zürich 1908. 
liches Öl, das auch beim Abkühlen nicht krystallisiert und in flüssiger Luft zu einer spröden, glasigen Gallerte erstarrt.

I. $0,2141 \mathrm{~g}$ ( $1 \mathrm{mal}$ fraktioniert) gaben $0,6307 \mathrm{CO}_{2}$ u. $0,2681 \mathrm{H}_{2} \mathrm{O}$.

II. $0,1880 \mathrm{~g}(2 \mathrm{maI} \quad ") \quad, \quad 0,5538 \mathrm{CO}_{2}$ u. $0,2376 \mathrm{H}_{2} \mathrm{O}$.

III. $0,1891 \mathrm{~g}(3 \mathrm{mal}, \quad) \quad, \quad 0,5572 \mathrm{CO}_{2}$ u. $0,2388 \mathrm{H}_{2} \mathrm{O}$.

\begin{tabular}{ccccc} 
& Ber. für. & \multicolumn{3}{c}{ Gef. } \\
& $\mathrm{C}_{\mathbf{2 0}} \mathrm{H}_{\mathbf{4 2}} \mathrm{O}$ & I & II & III \\
$\mathrm{C}$ & 80,45 & 80,43 & 80,34 & 80,36 \\
$\mathrm{H}$ & 14,19 & 14,01 & $\mathbf{1 4 , 1 4}$ & $\mathbf{1 4 , 1 3}$
\end{tabular}

$\mathrm{D}_{4}^{0}=0,8487, \quad \mathrm{~d}_{4}^{20}=0,8398 ; \quad \mathrm{n}_{\mathrm{D}}^{20}=1,45213$, Nol.-Refr. ber. 95,68 , gef, 95,86 .

Auch aus $\beta$-Phytol haben wir mit der gleichen Methode das Phytanol dargestellt und es mit Hilfe seiner Phthalestersäure identifiziert.

Das Dihydrophytol ist mit allen üblichen organischen Lösungsmitteln mischbar. Gegen Brom ist es vollkommen gesättigt, von Kaliumpermanganat wird es in Eisessiglösung ${ }^{1}$ ) weit langsamer als Phytol, jedoch merklich, angegriffen, sogar rascher als Phyten. Beim Frhitzen mit Natronkalk and bei der Einwirkung von Chromtrioxyd in Eisessig wird der Alkohol zur Phytansäure oxydiert.

Die Verbindungen des Phytanols neigen ebensowenig zur Krystallisation wie die Phytolderivate.

Das Dihydrophytol ist isomer mit dem normalen Arachylalkohol, den A. Haller und G. Blanc ${ }^{2}$ ) nach der Methode von L. Bouveault and G. Blanc aus Arachinsäureester dargestellt und als wachsartige Masse vom Schmelzp. $71^{\circ}$ beschrieben haben. Wir haben den Arachylalkohol für den Vergleich mit dem Phytanol aus dem Ester der Arachinsäure ${ }^{3}$ ) bereitet, er destillierte um mehr als $40^{\circ}$ höher als unser Alkohol, nämlich zwischen 243 and $250^{\circ}$ unter $8,5 \mathrm{~mm}$ Druck und schmolz unscharf bei $63-64^{\circ}$, bei $61-62^{\circ}$ erweichend.

1) Diese Annalen 354, 248 (1907).

2) Compt. rend. 144, 597 (1907).

3) Die Arachinsäure (Schmelzp. $75^{\circ}$ ) war z. 'T. von E. Merek bezogen und noch umkrystallisiert, z. T. aus Erucasäure durch die Kalischmelze gewonnen worden. 
Gleichfalls als ein Isomeres des Arachylalkohols hat A. Haller den Hauptbestandteil eines Palmenwachses von Madagascar (aus Raphia Ruffia) angesprochen. Fr kennzeichnet ihn mit dem ungefähren Siedep. $280-300^{\circ}$ (10 mm Druck) und dem Schmelzp. 80. Da indessen dieser Siedepunkt soviel höher liegt als der des normalen Paraffinalkohols, so erfordert die Erklärung des Raphiawachses noch weitere Untersuchungen.

Andere krystallisierende Alkohole, denen die Formel $\mathrm{C}_{20} \mathrm{H}_{42} \mathrm{O}$ zukommen soll, hat A. Etard ${ }^{\prime}$ ) aus den Blättern mehrerer Pflanzen isoliert, und nach ihrer Herkunft Avenol, Hordeol, Triticol genannt. Endlich hat W. Heubner ${ }^{2}$ ) einen Alkohol von der nämlichen Zusammensetzung, bei $63-64^{\circ}$ schmelzend, im Spinat anfgefunden.

Natriumsalz, $\mathrm{C}_{20} \mathrm{H}_{41}$ ONa. Die absolut-ätherische Lösung von Dihydrophytol reagiert in der Kälte nur träge, beim Erwärmen lebhaft mit Natrium, wobei sie klar bleibt und stark alkalische Reaktion annimmt. Das Natriumsalz ist ein dickes Öl von ähnlichen Eigenschaften wie Phytolnatrium, nämlich leicht löslich in Äther und sogar in Petroläther. Zur Analyse wurde die mit dem Metall gesättigte Lösung von gewogenem Dihydrophytol mit Säure zersetzt und das Natrium als Sulfat bestimmt.

$2,0109 \mathrm{~g}$ gaben $0,4892 \quad \mathrm{Na}_{2} \mathrm{SO}_{4}$.

Ber. für $\mathrm{C}_{70} \mathrm{H}_{41} \mathrm{ONa}$

$\mathrm{Na} \quad 7,73$

Gef.

7,9

Phenylurethan, $\mathrm{C}_{20} \mathrm{H}_{41} \mathrm{O} . \mathrm{CO}\left(\mathrm{NHC}_{6} \mathrm{H}_{5}\right)$. Der Alkohol wurde mit dem halben Gewicht Phenylcyanat vermischt und nach einigem Stehen in der Kälte 2 Stunden lang anf $130^{\circ}$ erhitzt. Dann fügten wir etwas Wasser hinzu und trennten das Urethan von entstandenem Diphenyl-

1) I,a Biochimie et les Chlorophylles, Paris, Masson et Cie. 1906. - Für Medicagol, dem Etard früher anch die Formel $\mathrm{C}_{40} \mathrm{H}_{48} \mathrm{O}$ zageschrieben hatte (Compt. rend. 114, 364 [1892]), wird in diesem Buche die Zusammensetzung $\mathrm{C}_{16} \mathrm{H}_{32} \mathrm{O}$ angenommen.

9) Nach einer brieflichen Mitteilung. 
harnstoff durch Extraktion mit wenig Hexan und nach dem Abdampfen durch wiederholtes Aufnehmen mit diesem. Das Urethan bildete ein in den gewöhnlichen Lösungsmitteln leicht lösliches, dickes Öl, das auch bei tiefer Temperatur nicht krystallisierte.

$0,2943 \mathrm{~g}$ gaben $9,5 \mathrm{cem}$ Stickgas bei $19^{\circ}$ und $724 \mathrm{~mm}$ Druck.

$$
\begin{array}{ccc} 
& \text { Ber. für } \mathrm{C}_{27} \mathrm{H}_{47} \mathrm{O}_{2} \mathrm{~N} & \text { Gef. } \\
\mathrm{N} & 3,35 & 3,5 \mathrm{l} 1
\end{array}
$$

Phthalestersäure. Phytanol verbindet sich mit Phthalsäureanhydrid beim Kochen in benzolischer Lösung auf dem Wasserbad. Die Estersäure läßt sich mit Hilfe

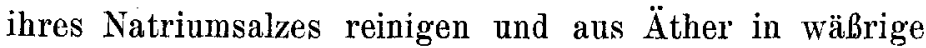
Lösung bringen; das Salz wird durch Kochsalz gefällt and wieder in Äther übergeführt. Die freie Säure ist ein in den organischen Solvenzien leicht löslicher Sirup.

$0,3923 \mathrm{~g}$ erforderten $8,84 \mathrm{ccm}{ }^{\mathrm{n}} / 10-\mathrm{Ba}(\mathrm{OH})_{2}$, ber. für $\mathrm{C}_{28} \mathrm{H}_{48} \mathrm{O}_{4}$ $8,90 \mathrm{cem}$.

Das Silbersalz der Dihydrophytolphthalestersäure, dargestellt wie das Phytolderivat, ist leicht löslich in Äther, Benzol, Chloroform und warmem Ligroin, recht leicht in heißem Äthyl- und Methylalkohol; hieraus krystallisiert es in weißen, warzigen Konglomeraten vom Schmelzp. $106-106,5^{0}$.

$0,1695 \mathrm{~g}$ gaben $0,0329 \mathrm{Ag}$.

$$
\begin{array}{ccc} 
& \text { Ber. für. } \mathrm{C}_{28} \mathrm{H}_{45} \mathrm{O}_{4} \mathrm{Ag} & \text { Gef. } \\
\mathrm{Ag} & 19,51 & 19,41
\end{array}
$$

Brenztraubensäurester, $\mathrm{C}_{20} \mathrm{H}_{41} \mathrm{CO}_{2} \mathrm{COCH}_{3}$. L. Bouveault ${ }^{1}$ ) empfiehlt zur Charakterisierung von Alkoholen die Semicarbazone ihrer Brenztraubensäureester, welche man nach L. Simon ${ }^{2}$ ) durch Erhitzen der Komponenten auf $110-120^{\circ}$ erhält. Wir gewannen so mit frisch im Vakuum destillierter Brenztraubensäure den Phytanolester und reinigten ihn nach vollständigem Wegwaschen der Brenztraubensäure mit Wasser durch melırmals

1) Compt. rend, 138, 984 (1904).

$\left.{ }^{2}\right)$ Bull. soc. chim. [3] 13, 477 (1895).

Annulen der Chemie 378. Band. 
wiederholte Fraktionierung im Vakuum. Das Öl destillierte unter $10 \mathrm{~mm}$ Druck bei $219-220^{\circ}$. Viel leichter als nach der Literaturvorschrift erhält man den Brenztraubensänreester in reinem Zustand durch sehr lang dauerndes Schütteln des Alkohols mit der fünffachen Menge Brenztraubensäure in der Kälte.

$0,1807 \mathrm{~g}$ gaben $0,4986 \mathrm{CO}_{2}$ und $0,1991 \mathrm{H}_{2} \mathrm{O}$.

$\begin{array}{lcr} & \text { Ber. für } \mathrm{C}_{23} \mathrm{H}_{44} \mathrm{O}_{3} & \text { Gef. } \\ \mathrm{C} & \mathbf{7 4 , 9 3} & \mathbf{7 5 , 2 5} \\ \mathrm{H} & 12,03 & 12,32\end{array}$

Das Semicarbazon des Esters krystallisiert aus warmem Holzgeist in Nadeln von wachsartiger Konsistenz, die bei $88-91^{\circ}$ schmelzen. Es ist schwer löslich in kaltem Methylalkohol und in Petroläther.

$0,1392 \mathrm{~g}$ gaben $12,1 \mathrm{~cm}$ Stickgas bei $17^{\circ}$ und $728,5 \mathrm{~mm}$ Druck.

$$
\mathrm{N} \quad \begin{array}{cc}
\text { Ber. für } \mathrm{C}_{93} \mathrm{H}_{47} \mathrm{O}_{3} \mathrm{~N}_{3} & \text { Gef. } \\
9,87 & 9,61
\end{array}
$$

Den Cetylester der Brenztraubensäure stellten wir zum Vergleich ebenfalls in der Kälte dar. Er schmilzt in rohem Zustand bei $26,5-27,5^{\circ}$ und gibt ein schönes Semicarbazon, das aus Essigester nmkrystallisiert bei 140-141 ${ }^{\circ}$ schmilzt. Es bildet tafelige Prismen und ist in Alkohol und Essigester schwer in der Kälte, leichter in der Wärme löslich.

$0,1371 \mathrm{~g}$ gaben $14,9 \mathrm{ccm}$ Stickgas bei $17^{\circ}$ u. 725,5 mm Druck Ber. für $\mathrm{C}_{19} \mathrm{H}_{39} \mathrm{O}_{3} \mathrm{~N}_{3}$

$$
\mathrm{N} \quad 11,76 \quad 11,96
$$

\section{Esterifizierung von Phytol und Dihydrophytol.}

Zur Kennzeichnung des Phytols als primärer Alkohol wurde in der ersten Arbeit ${ }^{1}$ ) die Geschwindigkeit der Esterbildung bestimmt gemäß der Methode der älteren Untersuchungen von N. Menschutkin. ${ }^{2}$ ) Wenn der Wert dieser Methode auch zweifelhaft geworden ist und die Folgerungen hinsichtlich der wahren Geschwindig-

1) Diese Annalen 354, 249 (1907).

2) Diese Annalen 195, 334 (1879) und 197, 193 (1879). 
keit der Reaktion strittig sind, ${ }^{1}$ ) so bleiben doch die Zahlen für Anfangsgeschwindigkeit und Grenze der Esterbildung nach der alten Arbeitsweise von Menschutkin sehr nützlich für die Beschreibung und den Vergleich unserer Alkohole miteinander und mit anderen höheren aliphatischen Alkoholen.

Die Mischungen der Alkohole mit Eisessig stellten wir her, indem wir auf den Boden des kleinen Einschlußrohres zuerst ans einer Kapillarpipette Eisessig und danach die berechnete Menge Alkohol fließen ließen; man erzielt so genaue Mischungsfaktoren, da man die gröhere Menge des Alkohols schärfer abmessen kann als die Säure. Schwieriger ist das Arbeiten init den festen Alkoholen; hier wurde zuerst der Alkohol abgewogen und dann die berechnete Menge Säure hinzugefügt; die Abweichungen der angewandten Faktoren von den berechneten werden so etwas größer. Feste Reaktionsprodukte haben wir aus dem Röhrchen mit Hilfe eines indifferenten Lösungsmittels herausgespült. Für den Vergleich der hohen Alkohole mit den von Menschutkin untersuchten niedrigen gilt die Einschränkung, die Menschutkin schon beim Octyl- und Cetylalkohol gemacht hat. Menschutkin sowie Berthelot haben in diesen Fällen die Inhomogenität der Systeme erwähnt. Es ist möglich, daß der hohe Wert der Esterifizierungsgrenze bei den hohen Alkoholen wenigstens zum Teil durch die Inhomogenität bedingt wird, die ihrerseits eine Folge der von Molekulargewicht und Konstitution abhängigen Schwerlöslichkeit ist.

a) Phytol und andere ungesättigte Alkohole.

$\beta$-Phytol stimmt mit $\alpha$ - überein in der Anfangsgeschwindigkeit and unterscheidet sich charakteristisch durch den Fndwert bei $155^{\circ}$. Beim rohen Phytol ist

1) Siehe A. Michael und K. Wolgast, Ber. d. d. chem. Ges. 42, 3157 (1909); A. Michael, Ber. d. d. chem. Ges. 43, 464 (1910); B. N. Menschutkin, Ber. d. d. chem. Ges. 42, 4020 (1909). 
bei dieser Temperatur die Endausbente an Ester nicht größer als der Betrag nach einer Stunde, beim destillierten Phytol aber sinkt die Ausbeute sogar auf 7 Proz. infolge einer sekundären Zersetzung von entstandenem Ester (Bildung von Phytadien). Die Versuche 3 und 4 sind gleichzeitig ausgeführt worden. Einen ganz analogen Fall für das Zurückgehen des gebildeten Esters bis auf wenige Prozente beobachten wir bei zwei anderen primären Alkoholen, Geraniol und Nerol. ${ }^{1}$ ) Das Verhalten des Phytols gegen Phthalsäureanhydrid erklärt diese Anomalie.

\begin{tabular}{|c|c|c|c|c|c|c|c|c|}
\hline \multirow{2}{*}{$\mathrm{Nr}$. } & \multirow{2}{*}{\multicolumn{3}{|c|}{ Alkohol }} & \multicolumn{2}{|c|}{ Faktor } & \multirow{2}{*}{ Temp. } & \multirow{2}{*}{ Zeit } & \multirow{2}{*}{$\begin{array}{l}\text { Ester } \\
\text { Proz. a } \\
\text { angew. } \\
\text { Siüre }\end{array}$} \\
\hline & & & & ber. & angew. & & & \\
\hline 1 & $\beta$-Phytol & . & & 0,1685 & 0,1692 & $156^{\circ}$ & 1 Stunde & 34,5 \\
\hline 2 & " & . & . & 0,1685 & 0,1672 & 155 & 144 Stunden & 6,9 \\
\hline 3 & , & . & & 0,1685 & 0,1688 & 155 & $144 \quad$, & 6,8 \\
\hline 4 & $\alpha-\quad$, & - & & 0,1685 & 0,1694 & 155 & 144 & 29,5 \\
\hline 5 & Geraniol & . & & 0,2803 & 0,2796 & 155 & 144 & 3,8 \\
\hline 6 & Nerol. & . & & 0,2803 & 0,2842 & 155 & 144 & 3,3 \\
\hline
\end{tabular}

Die Anfangsgeschwindigkeiten sind bei den Olefinalkoholen niedriger als bei den gesättigten. Wenngleich diese Unterschiede bei den höher molekularen, sogar bei dem doppelt ungesättigten Geraniol und Nerol, viel kleiner sind als bei dem von Menschutkin untersuchten Allylalkohol (Anfangsgeschwindigkeit 36,1; Esterifizierungsgrenze 59,4), so bleiben sie doch deutlich. Auch bei einem sekundären Olefinalkohol, dem Cholesterin, und seinem Dihydroderivat ${ }^{2}$ ) fanden wir eine analoge Differenz. Die Esterifizierungsgrenzen nehmen bei den nngesättigten Alkoholen mit steigendem Molekular-

1) Wix verdanken reine Präparate von Geraniol und Nerol der Frenndlichkeit der Firma Heine \& Co. in Leipzig. Die beiden Alkohole waren durch ihre Urethane gereinigt und fraktioniert.

2) R. Willstäter und E. W. Mayer, Ber.d. d. chem. Ges. 41, 2199 (1908). 
gewichte $\mathrm{zu}$, aber sie sind gleichfalls etwas tiefer als die entsprechenden Werte der Paraffinalkohole.

\begin{tabular}{|c|c|c|c|c|c|c|c|}
\hline \multirow{2}{*}{ Nr. } & \multirow{2}{*}{\multicolumn{2}{|c|}{ Alkohol }} & \multicolumn{2}{|c|}{ Faktor } & \multirow{2}{*}{ 'Temp. } & \multirow{2}{*}{ Zeit } & \multirow{2}{*}{$\begin{array}{l}\text { Ester } \\
\text { Proz. d. } \\
\text { angew. } \\
\text { Säure }\end{array}$} \\
\hline & & & ber. & augew. & & & \\
\hline 7 & Oleinalkohol & - & 0,1829 & 0,1806 & $155^{\circ}$ & 1 Stunde & 42,2 \\
\hline 8 & $"$ & . & 0,1829 & 0,1815 & 155 & $1 " n$ & 42,3 \\
\hline 9 & ", & . & 0,1829 & 0,1829 & 155 & 144 Stunden & 70,7 \\
\hline 10 & Erutylalkoho & . & 0,1540 & 0,1538 & 155 & 1 Stunde & 41,6 \\
\hline 11 & $"$ & . & 0,1540 & 0,1569 & 155 & 144 Stunden & 73,6 \\
\hline 12 & Geraniol. & - & 0,2803 & 0,2805 & 155 & 1 Stunde & 43,5 \\
\hline 13 & Nerol . . & . & 0,2803 & 0,2753 & 155 & $1 n$ & 42,9 \\
\hline 14 & Cholesterin & . & 0,1339 & 0,1351 & 154 & $"$ & 27,8 \\
\hline 15 & " & . . & 0,1339 & 0,1356 & 154 & 1 & 28,5 \\
\hline 16 & Dihydrochole & sterin & 0,1334 & 0,1311 & 154 & $"$ & $\mathbf{3 0}, 0$ \\
\hline 17 & $"$ & & 0,1334 & 0,1323 & 156 & $"$ & 30,3 \\
\hline
\end{tabular}

Für diese Versuche haben wir den noch unbekannten

$$
\text { Erucylalkohol, } \mathrm{C}_{22} \mathrm{H}_{44} \mathrm{O} \text {, }
$$

nach der schönen Methode von L. B o uveault und G. B]anc dargestellt. Die siedend heiße Mischung von $15 \mathrm{~g}$ Erucasäureäthylester (Siedepunkt zwischen 226 und $233^{\circ}$ bei $8,5 \mathrm{~mm}$ Druck) mit $30 \mathrm{~g}$ Amylalkohol ließen wir zl $15 \mathrm{~g}$ Natrinm fließen. Die stürmische Reaktion wurde durch Erhitzen unterstützt und das Metall durch heftiges Schütteln in kleine Kugeln zerteilt. Sobald Krusten von Natriumamylat sich ansetzten, fügten wir langsam in kleinen Portionen innerhalb $2-21 / 2$ Stunden noch $120 \mathrm{~g}$ Amylalkohol hinzu. Dann bliesen wir den Amylalkohol mit Wasserdampf ab und isolierten den Erucylalkohol durch häufiges Anschütteln der Erucaseife mit Äther und Dekantieren in einer Ausbeute von $3-4 \mathrm{~g}$.

Den Frucylalkohol kann man jdurch Abkühlen der heiß gesättigten Lösung in Holzgeist auf $-30^{\circ}$ umkrystallisieren. Die dreimal umkrystallisierte Substanz destillierte unter $10 \mathrm{~mm}$ Druck scharf bei $240,5-241,5^{\circ}$ und 
erstarrte zu spitz rhomboedrischen Krystallen vom Schmelzpunkt $34,5-35,5^{\circ}$.

$0,1934 \mathrm{~g}$ gaben $0,5764 \mathrm{CO}_{2}$ und $0,2348 \mathrm{H}_{2} \mathrm{O}$.

$\begin{array}{ccc} & \text { Ber. für } \mathrm{C}_{22} \mathrm{H}_{44} \mathrm{O} & \text { Gef. } \\ \mathrm{C} & 81,40 & 81,28 \\ \mathrm{H} & 13,67 & 13,58\end{array}$

Erucylalkohol ist eine paraffinähnliche Substanz, die sich in der Kälte leicht löst in Petroläther, Benzol und Fisessig, mäßig in den Alkoholen. Hr entfärbt Permanganat momentan in Fisessiglösung, wie auch Frucasäure, während diese in Sodalösung nur träge die von Baeyersche Reaktion zeigt. Der ungesättigte Alkohol addiert bei $0^{\circ}$ in Chloroform glatt $1 \mathrm{Mol}$. Brom; sein Dibromid bildet, aus Holzgeist und aus Essigester umkrystallisiert, nierenartige Drusen oder seidenglänzende Prismen vom Schmelzp. 45-45,5 ${ }^{\circ}$. Es ist leicht löslich in Essigester and Benzol, mäßig in Petroläther, schwer in kaltem Methylalkohol.

$0,1836 \mathrm{~g}$ gaben 0,1415 AgBr.

$$
\begin{array}{ccc} 
& \text { Ber. für } \mathrm{C}_{22} \mathrm{H}_{44} \mathrm{OBr}_{2} & \text { Gef. } \\
\mathrm{Br} & \mathbf{3 3 , 0 2} & 34,80
\end{array}
$$

Der Erucylalkohol wird bei Gegenwart von Platin durch Wasserstoff leicht in den gesättigten Alkohol verwandelt. Der gegen Brom oder Permanganat beständige Dokosylalkohol krystallisiert aus Chloroform in glänzenden Schuppen, die bei $71-71,5^{\circ}$ schmelzen. Er ist schwer löslich in kaltem Äther, leicht in warmem, in Chloroform und Petroläther mäßig in der Kälte, leicht in der Wärme, in kaltem Holzgeist und Alkohol leicht löslich.

$0,1927 \mathrm{~g}$ gaben $0,5731 \mathrm{CO}_{2}$ und $0,2460 \mathrm{H}_{2} \mathrm{O}$.

$\begin{array}{ccc} & \text { Ber. für } \mathrm{C}_{22} \mathrm{H}_{46} \mathrm{O} & \text { Gef. } \\ \mathrm{C} & 80,90 & 81,11 \\ \mathrm{H} & \mathbf{1 4 , 2 0} & 14,28\end{array}$

Das Phenylurethan des Dokosylalkohols bildet beim Umkrystallisieren aus Essigester lange seidenglänzende Prismen, an den Enden schräg abgeschnitten. Schmelzpunkt $86-86,5^{\circ}$. 
$0,1915 \mathrm{~g}$ gaben $6,0 \mathrm{cem}$ Stickgas bei $17^{\circ}$ und $724 \mathrm{~mm}$ Druck.
Ber. für $\mathrm{C}_{29} \mathrm{H}_{51} \mathrm{O}_{2} \mathrm{~N}$
Gef.
$\mathbf{N}$
3,15
3,44

b) Dihydrophytol und andere Paraffinalkohole.

Die Anfangsgeschwindigkeit, die sonst ziemlich unabhängig vom Molekulargewicht $=47$ bis 48 gefunden wird, erscheint bei dem Dihydrophytol etwas zu niedrig. Für die Grenze der Esterbildung gibt das Dihydrophyto] einen entschieden tieferen Wert als das normale Isomere. Auch das Beispiel des Tetrahydrogeraniols spricht dafür, daß die Verzweigung der Kohlenstoffkette die Esterifizierungsgrenze herabsetzt. Hingegen beobachten wir bei Dihydrophytol und Arachylalkohol hinsichtlich der „relativen Anfangsgeschwindigkeit" (Dihydrophytol 62,8 und Arachylalkohol 62,6) nicht den Einfluß der Verzweigung, den Menschutkin beim Butyl- und Isobutylalkohol verzeichnet hat. Mit wachsendem Molekulargewicht finden wir in Übereinstimmung mit den älteren Beobachtungen die Grenze der Esterbildnng ansteigend.

\begin{tabular}{|c|c|c|c|c|c|c|}
\hline \multirow{2}{*}{ Nr. } & \multirow{2}{*}{ Alkohol } & \multicolumn{2}{|c|}{ Faktor } & \multirow{2}{*}{ Temp. } & \multirow{2}{*}{ Zeit } & \multirow{2}{*}{$\begin{array}{l}\text { Ester } \\
\text { Proz. d. } \\
\text { angew. } \\
\text { Säure }\end{array}$} \\
\hline & & ber. & angew. & & & \\
\hline 18 & Dihydrophytol . . & 0,1675 & 0,1673 & $155^{\circ}$ & 1 Stunde & 45,8 \\
\hline 19 & . & 0,1675 & 0,1701 & 156 & 144 Stunden & 73,0 \\
\hline 20 & " $\quad$. . & 0,1675 & 0,1681 & 155 & $144 \quad n$ & 73,2 \\
\hline 21 & Arachylalkohol. . & 0,1675 & 0,1664 & 155 & 1 Stunde & 47,7 \\
\hline 22 & & 0,1675 & 0,1679 & 155 & 144 Stunden & 76,2 \\
\hline 23 & Tetrahydrogeraniol & 0,2751 & 0,2732 & 155 & 1 Stunde & 48,0 \\
\hline 24 & $"$ & 0,2751 & 0,2762 & 155 & 144 Stunden & 68,5 \\
\hline
\end{tabular}

Dihydrophytol liefert nach der Methode von J. Dumas und J.S. Stass ${ }^{1}$ ) die entsprechende Carbonsäure in einer Ausbeute von über 50 Proz. der Theorie. Beim Erhitzen der Mischung des Alkohols mit ausgeglühtem Natronkalk in einem einseitig geschlossenen Rohr begann dio Ent-

1) Diese Annalen 35, 129 (1840). 
wickelung von Wasserstoff bei $260^{\circ}$; die Temperatur warde auf $280^{\circ}$ gesteigert, solange als Wasserstoff entwich. Der saure Anteil des Reaktionsproduktes war reine Phytansäure (Analyse I).

Noch besser war die Ausbente bei der Oxydation mit Chromsäure in Fisessig unter Zusatz von Kaliumbisulfat nach dem Verfahren, das uns für den Abbau des Phytols gedient hat (Präparat für Bestimmung II).

Phytansäure ist ein schwer bewegliches farbloses öl rom Siedep. $221^{\circ}$ unter $7,5 \mathrm{~mm}$ Druck, das ist vom gleichen Siedepunkt mit Stearinsäure.

$$
\mathrm{d}_{4}^{0}=0,8879, \quad \mathrm{~d}_{4}^{20}=0,8761 .
$$

I. $0,1637 \mathrm{~g}$ gaben $0,4605 \mathrm{CO}_{2}$ und $0,1909 \mathrm{H}_{2} \mathrm{O}$.

II. $0,1738 \mathrm{~g} \quad, \quad 0,4922 \quad \mathrm{CO}_{9} \quad, \quad 0,2031 \quad \mathrm{H}_{2} \mathrm{O}$.

\begin{tabular}{cccc} 
& Ber. für & \multicolumn{2}{c}{ Gef. } \\
& $\mathrm{C}_{20} \mathrm{H}_{40} \mathrm{O}_{2}$ & I & II \\
$\mathrm{C}$ & 76,85 & 76,72 & 77,24 \\
$\mathrm{H}$ & 12,94 & 13,04 & 13,07
\end{tabular}

Die Säure wurde in alkoholischer Lösung unter Anwendung von Phenolphthalein titriert.

$0,2131 \mathrm{~g}$ erforderten $6,87 \mathrm{ccm}{ }^{n} / 10^{-} \mathrm{Ba}(\mathrm{OH})_{2}$, ber. für $\mathrm{C}_{20} \mathrm{H}_{40} \mathrm{O}_{z}$ $6,87 \mathrm{ccm}$.

Phytansäure ist mit den gewöhnlichen Solvenzien mischbar; sie wird aus ätherischer Lösung durch Ammoniakgas nicht gefällt. Sie addiert nicht Brom und ist in Eisessiglösung gegen Permanganat momentan beständig, entfärbt aber allmählich das Reagens, und zwar schneller als Dihydrophytol.

Silbersalz, $\mathrm{C}_{20} \mathrm{H}_{39} \mathrm{O}_{2} \mathrm{Ag}$. In alkoholischer Lösung gab phytansaures Natrinm mit Silbernitrat eine Fällung, die ans Benzol mit Holzgeist umgeschieden wurde. Das Salz ist in Alkohol und Äther schwer, in kaltem Holzgeist sehr schwer, in Benzol beträchtlich löslich. Es bräunt sich allmählich beim Erhitzen, stark bei $165^{\circ}$ unter Zusammenschrumpfen und schmilzt bei $177-177,5^{\circ}$.

$0,1677 \mathrm{~g}$ gaben $0,0435 \mathrm{Ag}$.

$$
\begin{array}{ccc} 
& \text { Ber. für: } \mathrm{C}_{20} \mathrm{H}_{38} \mathrm{O}_{2} \mathrm{Ag} & \text { Gef. } \\
\mathrm{Ag} & 25,75 & \mathbf{2 5 , 9 4}
\end{array}
$$


Phytansäureamid, $\mathrm{C}_{19} \mathrm{H}_{39} \mathrm{CONH}_{2}$. Beim Eintragen des mit Phosphortrichlorid bereiteten Säurechlorides in abgekühltes konz. Ammoniak schied sich das Amid als wachsartige Masse aus. Nach wiederholtem Umkrystallisieren, wofür die Lösung in Petroläther und in Methylalkohol eingeengt und stark abgekühlt werden mußte, schmolz die Substanz bei $53-53,5^{\circ}$. Sie ist in den angeführten Solvenzien und in Äther sowie Aceton leicht löslich und zeigt Löslichkeitsunterschiede erst bei tiefen Temperaturen. Läßt man einen Tropfen petrolätherischer Lösung auf dem Objektträger verdunsten, so beobachtet man schöne Prismen eingebettet in eine paraffinartige Grund masse.

$0,2659 \mathrm{~g}$ gabeu $11,1 \mathrm{cem}$ Stickgas bei $17^{\circ}$ und $732 \mathrm{~mm}$ Drtuck.

$$
\begin{array}{cr}
\text { Ber. für } \mathrm{C}_{20} \mathrm{H}_{41} \mathrm{ON} & \text { Gef. } \\
4,50 & 4,64 \\
\text { I'-Phytensäure, }^{\prime} & \mathrm{C}_{20} \mathrm{H}_{38} \mathrm{O}_{2} \text {. }
\end{array}
$$

Bei der Oxydation von Phytol mit Chromsäure zum Keton $\mathrm{C}_{15} \mathrm{H}_{30} \mathrm{O}$ tritt unter allen Umständen als Nebenprodukt Säure auf, und zwar zumeist ein Gemisch von Phytensäure mit gesättigten Säuren von geringerer Kohlenstoffatomzahl. Unter den günstigsten Bedingungen für die Darstellung des Ketons, nämlich bei der Einwirkung von 5 At. Sauerstoff in Eisessig bei Gegenwart von Kaliumbisulfat, wird zwar die Ausbeute an Säure nur gering, aber in diesen Falle erweist sich der saure Anteil als reine Phytensäure. Wir verarbeiteten $50 \mathrm{~g}$ Phytol in acht Portionen von 6,25 g in Eisessig unter Zusatz des feingepulverten Kaliumbisnlfates und führten die Oxydation mit der konz. wäßrigen Lösung von je $7,1 \mathrm{~g}$ Chromsäure aus. Die Temperatur stieg dabei auf $55^{\circ}$. Aus der ätherischen Lösung des rohen Ketons trennt man mit sehr verdünnter Natronlange das saure Nebenprodukt ab. Mit Hilfe von Äther isoliert und nach dem Eindampfen von Spuren desselben durch Erwärmen mit eingetauchter Kapillare im Vakuum befreit, bildete die Säure ein bräunliches Öl in einer Ausbente von $3,6 \mathrm{~g}$. 
Bei der Destillation im Vakuum von $11,5 \mathrm{~mm}$ ging die Phytensäure zwischen 210 und $220^{\circ}$ über als ein noch schwach gelbliches dickes Öl; ihr spez. Gewicht ist beträchtlich höher als das der gesättigten Säure, nämlich $\mathrm{d}_{4}^{0}=0,917$ und $\mathrm{d}_{4}^{20}=0,893$.

$0,3005 \mathrm{~g}$ gaben $0,8491 \mathrm{CO}_{2}$ und $0,3408 \mathrm{H}_{2} \mathrm{O}$.

$\begin{array}{ccc} & \text { Ber. für } \mathrm{C}_{20} \mathrm{H}_{38} \mathrm{O}_{2} & \text { Gef. } \\ \mathrm{C} & 77,34 & 77,06 \\ \mathrm{H} & 12,34 & 12,69\end{array}$

$0,3914 \mathrm{~g}$ erforderten $1,22 \mathrm{~cm} \mathrm{n-KOH}$ statt ber. $1,26 \mathrm{ccm}$.

Phytensäure ist mit den üblichen organischen Solvenzien mischbar. Sie reduziert in Eisessiglösung Per manganat momentan und addiert in verdünnter Tetrachlorkohlenstofflösung langsam die molekulare Menge von Brom.

$0,3785 \mathrm{~g}$ entfärbten in mehr als einem Tage ohne Entwickelung

von Bromwassertoff $0,1924 \mathrm{~g}$ Brom, das ist 98,7 Proz. der Theorie und weitere $0,0107 \mathrm{~g}$ unter starker Bromwasserstoffabspaltung.

Jodzahl nach v. Hübl.

$0,1536 \mathrm{~g}$ erforderten entsprechend $9,7 \mathrm{cem}{ }^{\mathrm{n}} / 10^{-}$Thiosulfat $0,1232 \mathrm{~g}$

Jod, das ist 0,98 Mol. Jodzahl gef. 80,2, ber. 81,8.

Die Phytensäure enthält die Äthylenbindung am gleichen Ort wie Phytol. Sie erweist sich als $\Delta^{\beta, \gamma_{-} \text {Säure }}$ durch ihre Lactonisierung nach der Methode von R.Fittig. Wir erhitzten die ungesättigte Säure mit dem Gemisch gleicher Volumina konz. Schwefelsäure und Wasser unter Durchschütteln zum Sieden und fanden hiernach das Öl völlig alkaliunlöslich und gesättigt. Es destillierte unter $10 \mathrm{~mm}$ Druck bei ungefähr $170^{\circ}$.

$0,1069 \mathrm{~g}$ galuen $0,3046 \mathrm{CO}_{2}$ und $0,1206 \mathrm{H}_{2} \mathrm{O}$.

$\begin{array}{ccc} & \text { Ber. für } \mathrm{C}_{20} \mathrm{H}_{38} \mathrm{O}_{2} & \text { Gef. } \\ \mathrm{C} & 77,34 & 77,71 \\ \mathrm{H} & 12,34 & 12,62\end{array}$

Das so gebildete $\gamma$-Lacton ist bereits beobachtet worden von $R$. Willstätter und F. Hocheder. ${ }^{2}$ ) Unter

1) Diese Annalen 283, 51 (1894).

2) Diese Annalen 354, 254 (1907). 
etwas anderen Bedingungen der Oxydation mit Chromsäure war eine komplexe Chromverbindung erhalten worden, die beim Kochen mit alkoholischer Kalilauge das Chrom abgab und das indifferente Isomere der Phytensäure als ein dickes öl lieferte.

Silbersalz, $\mathrm{C}_{20} \mathrm{H}_{37} \mathrm{O}_{2} \mathrm{Ag}$. Phytensaures Kalium gibt in alkoholischer Lösung mit Silbernitrat eine flockige weiße Fällung, die in Alkohol und Äther nicht löslich ist und von Benzol gelatiniert wird.

$0,2003 \mathrm{~g}$ gaben $0,4207 \mathrm{CO}_{2}$ und $0,1667 \mathrm{H}_{2} \mathrm{O}$.

$0,0849 \mathrm{~g} \quad, \quad 0,0219 \mathrm{Ag}$.

$\begin{array}{lcr} & \text { Ber. für } \mathrm{C}_{20} \mathrm{H}_{37} \mathrm{O}_{2} \mathrm{Ag} & \text { Gef. } \\ \mathrm{C} & 57,54 & 57,28 \\ \mathrm{~B} & 8,94 & 9,31 \\ \mathrm{Ag} & 25,86 & 25,80\end{array}$

Phytan, $\mathrm{C}_{20} \mathrm{H}_{42}$.

Der gesättigte Kohlenwasserstoff entsteht rasch und glatt durch die Reduktion von Phyten mit Platin und Wasserstoff (Analyse I). Ferner begleitet er das Dihydrophytol sowohl bei der elektrolytischen Reduktion von Phytol, wie bei der Hydrierung mittelst der Platinmethode. Wir trennten das Phytan durch gründliches Fraktionieren unter vermindertem Druck von dem höher siedenden Alkohol und reinigten es durch Verdünnen der Vorläufe mit der doppelten Menge Methylalkohol. Der in Holzgeist schwer lösliche Teil gab bei weiterer zweimaliger Destillation reines Phytan vom Siedep. 169,50 unter 9,5 mm Druck (Analyse II).

I. $0,1874 \mathrm{~g}$ gaben $0,5821 \mathrm{CO}_{2}$ und $0,2517 \mathrm{H}_{2} \mathrm{O}$.

II. $0,2080 \mathrm{~g} \quad, \quad 0,6451 \quad \mathrm{CO}_{2} \quad, \quad 0,2770 \mathrm{H}_{2} \mathrm{O}$.

\begin{tabular}{cccc} 
& Ber. für & \multicolumn{2}{c}{ Gef. } \\
& $\mathrm{C}_{20} \mathrm{H}_{42}$ & I & II \\
$\mathrm{C}$ & 85,01 & 84,71 & 84,59 \\
$\mathrm{H}$ & 14,99 & 15,02 & 14,90
\end{tabular}

Phytan ist eine farblose, leicht bewegliche, in flüssiger Luft krystallinisch erstarrende Flüssigkeit von $d_{4}^{0}=0,803$. Es ist anders als die Alkohole mit 20 Kohlenstoffatomen in Holzgeist und Eisessig kalt schwer löslich, leichter 
in der Wärme. Mit Petroläther und vielen anderen Iösungsmitteln ist Phytan mischbar. Es ist in Chloroform völlig beständig gegen Brom und wirkt in Eisessig nur äußerst langsam auf Kaliumpermangat ein.

\section{Phyten, $\mathrm{C}_{20} \mathrm{H}_{40}$.}

Ein Phyten entstand ${ }^{1}$ ) bei der Behandlung von Phytol mit Jodwasserstoff und dann mit Zinkstaub als Hauptprodukt. Es ist mit dem Siedep. $167-168^{\circ}(7,5 \mathrm{~mm}$ Druck) und $d_{4}^{0}=0,817$ beschrieben worden.

Bei dieser eigentümlichen Umwandlung des Olefinalkoholes in das Olefin wird in der ersten Phase das alkoholische Hydroxyl durch den Jodwasserstoff esterifiziert und ein zweites Molekül Jodwasserstoff an die Doppelbindung addiert. Trotzdem die zwei eingetretenen Jodatome nicht benachbart sind, gibt das gebildete Dijodphytan, das einer der beiden Strukturformeln

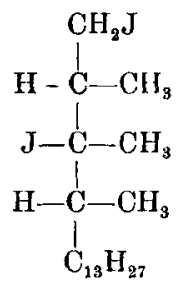

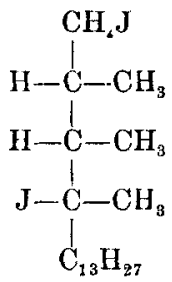

entspricht, bei der Reduktion den ungesättigten Kohlenwasserstoff. Wir bestimmten bei eintägigem Schütteln von Phytol mit konzentriert-wäßriger Jodwasserstoffsäure den angewandten und den übriggebliebenen Jodwasserstoff und fanden, daß $5 \mathrm{~g}$ Phytol 4,0 statt ber. (für $2 \mathrm{Mol}$. JH) $4,4 \mathrm{~g}$ und $6 \mathrm{~g}$ Phytol $5,2 \mathrm{~g}=$ ber. $5,2 \mathrm{~g}$ Jodwasserstoff verbraucht hatten.

Das Dijodid, ein schweres öl, das eine kleine Menge von Krystallen (Schmelzp. 108-109 ${ }^{\circ}$ ) enthielt, reduzierten wir mit Zinkstaub und Eisessig, oder mit Zinkstaub and . Iodwasserstoff und erhielten so unreines Phyten. Durch Umscheiden aus Holzgeist und Behandlung mit Per-

1) Diese Annalen 354, 255 (1907). 
manganat und Eisessig, wobei es von einer stärker ungesättigten Beimischung befreit wurde, erhielten wir das Phyten in reinem Zustand.

Der Kohlenwasserstoff reduziert Permanganat in Eisessig nur sehr träge, aber er addiert beim Schütteln mit wäßriger Jodwasserstoffsäure ein Molekül davon und verbindet sich auch in Chloroformlösung mit genau 1 Mol. Brom; diese Addition beginnt langsam und wird erst rasch, wenn ein größerer Teil des erforderlichen Broms anf einmal zngesetzt wird.

$0,4430 \mathrm{~g}$ erforderten 2,60 Brom statt ber. $\mathrm{C}_{20} \mathrm{H}_{40} 2,55 \mathrm{~g}$.

Den Siedepunkt des Phytens beobachteten wir unter $10,5 \mathrm{~mm}$ Druck bei ungefähr $177-178^{\circ}$.

\section{Phytadien $\mathrm{C}_{20} \mathrm{H}_{38}$.}

Bei eintägigem Kochen von $3 \mathrm{~g}$ Phytol mit $3 \mathrm{~g}$ Phthalsäureanhydrid und $13 \mathrm{~g}$ trocknem Benzol im Baboschen Trichter begann die anfangs klare Lösung bald Phthalsäure auszuscheiden, und die Abscheidung entsprach schließlich fast der molekularen Menge. Um ihn von beigemischtem Anhydrid zu befreien, ließen wir den Abdampfrückstand der benzolischen Lösung von zwei Versuchen mit methylalkoholischem Kali stehen und isolierten dann das Phytadien aufs neue mit Hilfe von Äther. In größerem Maßstabe haben wir den Kohlenwasserstoff aus $\beta$-Phytol dargestellt. $\operatorname{Fr}$ destillierte unter $13 \mathrm{~mm}$ Druck bei etwa $186-187^{\circ}$ als farbloses, ziemlich leicht bewegliches Öl.

$0,1100 \mathrm{~g}$ gaben $0,3463 \mathrm{CO}_{2}$ und $0,1366 \mathrm{H}_{2} \mathrm{O}$.

$$
\begin{array}{ccc} 
& \text { Ber. für } \mathrm{C}_{90} \mathrm{H}_{38} & \text { Gef. } \\
\mathrm{C} & 86,24 & 85,86 \\
\text { II } & 13,76 & 13,89
\end{array}
$$

$\mathrm{d}_{4}^{0}=0,826$. Phytadien ist im Gegensatz zum Phytan und Phyten mit Holzgeist und Eisessig mischbar, ebenso mit Petroläther. Es entfärbt Permanganat in Eisessig und addiert Brom; ein Molekül wird schnell aufgenommen, ein zweites äußerst langsam unter Entwickelung 
von Bromwasserstoff und ohne daß ein Ende im Verbranch von Brom bestimmt werden kann.

$0,2503 \mathrm{~g}$ entfärbten momentan $0,1418 \mathrm{~g}$ Brom; ber. für $\mathrm{C}_{20} \mathrm{H}_{38}$ $1 \mathrm{Mol}=0,1440 \mathrm{~g} \mathrm{Br}$.

Die Jodzahl deutet hingegen darauf hin, daß der Kohlenwasserstoff ein Diolefin ist.

$0,2610 \mathrm{~g}$ erforderten entsprechend $33,6 \mathrm{cem} \mathrm{n/10}$ - Thiosulfat $0,4267 \mathrm{~g}$ Jod d. i. $1,8 \mathrm{Mol}$.

\section{Ozonide des $\alpha$-Phytols.}

Für die Behandlung des Phytols mit Ozon sind uns die Methoden maßgebend gewesen, die C. Harries ${ }^{1}$ ) in seiner ersten Abhandlung ,Über die tinwirkung des Ozons auf organische Verbindungen" gelehrt hat. Wir haben $500 \mathrm{~g} \alpha$-Phytol mit Ozon oxydiert. Unsere Arbeitsweise und die erhaltenen Ozonide beschreiben wir im Folgenden, die Spaltung derselben bildet den Inhalt eines späteren Abschnittes (siehe Keton $\mathrm{C}_{15} \mathrm{H}_{30} \mathrm{O}$ ).

Zur Erzengung des Ozons dient uns ein Ozonapparat von Siemens \& Halske, der aus fünf hintereinander geschalteten Berthelotröhren besteht; für seinen Betrieb steht uns der auf 10000 Volt transformierte städtische Wechselstrom von 220 Volt zur Verfügung. Mit dem neuen Apparat haben wir (1908) bei verschiedenen Durchströmungsgeschwindigkeiten nachstehende Ausbeuten an Ozon erhalten, die nach A. Ladenburg und R. Quasig ${ }^{2}$ ) bestimmt worden sind. ${ }^{3}$ )

1) Diese Annalen 343, 311 (1905).

2) Ber. d. d, chem. Ges. 34, 1184 (1901).

3) Der ozonisierte Sauerstoff entwickelte beim Durchströmen der Absorptionsgefäße mit Jodkaliumlösung stets die in der Literatur (Gmelin-Kraut-Friedheim Bd. I, 47) oft besprochenen weißen Nebel. A. Engler und W. Wild (Ber. d. d. ehem. Ges. 29, 1929 [1896], siehe auch Garzarolli-Thurnlackh, Monatsh. f. Chem. 22, 955 [1901]) haben angegeben, daB die Nebel aus Jodpentoxyd bestehen und diese Ansicht ist auch in Lehrbücher übergegangen. Wir stoßen indessen auf ernstliche Widersprüche gegen diese Auffassung. Die Nebel, die am stärksten bei Anwendung von n/2-Jodkaliumlösung auftraten, konnten wir durch eine Zehnkugel- 
22 Liter pro Stunde; $0,12 \mathrm{~g} \mathrm{O}_{3}$ aus 1 Liter; 8,4 proz. Ozon.

11-12 " " $" \quad 0,13-0,14 \mathrm{~g} \mathrm{O}_{3}$ aus 1 Liter; 9,8 proz. Ozon

$5 " \quad " \quad 0,16 \mathrm{~g} \mathrm{O}_{3}$ aus 1 Liter; 11,1 proz. Ozon.

Unser Apparat ist leider nicht wie der des Herrn Harries ${ }^{1}$ ) mit den Jahren besser geworden, sondern er hat uns später kein so hochprozentiges Ozon mehr geliefert. Wir haben ihn meistens mit einer Durchströmung von 12 Liter pro Stunde arbeiten lassen und später stets 0,08-0,1 g $\mathrm{O}_{3}$ aus 1 Liter Sauerstoff, also 5,6-6,3 prozentiges Ozon bekommen.

Wir lösen je $5 \mathrm{~g}$ Phytol in $36 \mathrm{~g}$ getrocknetem Chloroform. Unter Kühlung leiten wir nur während einer Stunde gegen 12 Liter 6 prozentiges Ozon ein (berechnet sind 10 Liter); sobald die Chloroformlösung gegen Brom beständig ist, passiert Ozon die Flüssigkeit and die Behandlung wird abgebrochen. Das Chloroform wird im Bad von $20^{\circ}$ unter vermindertem Druck aus einem Helmkolben ${ }^{2}$ ) bis zur Gewichtskonstanz ${ }^{3}$ ) abgedampft. Die Ausbeute an rohem Ozonid ist fast quantitativ; sie betrug z. B. aus 5,33 g Phytol 6,15 g statt berechneter $6,19 \mathrm{~g}$ und aus $90 \mathrm{~g}$ Phytol $98 \mathrm{~g}$ statt theoretischer 104,6 $\mathrm{g}$.

Rohozonid. Das Produkt bildet einen dicken, nicht ganz klaren, schwach grünlichen Sirup von stechendem Geruch, dem sich etwas Estergeruch beimischt. Das Rohozonid und ebenso das konstant getrocknete Ozonid $\mathrm{C}_{20} \mathrm{H}_{40} \mathrm{O} . \mathrm{O}_{3}$ zeigt alle von Harries angegebenen Merkmale der Ozonide; es setzt nämlich aus neutraler Jodid-

röhre, sowie eine lange festbeschickte Röhre mit feuchter Glaswolle nur zum kleinen 'Teile zurückhalten. Sie traten auch auf, wenn die Jodkaliumlösung viel freies Ätzkali enthielt, sie passierten, ohne Jod auszuscheiden, allerdings auch ohne geschwächt zu werden, angesäuertes Jodkalium. Auch konzentrierte Schwefelsäure brachte sie nicht zum Verschwinden. Die Nebel waren ohne Reaktion auf Lackmus und Indigolösung und ohne Wirkung beim Einatmen.

1) Diese Annalen 374, 311 (1910).

2) Diese Annalen 371, 19 (1910).

3) Nämlich eine halbe Stunde lang in der zweiten Dezimale nicht abnehmend. 
]ösung Jod frei, bleicht Indigotinktur und gibt beim schütteln mit Titansulfat kräftige Hydroperoxydreaktion. Es ist nicht explosiv, aber beim Betupfen mit Schwefelsäure zersetzt es sich stürmisch unter Verkohlung.

Das durch kurze Ozonisierung erhaltene Rohozonid Analyse I) besaß ungefähr die normale Ozonidzusammensetzung $\left(\mathrm{C}_{20} \mathrm{H}_{40} \mathrm{O} . \mathrm{O}_{3}\right)$, ein Produkt der Überozonisierung (Analyse II) näherte sich der Zusammensetzung des Oxozonides $\left(\mathrm{C}_{20} \mathrm{H}_{40} \mathrm{O} . \mathrm{O}_{4}\right)$.

I. $0,2030 \mathrm{~g}$ gaben $0,5099 \mathrm{CO}_{2}$ und $0,2050 \mathrm{H}_{2} \mathrm{O}$.

II. $0,2080 \mathrm{~g} \quad, \quad 0,505+\mathrm{CO}_{2} \quad " \quad 0,1997 \mathrm{H}_{2} \mathrm{O}$.

\begin{tabular}{ccccc} 
& \multicolumn{2}{c}{ Ber. für } & \multicolumn{2}{c}{ Gef. } \\
& $\mathrm{C}_{20} \mathrm{H}_{40} \mathrm{O}_{4}$ & $\mathrm{C}_{20} \mathrm{H}_{40} \mathrm{O}_{5}$ & I & II \\
$\mathrm{C}$ & 69,70 & 66,61 & 68,51 & 66,27 \\
$\mathrm{H}$ & 11,71 & $\mathbf{1 1 , 1 9}$ & 11,30 & 10,50
\end{tabular}

Das Ozonid ist leicht löslich in Petroläther, Ligroin, Benzol, Ather, Eisessig und Essigester; es kann daher nicht nach Harries aus Essigester mit Petroläther umgeschieden werden. Es war überraschend, daß sich das Rohozonid durch Holzgeist in zwei Bestandteile ${ }^{1}$ ) zerlegen ließ, nämlich in unlösliches Oxyd $\mathrm{C}_{20} \mathrm{H}_{40} \mathrm{O} . \mathrm{O}_{2}$ (Moloxyd) and lösliches Oxozonid $\mathrm{C}_{20} \mathrm{H}_{40} \mathrm{O} . \mathrm{O}_{4}$.

Das unlösliche Moloxyd bildete bei kurzem Ozonisieren etwa ein Drittel des Gemisches, dagegen sank es bei zu langem Behandeln mit Ozon (Präp. f. Analyse) auf ein /ehntel vom Rohprodukt und noch weniger. Die Fraktionierung von $98 \mathrm{~g}$ Rohozonid mit Methylalkohol lieferte $28 \mathrm{~g}$ Moloxyd und $62 \mathrm{~g}^{2}$ ) Oxozonid. Bei starkem $\mathrm{Ab}$ kïhlen der methylalkoholischen Ozonidlösung schied sich das Moloxyd in krystallinischem Zustande ab und die Lösung konnte dekantiert werden. Die Auflösung und Abscheidung bei tiefer Temperatur wiederholten wir mehrmals und verjagten dann den Holzgeist im Vakuum

1) Siehe die Dissertation von E. W. Mayer, Zürich 1908.

2) Durch einen Unfall war ein kleiner Teil des holzgeistlöslichen Ozonides verlorengegangen. 
bis zur Gewichtskonstanz des Peroxydes. Das Moloxyd stellt bei gewöhnlicher Temperatur ein Öl dar.

Bei der Spaltung durch Verkochen mit Wasser hat das Moloxyd die nämlichen Produkte wie das Oxozonid ergeben und in gleicher Ausbeute.

Im Vakuum über Phosphorpentoxyd wurde das Moloxyd mit einer ganz geringfügigen Abnahme in einem Tage vollkommen gewichtskonstant. Für die Analyse haben vier verschiedene Darstellungen gedient, die Präparate I, II, III waren kurz, IV lang getrocknet.

I. $0,1251 \mathrm{~g}$ gaben $0,3345 \mathrm{CO}_{2}$ und $0,1347 \mathrm{H}_{2} \mathrm{O}$.

II. $0,1890 \mathrm{~g} \quad \# \quad 0,5096 \quad \mathrm{CO}_{\mathrm{z}} \quad, \quad 0,2047 \mathrm{H}_{\mathrm{z}} \mathrm{O}$.

III. $0,1264 \mathrm{~g} " \quad 0,3414 \mathrm{CO}_{2} \quad " \quad 0,1407 \mathrm{H}_{2} \mathrm{O}$.

IV. $0,3324 \mathrm{~g} \quad, \quad 0,3679 \mathrm{CO}_{2} \quad, 0,1491 \mathrm{H}_{\mathbf{g}} \mathrm{O}$.

\begin{tabular}{cccccc} 
& Ber. für & \multicolumn{4}{c}{ Gef. } \\
& $\mathrm{C}_{20} \mathrm{H}_{40} \mathrm{O}_{3}$ & I & II & III & IV \\
$\mathrm{C}$ & 73,10 & $\mathbf{7 2 , 9 2}$ & $\mathbf{7 3 , 5 4}$ & $\mathbf{7 3 , 6 6}$ & $\mathbf{7 3 , 7 2}$ \\
$\mathrm{H}$ & 12,28 & 12,04 & 12,12 & 12,45 & 12,25
\end{tabular}

Das lösliche Ozonid ist nach der Trennung mit Holzgeist für die Analyse durch Eindampfen der Lösung zur annähernden Gewichtskonstanz und kurzes Aufbewahren im Vakuumexsiccator vorbereitet worden. Die Analyse würde zwar gut für das Oxozonid stimmen, aber die unten angeführte Gewichtsabnahme bei der Konstanztrocknung verrät, daß das Produkt ein Molekül Holzgeist gebunden hat.

I. ${ }^{1)} 0,2013 \mathrm{~g}$ gaben $0,4159 \mathrm{CO}_{2}$ und $0,1971 \mathrm{H}_{2} \mathrm{O}$.

II. $0,1742 \mathrm{~g} " 0,4301 \mathrm{CO}_{2}, 0,1782 \quad \mathrm{H}_{2} \mathrm{O}$.

\begin{tabular}{ccccc} 
& \multicolumn{2}{c}{ Ber. für } & \multicolumn{2}{c}{ Gef. } \\
& $\mathrm{C}_{90} \mathrm{H}_{40} \mathrm{O}_{5}$ & $\mathrm{C}_{20} \mathrm{H}_{40} \mathrm{O}_{5}+\mathrm{CH}_{3} \mathrm{OH}$ & I & II \\
$\mathrm{C}$ & 66,61 & 65,89 & 67,18 & 67,34 \\
$\mathrm{H}$ & 11,19 & 11,31 & 10,95 & 11,44
\end{tabular}

Auch an diesem Oxozonid hat sich nämlich etwas Neues gezeigt. Bei monatelangem Aufbewahren im Vakuum über Phosphorpentoxyd erlitt es Dissoziation, durch welche es schließlich reines normales Ozonid der Formel

1) Dieses Präparat stammte aus der durch kurze Ozonisierung dargestellten Probe von Rohozonid der oben angeführten Analyse I.

Annalen der Chemie 378. Band. 
$\mathrm{C}_{20} \mathrm{H}_{40} 0 . \mathrm{O}_{3}$ lieferte, das keine weitere Gewichtsänderung zeigte. Die Gewichtsabnahme bei dieser Verwandlung: entspricht dem Verlust eines Sauerstoffatoms und eines Moleküls Holzgeist.

I. $1,1648 \mathrm{~g}$ verloren in 70 Tagen $0,1469 \mathrm{~g}$.

II. $0,9705 \mathrm{~g} \quad, \quad, 70 \quad, \quad 0,1161 \mathrm{~g}$.

$$
\begin{array}{cccc} 
& \text { Ber. für } & \multicolumn{2}{c}{\text { Gef. }} \\
\mathrm{O}+\mathrm{CH}_{3} \mathrm{OH} & \mathrm{C}_{20} \mathrm{H}_{40} \mathrm{O}_{5} & \text { I } & \text { II } \\
& 12,3 & 12,6 & 11,9
\end{array}
$$

I. $0,1766 \mathrm{~g}$ gaben $0,4573 \quad \mathrm{CO}_{2}$ und $0,1898 \mathrm{H}_{2} \mathrm{O}$.

II. $0,2612 \mathrm{~g} \quad, \quad 0,6755 \mathrm{CO}_{2} \quad " \quad 0,2698 \mathrm{H}_{8} \mathrm{O}$.

\begin{tabular}{lccc} 
& Ber. für & \multicolumn{2}{c}{ Gef. } \\
& $\mathrm{C}_{20} \mathrm{H}_{40} \mathrm{O}_{4}$ & I & II \\
$\mathrm{C}$ & 69,70 & 70,62 & 70,53 \\
$\mathrm{H}$ & 11,71 & $\mathbf{1 2 , 0 2}$ & 11,55
\end{tabular}

\section{Kapitel. Abbauprodukte. A. Ketone.} Keton $\mathrm{C}_{15} \mathrm{H}_{30} \mathbf{0}$.

1. Darstellung mit Chromsäure-Eisessig-Bisulfat.

Mit Chromsäure kann man Phytol an der Stelle der Doppelbindung spalten. Da der Verlauf der Reaktion wesentlich von den Bedingungen abhängt, haben wir die Oxydation so ausgearbeitet, dab das Keton in maximaler Ausbeute und höchstem Reinheitsgrad auftritt, und daB sein saures Nebenprodukt aus einheitlicher Phytensäure besteht. Im ganzen haben wir $53 \mathrm{~g}$ Keton $\mathrm{C}_{15} \mathrm{H}_{30} \mathrm{O}$ aus $95 \mathrm{~g} \alpha$-Phytol mit Chromsäure dargestellt.

Die für die Sprengung der Äthylenbindung berechnete Menge von Chromtrioxyd (2 Atome 0 ) ist unzureichend. Wenden wir so wenig Oxydationsmittel an, so tritt überhaupt fast kein Abbauprodukt auf, sondern das Oxydationsmittel zerstört einen kleinen Teil der Substanz und läbt die Hauptmenge des Phytols intakt (Versuch 2 der Tabelle). Am geeignetsten sind 4-5 Atome Sauerstoff, das ist reichlich so viel, als die Oxydation der Carbinolgruppe zum Carboxyl sowie die Spaltung des Moleküls an der Doppelbindung erfordert. 
Das Oxydationsprodukt ist in allen Fällen in indifferenten und sauren Anteil getrennt worden. Der indifferente Teil war bei gelungenen Versuchen mehr oder weniger reines Keton $\mathrm{C}_{15} \mathrm{H}_{30} \mathrm{O}$, bei einigen mißlungenen unverändertes Phytol. Der saure Anteil bestand aus Phytensäure im Gemisch mit einer gesättigten niedrigeren Säure von ungefähr der Formel $\mathrm{C}_{12} \mathrm{H}_{24} \mathrm{O}_{2}$. Die Zusammensetzung des Säuregemisches ist in mehreren Fällen durch die Jodzahl und die Elementaranalyse ermittelt worden. Die Ausbeuteangaben der nachstehenden Tabelle beziehen sich anf die vom Lösungsmittel quantitativ befreiten Rohprodukte, die analytischen Angaben hingegen auf die Hauptfraktionen der Destillationen im Vakuum.

a) Oxydation in Eisessig (Vers. 1). Die Lösung von $5,5 \mathrm{~g}$ Phytol in $100 \mathrm{ccm}$ Eisessig versetzten wir mit der konzentrierten wäßrigen Lösung von 6,2 $\mathrm{g}$ Chromtrioxyd. Die Oxydation verlief unter Kohlensäureentwickelung und die Temperatur stieg dabei von 17 anf $58^{\circ}$. Die schmutzig grüne Lösung wurde mit Wasser gefällt und ausgeäthert, und die Essigsäure aus dem ätherischen Extrakt gründlich herausgewaschen. Das indifferente Produkt der Oxydation war nicht ganz reines Keton $\mathrm{C}_{15} \mathrm{H}_{30} \mathrm{O}$.

b) Oxydation in Eisessig unter Zusatz von konzentrierter Schwefelsäure (Vers. 6-9 der Tab.). Wir lösten das Phytol in 25 Teilen Eisessig und fügten zugleich mit der konzentrierten Lösung der Chromsäure die zum Binden des Chroms erforderliche Menge Schwefelsäure hinzı. Die Temperatur stieg rapid auf $70-80^{\circ}$ und unter lebhafter Kohlensäureentwickelung war die Oxydation in 4 Minuten beendigt. Die Schwefelsäure fällt das Chromoxyd fast quantitativ in schön krystallinischer Form aus, so daß die Flüssigkeit über dem Chromsalz nur schwach grünlich gefärbt ist. Wir filtrierten vom Sulfat ab und verjagten den Eisessig unter vermindertem Druck, um die Reaktionsprodukte mit $\ddot{A}$ ther aufzunehmen. 
Die Ausbeute an Keton war nach diesem Verfahren am besten bei Anwendung von 4 Atomen Sauerstoff, aber reiner war das Produkt bei der Oxydation mit 5 Atomen.

Von erheblichem Einflub ist der Zeitpunkt des Schwefelsäurezusatzes. Es ist erforderlich, sie zugleich mit dem Chromtrioxyd oder unmittelbar vorher einzutragen. Wenn die Schwefelsäure einige Zeit (z. B. eine halbe Stunde) vorher zugefügt wird, so scheidet sich, wie im ersten Kapitel beschrieben, der Phytoläther aus. Bei einem solchen Versuch (Nr.3 der Tab.) nahm die Oxydation einen ganz anderen Verlauf. Wurde hingegen die Schwefelsäure eine halbe Minute nach dem Chromtrioxyd zugesetzt (Nr.5), so schnellte die bereits auf $60^{\circ}$ angestiegene Temperatur bis auf $90^{\circ}$ und das Chrom war momentan verbraucht. Das Indifferente von diesem Versuch war lediglich unverändertes Phytol.

Das Keton aus verschiedenen von diesen Oxydationsversuchen $(1,6,8)$ schien eher der Zusammensetzung $\mathrm{C}_{13} \mathrm{H}_{26} \mathrm{O}$ oder $\mathrm{C}_{14} \mathrm{H}_{28} \mathrm{O}$ zu entsprechen. Allein der zu tiefe Kohlenstoffgehalt beruhte wohl nur auf Verunreinigungen, und der Hauptmenge nach war die Kohlenstoffkette wahrscheinlich immer zwischen dem 15. und 16. Atom gesprengt. Wir fraktionierten $2,5 \mathrm{~g}$ von solchem unreinen Keton unter $9 \mathrm{~mm}$ Druck und analysierten von den Fraktionen:

$$
\begin{array}{rrr}
\text { I. bis } 168^{\circ} & 0,2 \mathrm{~g} \\
\text { II. } 168-172^{\circ} & 0.8 \mathrm{~g} \\
\text { III. } 172-175^{\circ} & 0,9 \mathrm{~g}
\end{array}
$$

die erste (Best. I) and dritte (Best. II und III) mit Ergebnissen, die für $\mathrm{C}_{15} \mathrm{H}_{30} \mathrm{O}$ genügend stimmten.

I. $0,1432 \mathrm{~g}$ gaben $0,4158 \mathrm{CO}_{2}$ und $0,1692 \mathrm{H}_{2} \mathrm{O}$.

II. $0,2071 \mathrm{~g} \quad, \quad 0,6080 \mathrm{CO}_{2} \quad, \quad 0,2476 \mathrm{H}_{2} \mathrm{O}$.

\begin{tabular}{|c|c|c|c|c|c|}
\hline & \\
\hline & $\mathrm{C}_{15} \mathrm{H}_{30} \mathrm{O}$ & $\mathrm{C}_{24} \mathrm{H}_{28} \mathrm{O}$ & I & II & III \\
\hline$y$ & 79,56 & 79,16 & 79,19 & 80,07 & 80,08 \\
\hline $\mathrm{H}$ & 13,37 & 13,25 & 13,22 & 13,37 & 18,38 \\
\hline
\end{tabular}

III. $0,1761 \mathrm{~g} \quad " \quad 0,5171 \mathrm{CO}_{2} \quad, \quad 0,2106 \mathrm{H}_{2} \mathrm{O}$.

Ber. für 
c) Oxydation in Eisessig bei Gegenwart von Kaliumbisulfat (Tab. Versuch 10,11,12). Der Zusatz des primären Kaliumsulfates bewirkt den glattesten Verlauf der Chromsäureoxydation des Phytols. Die Ausbente an Keton beträgt 73-97 Proz. der Theorie und das Präparat ist nach einmaliger Destillation im Vakuum von der schärfsten Reinheit. Die Ausfällung des Chroms durch das saure Sulfat ist allerdings nicht so vollständig wie bei der Eisessig-Schwefelsäuremethode, sondern ein Sechstel des Chromoxydes bleibt im Eisessig gelöst.

Wir haben folgende Vorschrift erprobt: $6 \mathrm{~g}$ Phytol werden mit $150 \mathrm{ccm}$ Eisessig vermischt und mit $30 \mathrm{~g}$ feingepulvertem Kaliumbisulfat versetzt. Das Chromtrioxyd $(6,8 \mathrm{~g}$ d. i. 5 Atome 0$)$ tragen wir in konzentrierter wäßriger Lösung auf einmal ein und schütteln lebhaft. Die Temperatur steigt nur auf $55^{\circ}$ und bleibt etwa 10 Minuten stehen; dabei erfolgt mäßige Kohlensäureentwickelung. Die dunkelgrüne Lösung wird vom Sulfatschlamm abfiltriert und mit Eisessig nachgewaschen. Dann konzentriert man die Eisessiglösung stark unter niedrigem Druck und nimmt den Rückstand mit Wasser auf. Er wird ausgeäthert und die ätherische Lösung mit Wasser gewaschen. Dem Äther entziehen wir den sauren Anteil des Oxydationsproduktes durch vorsichtiges Schwenken mit ganz verdünnter Natronlauge, dann isolieren wir das indifferente Produkt durch Abdampfen. Es geht bei der Destillation im Vakuum in seiner ganzen Menge in engen Grenzen über.

I. 0,1552 g gaben $0,4519 \quad \mathrm{CO}_{2}$ und $0,1867 \quad \mathrm{H}_{2} \mathrm{O}$.

II. $0,2001 \mathrm{~g} \quad, \quad 0,5861 \mathrm{CO}_{2} \quad, \quad 0,2393 \quad \mathrm{H}_{2} \mathrm{O}$.

\begin{tabular}{cccc} 
& Ber. für & \multicolumn{2}{c}{ Gef. } \\
& $\mathrm{C}_{13} \mathrm{H}_{30} \mathrm{O}$ & I & II \\
$\mathrm{C}$ & 79,56 & 79,41 & $\mathbf{7 9 , 5 2}$ \\
$\mathrm{H}$ & 13,37 & 13,46 & 13,32
\end{tabular}




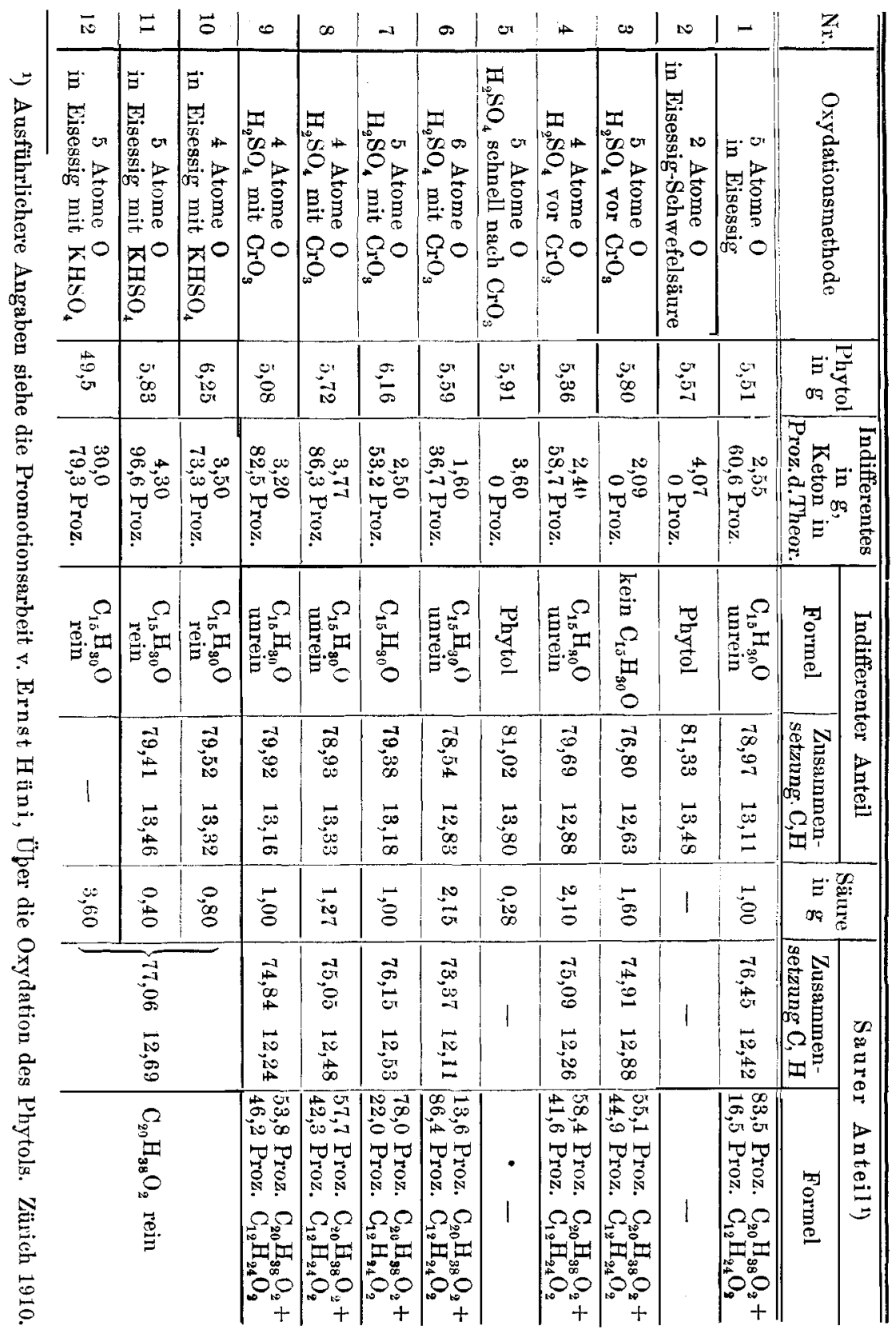




\section{Darstellung aus den Phytolozoniden.}

Nach der Ozonidmethode haben wir $220 \mathrm{~g}$ des Ketons dargestellt. Die Ausbeute beträgt beim Verarbeiten von $100 \mathrm{~g}$ Phytol, dessen Ozonid 5 g-weise bereitet und in Portionen von $25 \mathrm{~g}$ verkocht wird, $75 \mathrm{~g}$ vom rohen Keton and nach sorgfältigem Fraktionieren über $50 \mathrm{~g}$ vom reinen Keton, d. i. 63 Proz. der Theorie. Dabei ist kein Unterschied zwischen holzgeistlöslichen und unlöslichen Ozoniden zutage getreten.

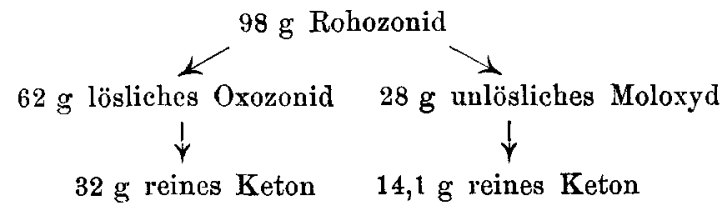

Die Phytolozonide spalteten wir nach dem älteren Verfahren von Harries durch Kochen mit Wasser am Rückflußkühler; nach etwa 3 Stunden gab das auf der Flüssigkeit schwimmende Öl keine Ozonidreaktion mehr. Es wurde mit Äther von der wäBrigen Flüssigkeit getrennt, die stark sauer reagierte und mit ammoniakalischer Silberlösung, fuchsinschwefliger Säure sowie Phenylhydrazin Aldehydreaktionen gab. Die in dieser wäßrigen Matterlauge enthaltenen kleinen Spaltungsstücke haben wir noch nicht genügend untersucht.

Der ätherischen Lösung des gebildeten Öles entzieht man durch vorsichtiges Waschen mit sehr verdünnter Natronlauge die als konstantes Nebenprodukt in kleiner Menge auftretende (3,5 Proz. vom Phytol) Säure, die im Kapitel der sauren Abbauprodukte beschrieben wird; sie besteht ans einem Gemische von $\mathrm{C}_{14} \mathrm{H}_{28} \mathrm{O}_{2}$ mit Phytensäure. Dann wird der indifferente Anteil durch Eindampfen isoliert; man kann ihm durch kurze Wasserdampfdestillation eine fruchtätherartig riechende Beimischung (wahrscheinlich Äther $\mathrm{C}_{20} \mathrm{H}_{42} \mathrm{O}$, s. S. 130) entziehen. Aber da das Keton selbst mit Wasserdampf erheblich flüchtig ist, empfiehlt es sich mehr, die Reinigung ausschließlich durch Fraktionierung unter ver- 
mindertem Druck vorzunehmen. Wir fanden diese sehr erleichtert durch die im Anhang beschriebene nene Fraktioniervorrichtung.

Unter $9 \mathrm{~mm}$ Druck lieferte das Rohketon aus $100 \mathrm{~g}$ Phytol folgende Fraktionen:

$$
\begin{aligned}
& \text { Vorlauf bis } 173^{\circ} 9,1 \mathrm{~g} \\
& 173-182^{\circ} 49,2 \mathrm{~g} \\
& \text { Nachlauf über } 182^{\circ} 2,5 \mathrm{~g} .
\end{aligned}
$$

Nach weiterem Anreichern der Hauptfraktion aus Vor- und Nachlauf gibt die wiederholte Fraktionierung konstant bei $177-178^{\circ}$ unter $12 \mathrm{~mm}$ Druck siedendes

\begin{tabular}{|c|c|c|c|c|c|c|}
\hline I. $0,1528 \mathrm{~g}$ & aben & $0,4438 \mathrm{CO}_{2}$ & and & 0,1813 & $\mathrm{H}_{2} \mathrm{O}$. & \\
\hline II. $0,2038 \mathrm{~g}$ & $n$ & $0,5910 \mathrm{CO}$ & 2 & 0,2393 & $\mathrm{H}_{2} \mathrm{O}$. & \\
\hline III. $0,1626 \mathrm{~g}$ & $\eta$ & $0,4720 \mathrm{CO}$ & $"$ & 0,1927 & $\mathrm{H}_{2} \mathrm{O}$. & \\
\hline IV. $0,1957 \mathrm{~g}$ & $"$ & $0,5706 \mathrm{CO}$ & $"$ & 0,2255 & $\mathrm{H}_{2} \mathrm{O}$. & \\
\hline V. $0,2111 \mathrm{~g}$ & $"$ & $0,6131 \mathrm{CO}_{2}$ & $"$ & 0,2491 & $\mathrm{H}_{2} \mathrm{O}$. & \\
\hline \multicolumn{4}{|c|}{ Ber. für } & Gef. & & \\
\hline & $\mathrm{H}_{80} \mathrm{O}$ & I & $\mathrm{II}$ & III & IV & $\mathrm{V}$ \\
\hline C &, 56 & 79,22 & 79,09 & 79,17 & 79,52 & 79,21 \\
\hline $\mathrm{H}$ & ,37 & 13,28 & 13,13 & 13,25 & 12,89 & 13,20 \\
\hline
\end{tabular}
Keton in analysenreinem, aber in nicht ganz so reinem Zustand, als die Chromsäurebisulfatmethode.

Der Vorlauf des Ketons enthält nur eine einzige Beimischung in merklicher Menge, nämlich den gesättigten Kohlenwasserstoff $\mathrm{C}_{15} \mathrm{H}_{32}$, der dem Keton entspricht. Durch wiederholte Fraktionierung, anfangs im Vakuum, dann unter gewöhnlichem Druck erhielten wir ihn nicht genügend rein. Aber da diese Substanz in Eisessig sehr schwer löslich, das Keton hingegen damit mischbar ist, konnten wir die Reinigung vervollständigen durch wiederholtes Ausschütteln des Kohlenwasserstoffes mit dem dreifachen Volumen Eisessig. Dann ging der Kohlenwasserstoff bei $723 \mathrm{~mm}$ konstant bei $258-261^{\circ}$ über (korr. Siedep. 260,5-263,50, während normales Pentadekan nach F. Krafft ${ }^{1}$ ) bei $270,5^{\circ}$ siedet).

1) Ber. d. d. chem. Ges. 15, 1701 (1882). 
$0,1627 \mathrm{~g}$ gaben $0,5025 \mathrm{CO}_{2}$ und $0,2218 \mathrm{H}_{2} \mathrm{O}$.
$\mathrm{H}$
Ber. für $\mathrm{C}_{15} \mathrm{H}_{32}$
Gef.
84,81
84,23
15,25

Denselben Kohlenwasserstoff, .unter 9,5 mm Druck bei $127-130^{\circ}$ siedend, haben wir, allerdings in schlechter Ausbeute, neben viel unverändertem Ausgangsmaterial, durch Reduktion des Ketons mit Zinkstaub und Eisessig erhalten. Er war beständig gegen Brom und Permanganat.

Der Kohlenwasserstoff $\mathrm{C}_{15} \mathrm{H}_{32}$ ist in Holzgeist schwer löslich, mit den meisten organischen Solvenzien aber mischbar.

$$
\begin{aligned}
& \mathrm{d}_{4}^{0}=0,789, \mathrm{~d}_{4}^{20}=0,779 ; \mathrm{n}_{\mathrm{D}}^{20}=1,43322 \text { Mol.-Refr. Gef. } 70,87, \\
& \text { ber. } 71,15 .
\end{aligned}
$$

\section{Beschreibung des Ketons.}

Das Keton $\mathrm{C}_{15} \mathrm{H}_{30} \mathrm{O}$ und unsere niedrigeren Nethylketone $\mathrm{C}_{13} \mathrm{H}_{26} \mathrm{O}, \mathrm{C}_{11} \mathrm{H}_{22} \mathrm{O}$ und $\mathrm{C}_{9} \mathrm{H}_{18} \mathrm{O}$ gehen bei der Destillation stets als hellgelbgrüne leicht bewegliche öle über, deren Farbe sich in einigen Tagen aufhellt und in ein paar Wochen ganz verschwindet; um bei der Destillation von neuem aufzutreten.

Das Keton siedet unter $9 \mathrm{~mm}$ Druck bei $173-174^{\circ}(\mathrm{Hg}$ im Dampf) und zeigt unter $722 \mathrm{~mm}$ nach der Methode von A. Schleiermacher ${ }^{1}$ ) den Siedep. 291,8-292,4 ${ }^{0}$. Dieser Siedepunkt erscheint im Vergleich mit den von F. Krafft untersuchten normalen Methylketonen merkwürdig hoch, was bei dem Keton $\mathrm{C}_{13} \mathrm{H}_{26} \mathrm{O}$ noch viel auffälliger wird. Nach Krafft ${ }^{2}$ ) siedet nämlich das Methyl-n-tridecylketon unter normalem Druck bei $294^{\circ}$ (unkorr.).

Das Keton ist mischbar mit den organischen Lösungsmitteln. Es ist optisch inaktiv.

Bestimmung des Molekulargewichtes nach Lehner in Aceton (Konstante 17,1):

1) Ber. d. d. chem. Ges. 24, 944 (1891).

$\left.{ }^{2}\right)$ Ber. d. d. chem. Ges. 12, 1669 (1879). 
$0,4615 \mathrm{~g}$ Substanz gaben in $11,42 \mathrm{~g}$ Aceton $0,286^{\circ}$ Siedepunktserhöhung. Mol.-Gew. gef. 241, ber. 226 .

$\mathrm{d}_{4}^{0}=0,853, \mathrm{~d}_{4}^{20}=0,844 ; \mathrm{n}_{\mathrm{D}}^{20}=1,44434$, Mol.-Refr. 71,06, ber. 71,33 .

Das Carbonyl in der Substanz wird nachgewiesen durch die Bildung von Oxim, Semicarbazon und Hydrazonen; die Aldehydreaktionen mit fuchsinschwefliger Säure, Diazobenzolsulfosäure und Natriumamalgam und mit Benzosulfohydroxamsäure nach $A$. Angeli ${ }^{1}$ ) bleiben aus, und namentlich die Reaktion von 0 . Doebner ${ }^{2}$ ) mit Brenztraubensäure und $\beta$-Naphthylamin gibt ein sicheres negatives Resultat.

Das Keton addiert in kalter Chloroformlösung Brom. Anfangs dauert das Verschwinden der Bromfarbe einige Zeit. Wenn aber die Reaktion eingeleitet ist, so wird Tropfen für Tropfen der Bromlösung ohne Bromwasserstoffentwickelung entfärbt bis beinahe zum Verbrauch von einem Molekül Brom. I)iese Beobachtung erklären wir als eine Reaktion der Enolform des Ketons, die mit Brom ein Additionsprodukt bildet, aus dem erst sekundär durch Abspaltung von Bromwasserstoff das Substitutionsprodukt hervorgeht:

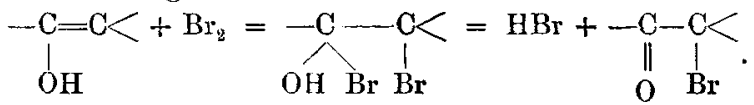

Beim Cholestanon ${ }^{3}$ ) haben wir die gleiche Beobachtung ${ }^{4}$ ) gemacht. Sie bestätigen alte, von E. Linne$\operatorname{man} n^{5}$ ) beim Aceton und von E. Lippmann ${ }^{6}$ ) beim Acetessigester angestellte gute Beobachtungen. ${ }^{7}$ )

1) Über einige sauerstoff haltige Verbindungen des Stickstoffes, Stuttgart (1908), S. 25.

Ger. d. d. chem. Ges.' 27,352 und 2020 (1894).

3) Ber. d. d. chem. Ges. 41, 2202 (1908).

4) Auch beim Methyläthylketon sowie beim Önanthol konnten wir die Bildung von farblosen Dibromiden in Lösung feststellen.

5) Diese Annalen 125, 307 (1863).

6) Zeitschr. f. Chem. 5, 29 (1869).

7) Die Untersuchungen von C. Duis berg [diese Annalen 213, $137(1882)]$ und die Versuehe von T. H. Norton und J. H. Westenh of f [Amer. chem. Journ. 10, 213 (1888)] widerlegen nicht die Bildung zersetzlicher Enoldibromide. 
Bei mehrstündigem Kochen mit Salpetersäure vom spez. Gew. 1,15 und 1,20 bleibt das Keton unverändert. Mit Natriumbypobromit gelingt es nicht, nachzuweisen, daß ein Methylketon vorliegt ${ }^{1}$ ); beim Digerieren mit Brom und Alkali und Erwärmen bis anf Wasserbadtemperatur wird nur eine Spur Bromoform und eine Spur Säure gebildet. Hingegen wird das Keton von Chromtrioxyd-Schwefelsäure in Eisessig leicht oxydiert zu einem Gemisch von überwiegend Keton $\mathrm{C}_{13} \mathrm{H}_{28} \mathrm{O}$ und wenig, aber reiner Säure $\mathrm{C}_{10} \mathrm{H}_{20} \mathrm{O}_{2}$, die auf diesem Wege schön gewonnen werden kann.

Durch Ozon wird das Keton in Peroxyde übergeführt, welche aus Jodkalium Jod frei machen und mit Schwefelsäure betupft verpuffen; der ozonisierte Sauerstoff wird von der Ketonlösung nur unvollständig desozonisiert.

I. $5,5 \mathrm{~g}$ Keton in $30 \mathrm{~g}$ Chloroform sind mit 36 Liter etwa 5,5 prozentigen Ozons behandelt worden.

$0,1704 \mathrm{~g}$ gaben $0,4468 \mathrm{CO}_{2}$ und $0,1825 \mathrm{H}_{2} \mathrm{O}$.

II. $5,7 \mathrm{~g}$ Keton in $35 \mathrm{~g}$ Chloroform sind mit 65 Liter etwa 5,5 prozentigen Ozons behandelt worden.

$0,1532 \mathrm{~g}$ gaben $0,411.9 \mathrm{CO}_{2}$ und $0,1684 \mathrm{H}_{2} \mathrm{O}$.

Ber. für

$\begin{array}{ccccc} & \mathrm{C}_{15} \mathrm{H}_{30} \mathrm{O} \cdot \mathrm{O}_{2} & \mathrm{C}_{15} \mathrm{H}_{30} \mathrm{O} \cdot \mathrm{O} & \mathrm{I} & \mathrm{II} \\ \mathrm{C} . & 70,06 & \mathbf{7 4 , 6 9} & \mathbf{7 1 , 5 1} & \mathbf{7 3 , 3 3} \\ \mathrm{H} & 11,71 & 12,48 & 11,98 & 12,30\end{array}$

Bei längerer BehandIung mit Ozon wird also das Oxyd sauerstoffärmer. Viele interessante Beobachtungen über das Verhalten gesättigter Aldehyde gegen Ozon, die C. Harries ${ }^{2}$ ) vor kurzem mitgeteilt hat, lassen sich wohl auch so deuten, daß die Carbonylverbindungen bei gelinder Behanding $\mathrm{O}_{2}$ aufnehmen und bei energischer Behandlung wieder ein Sauerstoffatom an den Ozonstrom abgeben. Es kann sich auch hier um ein Reagieren der Enolform handeln.

1) Ähnliche Erfahrungen bei Methylketonen haben C. Harries und F. Hübner mitgeteilt. Diese Annalen 296, 301 (1897).

2) Diese Annalen 374, 288 (1910). 
Durch Verkochen der Peroxyde des Ketons mit Wasser entstehen die Ketone $\mathrm{C}_{13} \mathrm{H}_{26} \mathrm{O}$ und $\mathrm{C}_{11} \mathrm{H}_{22} \mathrm{O}$.

\section{Derivate des Ketons.}

Oxim, $\left(\mathrm{C}_{15} \mathrm{H}_{30}\right) \mathrm{NOH}$. Beim Erwärmen mit alkoholischer Hydroxylaminlösung entsteht das Oxim, ein dickes farbloses Öl von $\mathrm{d}_{4}^{0}=0,885$ und dem Siedep. $201-202^{0}$ unter etwa $10 \mathrm{~mm}$ Druck. Es ist mit den organischen Lösungsmitteln mischbar, in Wasser unlöslich.

$0,2279 \mathrm{~g}$ gaben $12,5 \mathrm{ccm}$ Stickgas bei $15^{\circ} \mathrm{u}$. unter $723 \mathrm{~mm}$ Druck.

$$
\begin{array}{ccc} 
& \text { Ber. für } \mathrm{C}_{15} \mathrm{H}_{31} \mathrm{ON} & \text { Gef. } \\
\mathbf{N} & 5,81 & 6,16
\end{array}
$$

Die Beckmannsche Umlagerung tritt schwierig ein und verläuft nur mit geringer Ausbeute. Wir konnten sie aber nachweisen, indem wir nach dem Erhitzen mit Eisessig-Schwefelsäure, oder mit Eisessig-Chlorwasserstoff-Essigsäureanhydrid das Produkt hydrolisierten und gebildetes Methylamin durch die Analyse seines Chlorplatinates identifizierten.

Semicarbazon, $\left(\mathrm{C}_{15} \mathrm{H}_{30}\right)$ N.NH.CO. $\mathrm{NH}_{2}$. Läßt man das Keton mit der konz. Lösung von Semicarbazidbase in Methylalkohol bei Zimmertemperatur stehen, so erstarrt die Flüssigkeit beim Abkühlen zu einem Krystallbrei, der mit gekühltem Holzgeist nachgewaschen wird. Das Semicarbazon ist sehr leicht löslich in Essigester, Aceton und Benzol, sowie in den Alkoholen in der Wärme, auch leicht bei gewöhnlicher Temperatur. Beim Umkrystallisieren aus Äthyl- und Methylalkohol und aus Essigester bildet es schön ausgebildete schief abgeschnittene Prismen vom konstanten Schmelzp. $64,5^{\circ}$.

$0,1178 \mathrm{~g}$ gaben $16,5 \mathrm{ccm}$ Stickgas bei $20^{\circ}$ und $723 \mathrm{~mm}$ Druek Ber. für $\mathrm{C}_{18} \mathrm{H}_{33} \mathrm{ON}_{3} \quad$ Gef.

$$
\mathrm{N} \quad 14,84 \quad 15,14
$$

p-Nitrophenylhydrazon, $\left(\mathrm{C}_{15} \mathrm{H}_{30}\right): \mathrm{N}_{2} \mathrm{H} \cdot \mathrm{C}_{6} \mathrm{H}_{4} \cdot \mathrm{NO}_{2}$. Beim Versetzen des durch Alkohol verdünnten Ketons mit der Lösung von Nitrophenylhydrazin in 50 prozentiger Essigsäure fällt das Hydrazon als hellgelbes ÖI aus, das durch 
Waschen mit verdünnter Säure von etwa beigemengtem Hydrazin befreit wird. Bei langem Aufbewahren krystallisierte das dunkelbraun gewordene ÖI nicht.

$0,2067 \mathrm{~g}$ gaben $22,8 \mathrm{ccm}$ Stickgas bei $22^{\circ}$ und $722 \mathrm{~mm}$ Druck. Ber. für $\mathrm{C}_{31} \mathrm{H}_{35} \mathrm{O}_{2} \mathrm{~N}_{3}$ Gef.
$\mathbf{N}$ 11,63
11,79

Auch das Pikrylhydrazon erhielten wir in der Form eines tiefbraunen Öles.

\section{Alkohol, $\mathrm{C}_{15} \mathrm{H}_{32} \mathrm{O}$.}

Wir reduzierten das Keton in Portionen von $3 \mathrm{~g}$ mit je 3,2 g Natrium und der zehnfachen Menge Alkohol, und wiederholten mit dem einmal isolierten Reaktionsprodukt in größeren Portionen diese Bearbeitung. Der sekundäre Alkohol war dann rein und ging bei der Destillation im Vakuum in engen Grenzen über als eine wasserklare, sehr visköse Flüssigkeit, die zum Unterschied vom Keton die Glaswand schlecht netzt und mit Wasserdampf nicht flüchtig ist.

I. $0,1819 \mathrm{~g}$ gaben $0,5274 \mathrm{CO}_{2}$ und $0,2296 \mathrm{H}_{2} \mathrm{O}$.

II. $0,1624 \mathrm{~g} \quad, \quad 0,4705 \mathrm{CO}_{2} \quad, \quad 0,2025 \mathrm{H}_{2} \mathrm{O}$.

\begin{tabular}{lccc} 
& Ber. für & \multicolumn{2}{c}{ Gef. } \\
& $\mathrm{C}_{15} \mathrm{H}_{32} \mathrm{O}$ & I & II \\
$\mathrm{C}$ & $\mathbf{7 8 , 8 4}$ & 79,07 & $\mathbf{7 9 , 0 1}$ \\
$\mathrm{H}$ & 14,14 & 14,12 & 13,95
\end{tabular}

Der Alkohol siedet unter $12 \mathrm{~mm}$ Druck bei 178 bis $180^{\circ}$, unter $8 \mathrm{~mm}$ bei $173-174^{\circ}$ ( $\mathrm{Hg}$ im Dampf), also geradezu übereinstimmend mit dem Keton.

$$
\begin{aligned}
& \mathrm{d}_{4}^{0}=0,848, \mathrm{~d}^{20}=0,838 ; \mathrm{n}_{\mathrm{D}}^{20}=1,44912 ; \text { Mol.-Refr. gef. } 73,08, \\
& \text { ber. 72,67. }
\end{aligned}
$$

Bei der Esterbildung durch Erhitzen mit Eisessig fügt sich der Alkohol hinsichtlich der absoluten Anfangsgeschwindigkeit gut in die von N. Menschutkin ${ }^{1}$ ) untersuchte Reihe der sekundären Carbinole ein.

Faktor ber. 0,2205, angew. 0,2199, 1550 1 Std., Ester 21,1 Proz. der angew. Säure.

1) Diese Annalen 197, 200 (1879). 


\section{Olefin, $\mathrm{C}_{15} \mathrm{H}_{30}$.}

Der Abbau des Methylketons zur Säure $\mathrm{C}_{14} \mathrm{H}_{28} \mathrm{O}_{2}$, der nicht durch direkte Oxydation gelingt, ist auf dem Umwege über den durch Abspaltung von Wasser aus dem sekundären Alkohol entstehenden Kohlenwasserstoff ausgeführt worden. Das Olefin liefert nämlich die um ein Kohlenstoffatom ärmere Säure sowohl nach der Ozonidmethode, wie auch durch Hydrolyse seines Dibromides zum Glykol und Oxydation mit Chromsäure. Die Abspaltung von Wasser aus dem Carbinol ist demnach entgegen der Erwartung gemäß dem Schema<smiles>CCCCCC(C)C(C)CCCCCCC(C)O</smiles>

eingetreten, nur ist es zweifelhaft, ob der Kohlenwasserstoff in seiner ganzen Menge die Uoppelbindung am Ende der Kette enthält. Seine Konstitution ist übrigens von den Bedingungen der Darstellung abhängig; bei zu kräftiger Einwirkung von Phosphorpentoxyd ist dem Olefin ein gesättigtes Isomeres beigemischt. Der Austritt von Wasser hat dann teilweise unter Ringbildung stattgefunden.

Wir erwärmten $23 \mathrm{~g}$ Alkohol in kleinen Portionen mit $28 \mathrm{~g}$ Phosphorpentoxyd nur eine halbe Stande auf $60-30^{\circ}$; der gebildete Kohlenwasserstoff destillierte mit Hinterlassung von etwas sirupösem Rückstand bei 150 bis $152^{\circ}$ unter $11 \mathrm{~mm}$ Druck ${ }^{1}$, auch unter gewöhnlichem Druck $(724 \mathrm{~mm})$ unzersetzt bei $287-288^{\circ}$, d. i. bei $290^{\circ}$ korrigiert, also um beinahe $30^{\circ}$ höher, als der oben beschriebene gesättigte Kohlenwasserstoff $\mathrm{C}_{15} \mathrm{H}_{32}$.

J. $0,1532 \mathrm{~g}$ gaben $0,4806 \mathrm{CO}_{*}$ und $0,2035 \mathrm{H}_{2} \mathrm{O}$.

II. $0,1383 \mathrm{~g} \quad, \quad 0,4336 \mathrm{CO}_{\mathrm{z}}, \quad, \quad 0,1802 \mathrm{H}_{2} \mathrm{O}$.

1) Wir haben den unerwartet hohen Siedepunkt noeh bei drei Wiederholungen bestätigt gefunden mit folgenden Beobachtungen: $150-153^{\circ}(11 \mathrm{~mm}), 148-149^{\circ}(9 \mathrm{~mm}), 147-148^{\circ}(8 \mathrm{~mm})$. 


\begin{tabular}{cccc} 
& Bel. für & \multicolumn{2}{c}{ Gef. } \\
& $\mathrm{C}_{\mathrm{n}} \mathrm{H}_{2 \mathrm{n}}$ & I & II \\
$\mathrm{C}$ & 85,62 & 85,56 & $\mathbf{8 5 , 5 1}$ \\
$\mathrm{H}$ & 14,38 & 14,86 & 14,57
\end{tabular}

Das Olefin ist in Alkohol schwer, in Aceton und Eisessig sehr schwer löslich, mit den übrigen organischen Solvenzien mischbar. $d_{4}^{0}=0,803, d_{4}^{20}=0,790$. Der Kohlenwasserstoff reduziert sofort die Acetonlösung von Kaliumpermanganat und addiert momentan 1 Mol. Brom (Best. I). Wurde aber bei seiner Darstellung 1 Stunde lang mit Phosphorpentoxyd auf $150^{\circ}$ erhitzt, so nahm er merklich weniger Brom auf (Best. II); auch der reine Kohlenwasserstoff isomerisiert sich ein wenig bei mehrstündigem Erhitzen mit Phosphorsäureanhydrid auf $130^{\circ}$, wie die 'Titration mit Brom erkennen ließ. (Best. III u. IV.)

I. $0,3002 \mathrm{~g}$ addierten 0,2260 Brom d. i. 98,7 Proz. d. ber. Menge.

II. $0,4903 \mathrm{~g} \quad, \quad 0,3480$, d. i. $93,7 \quad, \quad, \quad$,

III. $0,1626 \mathrm{~g} \quad, \quad 0,1175$ " d. i. $94,8, ", \quad, \quad$,

IV. $0,2856 \mathrm{~g} \quad, \quad 0,1976 \quad$ d. i. $94,9 \quad ", \quad, \quad$ "

Ozonid, $\mathrm{C}_{15} \mathrm{H}_{30} \mathrm{O}_{3}$. Wir ozonisierten den Kohlenwasserstoff in Chloroform mit etwa 6-prozentigem Ozon und zwar in Portionen von 3-4 $\mathrm{g}$ mit je 12 Litern. Beim Abdampfen des Chloroforms im Vakuum zu annähernder Gewichtskonstanz hinterblieb das Ozonid als dickes Öl von schwachgrünlicher Farbe und süßlichem Geruch. Es war in Holzgeist spielend, in Petroläther mäBig löslich.

$0,1096 \mathrm{~g}$ gaben $0,2790 \quad \mathrm{CO}_{2}$ und $0,1144 \mathrm{H}_{2} \mathrm{O}$.

$\begin{array}{ccr} & \text { Ber. für } \mathrm{C}_{1 \mathrm{~B}} \mathrm{H}_{30} \mathrm{O}_{3} & \text { Gref. } \\ \mathrm{C} & 69,70 & 69,43 \\ \mathrm{H} & \mathbf{1 1 , 7 1} & 11,67\end{array}$

Bei langem Aufbewahren im Vakuum wurde das Ozonid sauerstoffärmer, ein erheblicher Teil verflüchtigte sich aber dabei. 


\section{Keton $\mathrm{C}_{13} \mathrm{H}_{26} \mathrm{O}$.}

\section{Gewinnung aus $\beta$-Phytol.}

a) Mit Chromsäure-Eisessig-Bisulfat. Wir oxydierten nach der bein $\alpha$-Phytol ausgearbeiteten Methode $18,9 \mathrm{~g}$ im Vakuum der Wasserstrahlpumpe destilliertes Ausgangsmaterial in drei Portionen mit der 5 Atomen Sauerstoff entsprechenden Menge Chromtrioxyd. Unter gelinder Entwickelung von Kohlensäure stieg die Temperatur auf $58^{\circ}$ und blieb eine Viertelstunde stehen; nach dem Erkalten war die Oxydation beendigt. Den indifferenten Teil des Produktes bilden $11,7 \mathrm{~g}$ reines Keton $\mathrm{C}_{13} \mathrm{H}_{28} \mathrm{O}$ vom Siedep. $169-170^{\circ}$ unter $12 \mathrm{~mm}$ Druck, d. i. 94 Proz. der berechneten Ausbeute (Analyse I); der saure Anteil $(2,8 \mathrm{~g})$ bestand aus einem ähnlichen Gemisch einer Phytensäure mit einer gesättigten niedrigeren Säure, wie es bei der Oxydation von $\alpha$-Phytol aufgetreten war.

Nach der Methode mit Chromsäure-Eisessig-Schwefelsäure verläuft die Oxydation heftiger. Sie liefert auch reines Keton $\mathrm{C}_{13} \mathrm{H}_{26} \mathrm{O}$ (Analyse $\mathrm{II}$ ), aber eine schlechtere Ausbeute $(4,1 \mathrm{~g}$ aus $10,4 \mathrm{~g} \beta$-Phytol), zugleich steigt der Betrag an Säuregemisch $(3,4 \mathrm{~g})$.

b) Mit Hilfe von Ozon. Der Zerfalj der Kohlenstoffkette findet an der gleichen Stelle statt, wenn man das Ozonid des $\beta$-Phytols, dargestellt wie das $\alpha$-Derivat, durch Kochen mit Wasser spaltet. Das Keton entsteht reiner als das analog aus Rohphytol gebildete, es hinterläBt bei der Destillation im Vakuum keinen Rückstand. Neben einer Spur Säure erhielten wir aus $5 \mathrm{~g}$ Phytol in rohem Zustand 3,4 g, reines Destillat (Analyse III) 2,8 g, d. i. 82 Proz. der Theorie.

\section{Bildung aus der Säure $\mathrm{C}_{14} \mathrm{H}_{28} \mathrm{O}_{2}$.}

Die Entstehung aus der Säure $\mathrm{C}_{14} \mathrm{H}_{28} \mathrm{O}_{2}$ ist ungeachtet der schlechten Ausbeute für die sichere Kenntnis des Ketons sehr wichtig, weil hier jede Ver- 
unreinigung durch ein höheres Homologes, also auch die Bildung eines Gemisches von der durchschnittlichen $\mathrm{Zu}$ sammensetzung $\mathrm{C}_{13} \mathrm{H}_{28} \mathrm{O}$ ausgeschlossen war. $5,14 \mathrm{~g}$ Säure haben wir in $150 \mathrm{ccm}$ Eisessig mit $4,5 \mathrm{~g}$ konz. Schwefelsäure und mit der konz. wäBrigen Lösung von 3,1 $\mathrm{g}$ Chromtrioxyd (entsprechend zwei Atomen 0) vermischt. Die Oxydation setzte träge ein, es kam nur zu einer geringen Erwärmung. Wir führten daher die Reaktion zu Ende, indem wir während zehn Minuten allmählich bis auf $60^{\circ}$ erwärmten. Aus der von Chromsulfat abfiltrierten Lösung isolierten wir nach dem $\mathrm{Ab}$ dampfen im Vakuum und der üblichen Trennung 1,3 $\mathrm{g}$ indifferentes Öl und $3,2 \mathrm{~g}$ sauren Anteil, der im $\mathrm{Ab}$ schnitt Säure $\mathrm{C}_{12} \mathrm{H}_{24} \mathrm{O}_{2}$ behandelt wird.

Das Keton enthielt im Vorlauf ein wenig von dem fruchtessenzartig riechenden $\ddot{\text { Atther }} \mathrm{C}_{20} \mathrm{H}_{42} \mathrm{O}$; die Hauptfraktion der Vakuumdestillation stimmt in der Zusammensetzung und in den Eigenschaften des Semicarbazons mit dem Keton aus $\beta$-Phytol überein.

\section{Darstellung aus dem Keton $\mathrm{C}_{15} \mathrm{H}_{30} \mathrm{O}$.}

a) Mit Chromsäure. Diese Oxydation ist eine wertvolle Abbanmethode, weil außer dem Keton mit 13 die reine Säure mit $10 \mathrm{Kohlenstoffatomen} \mathrm{dabei} \mathrm{auftritt.}$

Wir haben $30 \mathrm{~g}$ Keton in 6 Portionen oxydiert. Je $5 \mathrm{~g}$ in $150 \mathrm{ccm}$ Eisessig wurden mit 4,4 konz. Schwefelsäure und 2,92 $\mathrm{g}$ Chromtrioxyd (entsprechend zwei Atomen 0 ) in gesättigter Lösung versetzt. Die Temperatur stieg auf $40-50^{\circ}$, die Reduktion der Chromsäure ging in 2-3 Stunden zu Ende. Das Oxydationsprodukt setzte sich aus $7 \mathrm{~g}$ Säure $\mathrm{C}_{10} \mathrm{H}_{20} \mathrm{O}_{2}$ und $16,7 \mathrm{~g}$ rohem Keton zusammen. Dieses ging bei der Destillation unter $11 \mathrm{~mm}$ Druck zwischen 165 und $175^{\circ}$ über, größtenteils bei $168-169^{\circ}$. Es wurde wieder durch tnalyse (V) und die Umwandlung in das Semicarbazon als rein erkannt.

Im Vorlauf des indifferenten Produktes von dieser Aunalen der Chemie 378. Band. 
und einigen anderen Oxydationen war eine sauerstoffärmere Verbindung von intensivem, amylacetatähnlichem Geruch enthalten, die keine Carbonylreaktionen zeigte, nicht verseifbar war und für einen Alkohol zu niedrig siedete. Die Substanz besaß die Zusammensetzung des an $100^{\circ}$ höher siedenden Dihydrophytols. Sehr wahrscheinlich ist sie der mit ihm isomere Äther des Alkohols $C_{10} H_{21} O H$, welcher der erwähnten Carbonsäure mit gleich viel Kohlenstoffatomen entspricht. Das merkwürdige Auftreten des Äthers findet eine Analogie in der Bildung des Esters $\mathrm{C}_{8} \mathrm{H}_{19} \mathrm{COOC}_{10} \mathrm{H}_{21}$ aus dem Ozonid des Olefins $\mathrm{C}_{15} \mathrm{H}_{30}$.

Nach wiederholtem Fraktionieren unter gewöhnlichem Druck war der bei $220-235^{\circ}$ aufgefangene Äther noch nicht ganz rein.

$0,1246 \mathrm{~g}$ gaben $0,3626 \mathrm{CO}_{2}$ und $0,1547 \mathrm{H}_{2} \mathrm{O}$.

$\begin{array}{ccc} & \text { Ber. für } \mathrm{C}_{\mathbf{2 0}} \mathrm{H}_{42} \mathrm{O} & \text { Gef. } \\ \mathbf{C} & 80,44 & \mathbf{7 9 , 3 7} \\ \mathrm{H} & 14,19 & \mathbf{1 3 , 8 9}\end{array}$

Er ließ sich durch Behandeln mit methylalkoholischem Kali von etwas beigemischtem Ester befreien und dadurch rein erhalten.

$0,1492 \mathrm{~g}$ gaben $0,4421 \mathrm{CO}_{2}$ und $0,1897 \mathrm{H}_{2} \mathrm{O}$.

$\begin{array}{ccr} & \text { Ber. für } \mathrm{C}_{\mathbf{2 0}} \mathrm{H}_{42} \mathrm{O} & \text { Gef. } \\ \mathrm{C} & \mathbf{8 0 , 4 4} & 80,81 \\ \mathrm{H} & \mathbf{1 4 , 1 9} & \mathbf{1 4 , 2 2}\end{array}$

Bestimmung des Molekulargewichtes nach Lehner in Aceton (Konstante 17,1): 0,3126 $\mathrm{g}$ Substanz gaben in $9,86 \mathrm{~g}$ Aceton $0,171^{\circ}$ Siedepunktserhöhung. Molgew. gef. 317 , ber. 298 .

Der Äther ist ein mit den organischen Lösungsmitteln mischbares, leicht bewegliches ÖI von $\mathbb{d}_{4}^{0}=0,836$ und dem Siedep. $228-233^{\circ}$ bei $722 \mathrm{~mm}$ Barometerstand.

b) Mit Ozon. Keton $\mathrm{C}_{15} \mathrm{H}_{30} \mathrm{O}$ wird beim Behandeln mit Ozon und Verkochen des oben beschriebenen Peroxydes abgebant. Wir haben es in der Hand, je nach der Dauer der Ozonbehandlung zu Ketonen verschiedener 
Zusammensetzung zu gelangen, die wir aber (namentlich das Keton $\mathrm{C}_{13} \mathrm{H}_{28} \mathrm{O}$ ) nicht zu unseren reinen Präparaten zählen können.

Nur ganz kurze Ozonisierung gibt bei darauffolgendem Verkochen ein Keton von der genauen Zusammensetzung $\mathrm{C}_{13} \mathrm{H}_{26} \mathrm{O}$ (VI), mittellange oder lange Einwirkung aber Präparate von der Zusammensetzung $\mathrm{C}_{11} \mathrm{H}_{22} \mathrm{O}$. Das saure Nebenprodukt entspricht der Formel $\mathrm{C}_{13} \mathrm{H}_{28} \mathrm{O}_{2}$. Wiederholte Bearbeitung mit Ozon führt zu kohlenstoffärmeren Ketonen.

Wir leiteten in die Chloroformlösung von $5 \mathrm{~g}$ des ersten Ketons nur 14-15 Liter gegen 6 prozentigen Ozons ein, während für 1 Mol. Ozon 12,6 Liter berechnet waren. Nach dem Verkochen des Oxydes reinigten wir den ätherischen Extrakt durch Waschen mit verdünnter Natronlauge: Das oxydierte Keton betrug nach der Destillation im Vakuum $4 \mathrm{~g}$.

\section{Beschreibung des Ketons.}

Die Analysen der im Vakuum einmal destillierten Präparate aus den verschiedenen Darstellungen führen wir ohne Auslese an.

$$
\begin{aligned}
& \text { I. 0,1574 } \mathrm{g} \text { gaben } 0,4547 \mathrm{CO}_{2} \text { und } 0,1830 \mathrm{H}_{2} \mathrm{O} \text {. } \\
& \text { II. } 0,1141 \mathrm{~g} \quad " \quad 0,3299 \mathrm{CO}_{2} \quad " \quad 0,1370 \mathrm{H}_{2} \mathrm{O} \text {. } \\
& \text { III. } 0,1552 \mathrm{~g} \quad, \quad 0,4471 \mathrm{CO}_{\mathrm{z}} \quad, \quad 0,1861 \mathrm{H}_{2} \mathrm{O} \text {. } \\
& \text { IV. } 0,1448 \mathrm{~g} \quad " \quad 0,4167 \mathrm{CO}_{2} \quad, \quad 0,1709 \mathrm{H}_{2} \mathrm{O} \text {. } \\
& \text { V. } 0.1443 \mathrm{~g} \quad, \quad 0,4157 \mathrm{CO}_{2} \quad " \quad 0,1692 \mathrm{H}_{2} \mathrm{O} \text {. } \\
& \text { VI. } 0,1938 \mathrm{~g} \quad, \quad 0,5607 \quad \mathrm{CO}_{3} \quad, \quad 0,2341 \quad \mathrm{H}_{2} \mathrm{O} \text {. } \\
& \text { Ber. für } \\
& \begin{array}{lllllll}
\mathrm{C}_{13} \mathrm{H}_{26} \mathrm{O} & \text { I } & \text { II } & \text { III } & \text { IV } & \text { V } & \text { VI }
\end{array}
\end{aligned}
$$

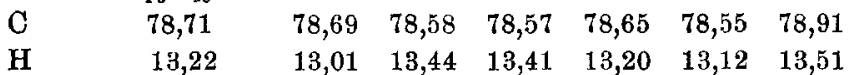

Das Keton ist dem um zwei Kohlenstoffatome höheren Homologen in seinen physikalischen Eigenschaften fast zum Verwechseln ähnlich, so daß nur seine Analyse und die seiner Derivate die sichere Unterscheidung erlaubt. Beim Destillieren größerer Mengen fanden wir den Siedepunkt unter $10 \mathrm{~mm}$ Druck um $5-6^{0}$ niedriger als 
bei dem Keton $\mathrm{C}_{\mathbf{1 5}} \mathrm{H}_{\mathbf{3 0}} \mathrm{O}$, nämlich bei $168-170^{\circ}$; unter gewöhnlichem Druck $(722 \mathrm{~mm})$ bestimmten wir nach Schleiermacher den Siedep. $288-289^{\circ}$, es siedet also $3-4^{0}$ niedriger als das höhere Keton, aber um etwa $25^{\circ}$ höher als das normale Methylundecylketon von F. Krafft ${ }^{1}$ ) (Siedep. unkorr. 263 ${ }^{\circ}$ ). Das Keton destilliert als hellgelbgrünes Öl und wird beim Stehen farblos; es ist leicht beweglich, mit den organischen Solvenzien mischbar. Die Dichte ist etwas höher, als die des ersten Ketons, nämlich $\mathrm{d}_{4}^{0}=0,865, \mathrm{~d}_{4}^{20}=0,848$. Unverdünnt im 1-dcm-Rohr geprüt, erweist sich die Substanz als optisch inaktiv.

Durch Chromsäure wird das neue Keton weniger glatt abgebaut als $\mathrm{C}_{15} \mathrm{H}_{30} \mathrm{O}$. Zum großen Teil wird es mit wenig veränderter Zusammensetzung wieder gewonnen als ein Gemisch mit etwas niedrigerem Keton; die zugleich gebildete Säure scheint eine Mischung von $\mathrm{C}_{10} \mathrm{H}_{20} \mathrm{O}_{2}$ und $\mathrm{C}_{12} \mathrm{H}_{24} \mathrm{O}_{2}$ zu sein.

Die Verbindung gibt die bekannten Carbonylreaktionen, ohne Aldehydeigenschaften zu zeigen.

Das Oxim $\left(\mathrm{C}_{13} \mathrm{H}_{26}\right) \mathrm{NOH}$ ist ein dickes öl vom Siedep. $196-198^{\circ}$ unter $11 \mathrm{~mm}$ Druck und $\mathrm{d}_{4}^{0}=0,891$; es ist mit Holzgeist, Eisessig und Petroläther mischbar.

$0,3333 \mathrm{~g}$ gaben $20,9 \mathrm{~cm}$ Stickgas bei $20^{\circ}$ und $720 \mathrm{~mm}$ Druck.

$$
\begin{array}{ccc} 
& \text { Ber. für } \mathrm{C}_{13} \mathrm{H}_{27} \mathrm{ON} & \text { Gef. } \\
\mathrm{N} & 6,57 & 6,77
\end{array}
$$

Semicarbazon, $\left(\mathrm{C}_{13} \mathrm{H}_{26}\right) \mathrm{N}_{2} \mathrm{H}$.CO. $\mathrm{NH}_{2}$. In methylalkoholischer Lösung reagiert das Keton beim Stehen mit der Semicarbazidbase. Bei tiefem Abkühlen krystallisiert ein Teil des Semicarbazons aus, etwas mehr nach starkem Einengen. Die Löslichkeitsunterschiede zwischen kalt und warm sind sehr klein. Die Substanz ist daher aus Benzol und Essigester schwierig umzukrystallisieren. Sie bildet feine Nädelchen, die ihren Schmelzp. $62^{\circ}$ beim Umkrystallisieren nicht ändern.

1) Ber. d. d. chem. Ges. 12, 1667 (1879). 
I. $0,1353 \mathrm{~g}$ gaben $20,1 \mathrm{ccm}$ Stickgas bei $18^{\circ} \mathrm{u} .724 \mathrm{~mm}$ Druck. II. $0,1004 \mathrm{~g} \quad, 15,05 \mathrm{~cm} \quad, \quad, 18^{\circ}, 724 \mathrm{~mm} \quad "$.

\begin{tabular}{cccc} 
& Ber. für & \multicolumn{2}{c}{ Gef. } \\
$\mathrm{N}$ & $\mathrm{C}_{14} \mathrm{H}_{29} \mathrm{~N}_{3} \mathrm{O}$ & \multicolumn{1}{c}{ I } & II \\
$\mathbf{1 6 , 4 7}$ & & $\mathbf{1 6 , 2 5}$ & $\mathbf{1 6 , 3 9}$
\end{tabular}

Keton $\mathrm{C}_{11} \mathrm{H}_{22} \mathrm{O}$.

\section{Bildung aus Dioxyphytanol.}

Wenn man an das $\alpha$-Phytol zwei Hydroxyle addiert hat, so zerfällt entgegen der Erwartung die Kohlenstoffkette bei der Einwirkung von Chromsäure nicht mehx zwischen dem 15. und 16. Kohlenstoffatom, sondern die Oxydation liefert als Hauptprodukte die bei verschiedenen Abbauversuchen auftretende Säure $\mathrm{C}_{\mathbf{1 4}} \mathrm{H}_{28} \mathrm{O}_{2}$ und das Methylketon $\mathrm{C}_{11} \mathrm{H}_{22} \mathrm{O}$, das wir auf diesem umständlichen Wege in zuverlässigerer Reinheit erhalten haben, als durch den Abban des Ketons $\mathrm{C}_{15} \mathrm{H}_{30} \mathrm{O}$ mit Ozon. Der dreiwertige Alkohol des Phytans ist aus dem Dibromid des $\alpha$-Phytols durch die Reaktion mit Acetat und Hydrolyse dargestellt und in rohem Zustand weiter verarbeitet worden.

Wir vereinigten $20 \mathrm{~g}$ Phytol in Eisessiglösung mit etwas mehr als der molekularen Menge von Brom in Eisessig und erhitzten die farblos gewordene Flüssigkeit mit dem Doppelten des erforderlichen Silberacetates unter Rühren 15 Stunden lang im Wasserbad, bis eine Probe des Öles nur noch Spuren von Brom enthielt. Die Lösung wurde vom Silberschlanm abfiltriert und so lange nachgewaschen, bis der Eisessig mit Wasser keine Trübung mehr gab. Die durch Verdünnen und Ausäthern isolierte Acetylverbindung dampften wir nach dem Waschen mit Sodalösung ein und verseiften den Rückstand in der Kälte mit konz. methylalkoholischer Kalilange. So gewannen wir $16 \mathrm{~g}$ eines sehr viskösen Öles, das in kaltem Holzgeist ziemlich schwer, in heißem leicht löslich, mit Eisessig und Petroläther mischbar war. Die Analyse eines solchen Präparates stimmte gut, 
die eines zweiten nur annähernd, für die Formel des dreiwertigen Alkohols $\mathrm{C}_{20} \mathrm{H}_{39}(\mathrm{OH})_{3}$. Es ist wahrscheinlich, daß der Alkohol dazn neigt, Wasser abzuspalten, und dadurch kohlenstoffreicher zu werden, vielleicht beim Eindampfen der ätherischen Lösung und längerem Erhitzen auf $95^{\circ}$ zum Verjagen des Lösungsmittels.

I. $0,1391 \mathrm{~g}$ gaben $0,3729 \mathrm{CO}_{2}$ und $0,1544 \mathrm{H}_{2} \mathrm{O}$.

II. $0,1885 \mathrm{~g} \quad, \quad 0,5118 \mathrm{CO}_{2} \quad " \quad 0,2085 \mathrm{H}_{2} \mathrm{O}$.

\begin{tabular}{cccc} 
& Ber. für. & \multicolumn{2}{c}{ Gef. } \\
& $\mathrm{C}_{20} \mathrm{H}_{48} \mathrm{O}_{3}$ & I & II \\
$\mathrm{C}$ & $7 \mathbf{7 2 , 6 5}$ & 73,11 & $\mathbf{7 4 , 0 5}$ \\
$\mathrm{H}$ & 12,82 & 12,42 & 13,38
\end{tabular}

Von dem rohen Trioxyphytan wurden $14,7 \mathrm{~g}$ in sechs Portionen mit der für zehn Atome Sauerstoff berechneten Menge Chromsäure oxydiert. Wir fügten zur Lösung von $2,5 \mathrm{~g}$ Substanz in $80 \mathrm{ccm}$ Eisessig auf einmal $1,9 \mathrm{~g}$ Schwefelsäure und $1,3 \mathrm{~g}$ Chromtrioxyd. Die Oxydation verlief fast momentan, wobei die Temperatur $45^{\circ}$ erreichte. Nach dem Erkalten wiederholten wir den Zusatz der Schwefelsäure und des Oxydationsmittels, das wieder rasch und fast ganz verbraucht wurde. Die vom Chromsulfat abfiltrierten Lösungen lieferten $6,9 \mathrm{~g}$ indifferentes und $5,4 \mathrm{~g}$ saures $0 \ddot{\mathrm{l}}$.

Das rohe Keton war dickflïssig und braun gefärbt und besaß den Geruch des Äthers, $\mathrm{C}_{20} \mathrm{H}_{42} \mathrm{O}$. Die fraktionierte Destillation im Vakuum, die durch Schäumen sehr erschwert war, gab viel zähen Rückstand nnd lieferte das Keton nur annähernd rein, wie die Analysen von Vorlauf (I), Hauptfraktion (II) und Nachlauf (III) zeigten.

I. $0,1083 \mathrm{~g}$ gaben $0,3058 \mathrm{CO}_{2}$ und $0,1253 \mathrm{H}_{2} \mathrm{O}$.

II. $0,1431 \mathrm{~g} \quad, \quad 0,4042 \quad \mathrm{CO}_{2} \quad, \quad 0,1664 \mathrm{H}_{2} \mathrm{O}$.

III. $0,1378 \mathrm{~g} \quad, \quad 0,3894 \mathrm{CO}_{2} \quad, \quad 0,1548 \mathrm{H}_{2} \mathrm{O}$.

\begin{tabular}{ccccc} 
& Ber. für & \multicolumn{3}{c}{ Gef. } \\
& $\mathrm{C}_{\mathbf{1 1}} \mathrm{H}_{22} \mathrm{O}$ & I & II & III \\
$\mathrm{C}$ & $\mathbf{7 7 , 5 6}$ & $\mathbf{7 7 , 0 1}$ & $\mathbf{7 7 , 0 3}$ & $\mathbf{7 7 , 0 7}$ \\
$\mathrm{H}$ & $\mathbf{1 3 , 0 4}$ & $\mathbf{1 2 , 9 4}$ & 13,01 & $12, \mathbf{5 7}$
\end{tabular}


Bei wiederholter gründlicher Fraktionierung wurde dann der reinste Anteil des Ketons fast ebenso siedend, wie die zwei homologen Methylketone, aufgefangen.

$0,1194 \mathrm{~g}$ gaben $0,3392 \mathrm{CO}_{2}$ und $0,1395 \mathrm{H}_{2} \mathrm{O}$.

$\begin{array}{ccc} & \text { Ber. für } \mathrm{C}_{11} \mathrm{H}_{22} \mathrm{O} & \text { Gef. } \\ \mathrm{C} & \mathbf{7 7 , 5 6} & \mathbf{7 7 , 4 8} \\ \mathrm{H} & \mathbf{1 3 , 0 4} & 13,07\end{array}$

2. Darstellung aus dem Keton $\mathrm{C}_{15} \mathrm{H}_{30} \mathrm{O}$ mit Ozon.

Nur die sehr kurze Behandlung mit Ozon hat zu einem Produkt von der Zusammensetzung $\mathrm{C}_{13} \mathrm{H}_{26} \mathrm{O}$ geführt. Wenn man überschüssiges Ozon länger auf das Methylketon $\mathrm{C}_{15} \mathrm{H}_{30} \mathrm{O}$ einwirken läßt, so liefern die Peroxyde beim Verkochen mit Wasser Präparate, die mit guter Annäherung der Formel $\mathrm{C}_{11} \mathrm{H}_{22} \mathrm{O}$ entsprechen. Wir haben die Proben von sauerstoffreicherem und -ärmerem Peroxyd verkocht, deren Analysen bei der Beschreibung des ersten Ketons angeführt worden sind. Im Kochwasser war etwas Formaldehyd und reichlich Ameisensäure enthalten, die wir mittelst ihres Silber-, Quecksilber- und Bleisalzes identifizierten. Schwer Jösliche Säure trat nur in sehr kleiner Menge auf. Aus $11 \mathrm{~g}$ Ausgangsketon gingen $9 \mathrm{~g}$ indifferentes öl hervor, die zum großen Teil bei $168-174^{\circ}$ unter $8 \mathrm{~mm}$ Druck destillierten. Für die Analysen haben zwei Darstellungen gedient.

\begin{tabular}{cccccc} 
I. $0,1789 \mathrm{~g}$ gaben 0,5117 & $\mathrm{CO}_{2}$ & and & 0,2084 & $\mathrm{H}_{2} \mathrm{O}$. \\
II. $0,1489 \mathrm{~g}$ & " 0,4260 & $\mathrm{CO}_{2}$ & & 0,1750 & $\mathrm{H}_{2} \mathrm{O}$. \\
& Ber. für & & \multicolumn{2}{c}{ Gef. } \\
& $\mathrm{C}_{11} \mathrm{H}_{22} \mathrm{O}$ & I & II \\
$\mathrm{C}$ & 77,56 & & 78,01 & 78,03 \\
$\mathrm{H}$ & 13,04 & & 13,02 & 13,14
\end{tabular}

\section{Beschreibung.}

Das Keton ist ein leicht bewegliches, farbloses Öl von sehr schwachem Geruch, das sich mit den üblichen Solvenzien in jedem Verhältnis mischt. Den Siedepunkt haben wir beim Destillieren einer hinlänglichen Menge sogar um ein Geringes höher als den des Homologen mit 
13 Kohlenstoffatomen gefunden, nämlich bei $168-170^{\circ}$ unter $8 \mathrm{~mm}$ Druck. Bei der Oxydation mit Chromsäure verhält sich das Keton $\mathrm{C}_{11} \mathrm{H}_{22} \mathrm{O}$ genau wie das Keton $\mathrm{C}_{13} \mathrm{H}_{26} \mathrm{O}$.

Semicarbazon $\left(\mathrm{C}_{11} \mathrm{H}_{22}\right) \mathrm{N}_{2} \mathrm{H}$.CO. $\mathrm{NH}_{2}$. Aus der methylalkoholischen Lösung der Komponenten wurde das Semicarbazon nur durch starkes Abkühlen abgeschieden in Nädelchen, die den unscharfen Schmelzpunkt $68-72^{\circ}$ besaßen und auch bei wiederholtem Umkrystallisieren aus Alkohol und Essigester keinen schärferen gewannen. Das Semicarbazon ist in Holzgeist, Essigester und anderen Solvenzien spielend löslich.

$0,0902 \mathrm{~g}$ gaben $14,98 \mathrm{ccm}$ Stickgas bei $19^{\circ}$ und $722 \mathrm{~mm}$ Druck. Ber. für $\mathrm{C}_{12} \mathrm{H}_{25} \mathrm{ON}_{3}$

Gef.

$\mathbf{N}$

18,49

18,03

\section{Keton $\mathbf{C}_{9} \mathbf{H}_{18} \mathbf{0}$.}

Wir haben mit dem Keton $\mathrm{C}_{15} \mathrm{H}_{30} \mathrm{O}$ die langdauernde Ozonisierung wiederholt durchgeführt. $3 \mathrm{~g}$ Keton wurden in Chloroformlösung 2 Stunden d.i. mit 40 Liter Ozon bearbeitet. Nach dem Verkochen des Peroxyds nahmen wir mit dem der Stufe $\mathrm{C}_{11} \mathrm{H}_{22} \mathrm{O}$ entsprechenden Zwischenprodukt genau die gleiche Behandlung abermals vor. So erhielten wir schließlich 1,8 g eines leicht beweglichen Öles von den physikalischen Eigenschaften der schon beschriebenen Methylketone, aber etwas tieferem Siedepunkt, nämlich $168^{\circ}$ unter $10 \mathrm{~mm}$ Druck. Die Analyse (I) ergab die geänderte Zusammensetzung. Ein damit ganz übereinstimmendes Ketonpräparat vom Siedepunkt etwa $170^{\circ}$ unter $14 \mathrm{~mm}$ Druck hat die dreimalige Ozonisierung des Ketons $\mathrm{C}_{15} \mathrm{H}_{30} \mathrm{O}$ geliefert, bei welcher die Einwirkung des Ozons in den zwei ersten Phasen kürzer, in der dritten fast ebenso lang ( $1 \%$ Stunden) gehandhabt wurde. (Analyse II).

I. $0,2348 \mathrm{~g}$ gaben $0,6525 \mathrm{CO}_{2}$ und $0,2642 \mathrm{H}_{2} \mathrm{O}$.

II. $0,1774 \mathrm{~g} \quad \# \quad 0,4936 \quad \mathrm{OO}_{2} \quad \# \quad 0,2001 \quad \mathrm{H}_{2} \mathrm{O}$.

Ber. fürr

Gef.

$\begin{array}{cccc} & \mathrm{C}_{8} \mathrm{H}_{18} \mathrm{O} & \text { I } & \text { II } \\ \mathrm{C} & 75,98 & \mathbf{7 5 , 7 9} & \mathbf{7 5 , 8 9} \\ \mathrm{H} & 12,76 & 12,59 & \mathbf{1 2 , 6 1}\end{array}$


Das neue Keton destillierte hellgelbgrün und wurde in einigen Wochen farblos; mit den gebränchlichen organischen Solvenzien war es mischbar, mit alkoholischer Kalilauge reagierte es nicht, bei $720 \mathrm{~mm}$ Barometerstand beobachteten wir nach Schleiermacher den Siedepunkt bei $282^{\circ}, d_{4}^{0}=0,836$. Das Semicarbazon bildete sehr leicht lösliche Nädelchen vom Schmelzpunkt $75^{\circ}$.

\section{Gemische der homologen Ketone.}

Von den Abbauversuchen durch wiederholte Behandlung mit Ozon oder Chromsäure, oder kombinierte Anwendungen beider Methoden sind hier diejenigen beschrieben worden, die zu wahrscheinlich homogenen Methylketonen geführt haben. Viele andere Versuche

\begin{tabular}{|c|c|c|c|c|c|c|}
\hline \multirow{2}{*}{ Nr. } & \multirow{2}{*}{$\begin{array}{l}\text { Ausgangs- } \\
\text { material }\end{array}$} & \multirow{2}{*}{ Oxydationsmethode } & \multicolumn{3}{|c|}{ Zusammensetzung } & \multirow{2}{*}{ Bestandteile } \\
\hline & & & $\mathrm{C}$ & $\mathbf{H}$ & 0 & \\
\hline 1 & $\mathrm{C}_{15} \mathrm{H}_{30} \mathrm{O}$ & $\begin{array}{l}\text { kurz ozonisiert und } \\
\text { verkocht, wiederbolt }\end{array}$ & 78,26 & 13,19 & 8,55 & $\mathrm{C}_{13} \mathrm{H}_{28} \mathrm{O}+\mathrm{C}_{11} \mathrm{H}_{22} \mathrm{O}$ \\
\hline 2 & $\mathrm{C}_{15} \mathrm{H}_{30} \mathrm{O}$ & $\begin{array}{l}\text { mäBig ozonisiert und } \\
\text { verkocht, wiederholt }\end{array}$ & 76,93 & 12,85 & 10,22 & $\mathrm{C}_{11} \mathrm{H}_{92} \mathrm{O}+\mathrm{C}_{2} \mathrm{H}_{18} \mathrm{O}$ \\
\hline 3 & $\mathrm{C}_{15} \mathrm{H}_{30} \mathrm{O}$ & $\begin{array}{l}\text { lang ozonisiert und } \\
\text { verkocht, wiederholt }\end{array}$ & 75,79 & 12,59 & 11,62 & $\mathrm{C}_{9} \mathrm{H}_{18} \mathrm{O}$ \\
\hline 4 & $\mathrm{C}_{15} \mathrm{H}_{30} \mathrm{O}$ & $\begin{array}{l}\text { sehr lang ozonisiert } u \\
\text { verkocht, wiederholt }\end{array}$ & 74,27 & 12,30 & 13,43 & $\mathrm{C}_{9} \mathrm{H}_{18} \mathrm{O}+\mathrm{C}_{7} \mathrm{H}_{14} \mathrm{O}$ \\
\hline 5 & $\mathrm{C}_{13} \mathrm{H}_{28} \mathrm{O}$ & $\begin{array}{c}\text { Chromsäure-Bisulfat } \\
\text { (3 At. O) }\end{array}$ & 78,32 & 13,14 & 8,54 & $\mathrm{C}_{19} \mathrm{H}_{29} \mathrm{O}+\mathrm{C}_{11} \mathrm{H}_{28} \mathrm{O}$ \\
\hline 6 & $\mathrm{C}_{18} \mathrm{H}_{28} \mathrm{O}$ & $\begin{array}{l}\text { Chromsäure- } \\
\text { Schwefelsäure } \\
(2 \text { At. O) }\end{array}$ & 78,27 & 12,83 & 8,90 & $\mathrm{C}_{19} \mathrm{C}_{26} \mathrm{O}+\mathrm{C}_{11} \mathrm{H}_{22} \mathrm{O}$ \\
\hline 7 & $\mathrm{C}_{13} \mathrm{H}_{23} \mathrm{O}$ & ozonisiert & 76,47 & 12,72 & 10,81 & $\mathrm{C}_{11} \mathrm{H}_{28} \mathrm{O}+\mathrm{C}_{9} \mathrm{H}_{18} \mathrm{O}$ \\
\hline 8 & $\mathrm{C}_{11} \mathrm{H}_{22} \mathrm{O}$ & $\begin{array}{l}\text { Chromsäure- } \\
\text { Schwefelsäure } \\
(2 \text { At. } 0)\end{array}$ & $\begin{array}{l}76,81 \\
77,12\end{array}$ & $\begin{array}{l}12,47 \\
12,66\end{array}$ & $\begin{array}{l}10,72 \\
10,22\end{array}$ & $\mathrm{C}_{11} \mathrm{H}_{22} \mathrm{O}+\mathrm{C}_{9} \mathrm{H}_{13} \mathrm{O}$ \\
\hline 9 & Phytoläther & $\begin{array}{l}\text { Chromsäure- } \\
\text { Schwefelsäure } \\
\text { (5 At. O) }\end{array}$ & $\begin{array}{l}76,80 \\
76,60\end{array}$ & $\begin{array}{l}12,63 \\
12,52\end{array}$ & $\begin{array}{l}10,67 \\
10,88\end{array}$ & $\mathrm{C}_{9} \mathrm{H}_{18} \mathrm{O}+\mathrm{C}_{7} \mathrm{H}_{14} \mathrm{O}$ \\
\hline
\end{tabular}


sind, obwohl sie nur Gemische geliefert haben, wertvoll für die Schlabfolgerung, daß beim Abbau des Phytols die Atomgruppierung der Methylketone immer wieder in gleichartiger Weise auftritt. Wir erhielten Präparate vom gleichen Siedepunkt und ganz gleichem Habitus, Carbonylverbindungen ohne Aldehydeigenschaften, nur dadurch voneinander unterschieden, daß der Sauerstoffgehalt ansteigt, je häufiger und energischer die Oxydation ausgeführt worden ist, Mischungen der Methylketone mit 13, 11, 9 und 7 Kohlenstoffatomen.

\section{B. Carbonsäuren.}

Säure $\mathrm{C}_{14} \mathrm{H}_{28} \mathrm{O}_{2}$.

\section{Bildung aus $\alpha$-Phytolozonid.}

Beim Verkochen der Phytolozonide wird in einer Ausbeute von etwa $3^{1 / 2}$ Proz. hochmolekulare Säure gebildet, die man durch Ausziehen der ätherischen Lösung des Rohketons mit sehr verdünnter Natronlauge isoliert. Bei der Destillation im Vakuum lieb sie viel wachsartigen Rückstand im Kolben; die Hauptfraktion, zwischen 180 bis $193^{\circ}$ unter $9 \mathrm{~mm}$ Druck übergehend, zerlegten wir durch erneute Destillation in Fraktionen vom Siedepunkt

$$
\begin{aligned}
& 182-184^{\circ} \\
& 184-186^{\circ} \\
& 186-189^{\circ},
\end{aligned}
$$

welche wir in der Form ihrer Silbersalze analysiert haben.

I. $0,1090 \mathrm{~g}$ gaben $0,0395 \mathrm{Ag}$.

II. $0,0804 \mathrm{~g}, \quad 0,0256 \mathrm{Ag}$.

III, $0,0640 \mathrm{~g}, \quad 0,0207 \mathrm{Ag}$.

Ber. für

$$
\text { Ag } \quad \mathrm{C}_{14} \mathrm{H}_{27} \mathrm{O}_{2} \mathrm{Ag}
$$

Gef.

$\begin{array}{ccc}\text { I } & \text { II } & \text { III } \\ 32,03 & 31,84 & 32,34\end{array}$

Die freie Säure war übrigens nicht so rein, wie ihr Silbersalz. Das Rohprodukt aus dem Ozonid hat nämlich Phytensäure enthalten; bei den Destillationen war sie in das tiefer siedende isomere $\gamma$-Lacton übergegangen und dieses begleitete die Säure $\mathrm{C}_{14} \mathrm{H}_{28} \mathrm{O}_{2}$ in den Haupt- 
fraktionen. Es ist daher zweckmäßig, die gesättigte Säure bei den Oxydationen des Phytols zu reinigen, indem man die im Rohprodukt enthaltene Phytensäure durch Erhitzen mit Schwefelsäure nach Fittig lactonisiert and dann Säure and Lacton mit verdünntem Alkali trennt.

\section{Aus Dioxyphytanol.}

Die beschriebene Oxydation des Dioxyphytanols hat neben dem Keton $\mathrm{C}_{11} \mathrm{H}_{22} \mathrm{O}$ ein saures Öl ergeben $(5,4 \mathrm{~g}$ aus $14,7 \mathrm{~g}$ Trioxyphytan). Davon destillierten unter Hinterlassung von viel Unflüchtigem nur $1,9 \mathrm{~g}$ zwischen 179-192 ${ }^{\circ}$ ( $8 \mathrm{~mm}$ Druck); bei nochmaligem Destillieren ging die Hauptfraktion zwischen $186-191^{\circ}$ als dickes Öl über (Analyse I). Sie stimmte im Siedepunkt, in der Dichte und den übrigen physikalischen Eigenschaften mit der Säure $\mathrm{C}_{14} \mathrm{H}_{28} \mathrm{O}_{2}$ aus den anderen Darstellungen überein. Auch der Nachlauf (Analyse II) bestand aus der reinen Säure.

I. $0,1163 \mathrm{~g}$ gaben $0,3160 \mathrm{CO}_{2}$ und $0,1274 \mathrm{H}_{2} \mathrm{O}$.

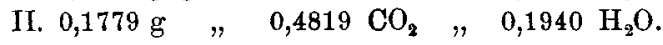
Ber. für $\mathrm{C}_{14} \mathrm{H}_{28} \mathrm{O}_{2}$ Gef.

$\begin{array}{cccc} & \mathrm{C}_{14} \mathrm{H}_{28} \mathrm{O}_{2} & \text { I } & \text { II } \\ \mathrm{C} & 73,61 & 74,10 & 73,88 \\ \mathrm{H} & 12,37 & 12,25 & 12,20\end{array}$

Die Identität der Säure ist durch die Umwandlung der Hauptfraktion in das Silbersalz sichergestellt worden.

Silbersalz.

I. $0,2088 \mathrm{~g}$ gaben $0,3844 \mathrm{CO}_{2}$ und $0,1542 \mathrm{H}_{2} \mathrm{O}$

II. $0,2219 \mathrm{~g} \quad, \quad 0,0713 \mathrm{Ag}$.

\begin{tabular}{lccc} 
& Ber, für & \multicolumn{2}{c}{ Gef. } \\
& $\mathrm{C}_{14} \mathrm{H}_{27} \mathrm{O}_{2} \mathrm{Ag}$ & I & II \\
$\mathrm{C}$ & 50,14 & 50,21 & - \\
$\mathrm{H}$ & 8,12 & 8,26 & - \\
$\mathrm{Ag}$ & 32,19 & - & $\mathbf{3 2 , 1 3}$
\end{tabular}

3. Aus dem Glykol $\mathrm{C}_{15} \mathrm{H}_{30}(\mathrm{OH})_{2}$.

Das Olefin $\mathrm{C}_{15} \mathrm{H}_{30}$ läßt sich zur Säure $\mathrm{C}_{14} \mathrm{H}_{28} \mathrm{O}_{2}$ abbauen durch die Umwandlung seines Dibromides in Glykol und Oxydation desselben mit Clromsäure. Wir 
versetzten unter Kühlung and Schüttehn die Suspension des Kohlenwasserstoffes in Eisessig mit der molekularen Menge von Brom im gleichen Solvens. Das Bromid fiel sofort als gelbliches Öl zu Boden und wurde ohne weiteres im Eisessig mit Silberacetat (2 Mol.) an der Maschine geschüttelt. Dabei reagierte nur ein Bromatom.

Das Bromid aus $1,06 \mathrm{~g}$ Olefin lieferte $0,524 \mathrm{~g} \mathrm{AgBr}$ statt für $1 \mathrm{Mol}$. berechnet $0,538 \mathrm{~g} \mathrm{AgBr}$.

Das Bromacetylderivat, ein dickes Öl, analysierten wir nach zweistündigem (Best. I) und nach weiterem 24 stündigem Schütteln (Best. II) mit dem Acetat.

I. $0,1552 \mathrm{~g}$ gaben $0,3314 \mathrm{CO}_{2}$ und $0,1366 \mathrm{H}_{2} \mathrm{O}$.

II. $0,1430 \mathrm{~g} \quad \# \quad 0,3087 \mathrm{CO}_{2} \quad \# \quad 0,1292 \mathrm{H}_{2} \mathrm{O}$.

\begin{tabular}{cccc} 
& Ber, für & \multicolumn{2}{c}{ Gef. } \\
& $\mathrm{C}_{17} \mathrm{H}_{38} \mathrm{O}_{2} \mathrm{Br}$ & I & II \\
$\mathrm{C}$ & 58,42 & 58,24 & 58,87 \\
$\mathrm{H}$ & 9,52 & 9,84 & 10,10
\end{tabular}

Beim Erwärmen der Monobromverbindung mit überschüssigem Silberacetat in Eisessig auf Wasserbadtemperatur unter Rühren mit der Turbine reagierte auch das zweite Bromatom; sodann verseiften wir das Diacetat mit konz. methylalkoholischer Kalilauge in der Kälte. Das im Vakuum bei $100^{\circ}$ vom Lösungsmittel befreite Produkt, ein bräunliches viscöses Öl (7,25 $\mathrm{g}$ aus $9 \mathrm{~g}$ Kohlenwasserstoff), besitzt nicht die erwartete $\mathrm{Zu}$ sammensetzung des $c$-Glykols. Wir schließen aus der Analyse ( $I$ und II), daß in der Hauptsache aus $2 \mathrm{Mol}$. des Glykols durch Austritt von 1 Mol. Wasser ein Äther entstanden ist, ein Diäthylenglykol, nicht etwa ein Gemisch von Glykol und Äthylenoxyd, denn mehrstündiges Erhitzen mit verdünnter Schwefelsäure bewirkt keine Anderung der Zusammensetzung (Analyse III).

I. $0,1659 \mathrm{~g}$ gaben $0,4605 \mathrm{CO}_{2}$ und $0,1967 \mathrm{H}_{2} \mathrm{O}$.

II. $0,1316 \mathrm{~g} \quad \# \quad 0,3671 \quad \mathrm{CO}_{2} \quad " \quad 0,1564 \mathrm{H}_{2} \mathrm{O}$.

III. $0,1506 \mathrm{~g} \quad \# \quad 0,4199 \mathrm{CO}_{3} \quad, \quad 0,1757 \mathrm{H}_{2} \mathrm{O}$.

Ber. für

\begin{tabular}{|c|c|c|c|c|c|}
\hline & $\mathrm{C}_{30} \mathrm{H}_{82} \mathrm{O}_{3}$ & $\mathrm{C}_{15} \mathrm{H}_{32} \mathrm{O}_{2} 7$ & I & II & III \\
\hline C & 76,52 & 73,69 & $7 \overline{0}, 70$ & 76,08 & 76,04 \\
\hline & 13,28 & 13,21 & 13,25 & 13,29 & 13,05 \\
\hline
\end{tabular}


Diese Verbindung ist ohne weitere Reinigung mit Erfolg für die Oxydation verwendet worden. Auf Portionen von $3 \mathrm{~g}$ ließen wir in Eisessiglösung $3,75 \mathrm{~g}$ Schwefelsäure und 2,5 g Chromtrioxyd (d. i. 3 At. Sauerstoff) einwirken. Nach eintägigem Stehen war die Chromsäure nicht verbraucht, wir führten dann die Reaktion durch 5 stündiges Erwärmen im Wasserbad zu Ende. Bei der üblichen 'Trennung in sauren und indifferenten Bestandteil isolierten wir nur $0,85 \mathrm{~g}$ Säure und mehr, nämlich $1,48 \mathrm{~g}$, von einem Zwischenprodukt, das um 2 At. Wasserstoff ärmer war, als das Glykol $\mathrm{C}_{15} \mathrm{H}_{30}(\mathrm{OH})_{2}$. Das indifferente Öl wurde bei zwei Versuchen für die Analyse im Vakuum vom Lösungsmittel befreit.

I. $0,0953 \mathrm{~g}$ gaben $0,2599 \mathrm{CO}_{2}$ und $0,1043 \mathrm{H}_{2} \mathrm{O}$.

II. $0,1018 \mathrm{~g} \quad, \quad 0,2772 \mathrm{CO}_{z} \# 0,1128 \mathrm{H}_{2} \mathrm{O}$.

Ber. für $\mathrm{C}_{15} \mathrm{H}_{30} \mathrm{O}_{2}$

Gef.

$\begin{array}{cccc} & \mathrm{C}_{15} \mathrm{H}_{30} \mathrm{O}_{\mathbf{3}} & \mathrm{I} & \text { II } \\ \mathrm{C} & \mathbf{7 4 , 3 8} & \mathbf{7 4 , 3 8} & \mathbf{7 4 , 2 6} \\ \mathrm{H} & \mathbf{1 2 , 3 9} & \mathbf{1 2 , 2 4} & \mathbf{1 2 , 4 0}\end{array}$

Diese Carbonylverbindung mußte bei weiterer Oxydation noch mehr von der gleichen Säure liefern, die in der ersten Phase erhalten worden war. Zu diesem Ende lösten wir $1,91 \mathrm{~g} \mathrm{Zwischenprodukt} \mathrm{in} 100 \mathrm{ccm}$ Eisessig und oxydierten unter Zusatz von 1,58 g Schwefelsäure mit $1,05 \mathrm{~g}$ Chromtrioxyd bei Wasserbadtemperatur. So entstanden noch $0,68 \mathrm{~g}$ von der Säure. Die Hauptfraktion destillierte zwischen $181-191^{\circ}$ unter $7,5 \mathrm{~mm}$ Druck; der Vorlauf enthielt stechend riechen de niedrigere Fettsäuren.

$0,1319 \mathrm{~g}$ gaben $0,3572 \mathrm{CO}_{2}$ und $0,1511 \mathrm{H}_{2} \mathrm{O}$.

$\begin{array}{ccc} & \text { Ber. für } \mathrm{C}_{14} \mathrm{H}_{\mathbf{2 8}} \mathrm{O}_{2} & \text { Gef. } \\ \mathrm{C} & \mathbf{7 3 , 6 1} & \mathbf{7 3 , 8 5} \\ \mathrm{H} & 12,37 & \mathbf{1 2 , 8 1}\end{array}$

Silbersalz.

1. $0,1044 \mathrm{~g}$ gaben $0,1909 \mathrm{CO}_{2}$ und $0,0782 \mathrm{H}_{2} \mathrm{O}$.

II. $0,1423 \mathrm{~g} \quad, \quad 0,2606 \quad \mathrm{CO}_{2} \quad, \quad 0,1057 \quad \mathrm{H}_{2} \mathrm{O}$.

III. $0,2000 \mathrm{~g} ", 0,0648 \mathrm{Ag}$. 


\begin{tabular}{lcccc} 
& Ber. für & \multicolumn{3}{c}{ Gef. } \\
& $\mathrm{C}_{14} \mathrm{H}_{27} \mathrm{O}_{2} \mathrm{Ag}$ & $\mathrm{I}$ & II & III \\
$\mathrm{C}$ & $\mathbf{5 0 , 1 4}$ & 49,87 & 49,94 & - \\
$\mathrm{H}$ & 8,12 & 8,38 & 8,31 & - \\
$\mathrm{Ag}$ & 32,19 & - & - & 32,40
\end{tabular}

\section{Darstellung aus dem Ozonid des Olefins $\mathrm{C}_{15} \mathrm{H}_{30}$.}

Das Ozonid des Kohlenwasserstoffs wird schwieriger hydrolysiert, als das des Phytols; es gab nach 3stündigem Kochen noch kräftige Reaktion auf Jodkalium und war erst nach 5 Stunden vollständig gespalten. Das Ozonid aus $34 \mathrm{~g}$ des Olefins gab beim Verkochen $10 \mathrm{~g}$ Säure neben $18 \mathrm{~g}$ eines indifferenten Öles von der Zusammensetzung $\mathrm{C}_{9} \mathrm{H}_{17} \mathrm{CO}_{2} \mathrm{C}_{10} \mathrm{H}_{21}$, das bei der Säure $\mathrm{C}_{10} \mathrm{H}_{20} \mathrm{O}_{2}$ besprochen wird. Bei einer Darstellung analysierten wir den unter $8,5 \mathrm{~mm}$ Druck bei $179-184^{\circ}$ übergegangenen Vorlauf (Best. I), sowie die darauffolgende Hauptfraktion (Best. II), bei einem anderen Versuche teilten wir das Destillat in drei Fraktionen, nämlich bei $8 \mathrm{~mm} 181$ bis $184^{\circ}$ (Analyse III), $184-188^{\circ}$ (IV), $188-190^{\circ}(\mathrm{V})$.

I. $0,0984 \mathrm{~g}$ gaben $0,2684 \mathrm{CO}_{2}$ und $0,1133 \mathrm{H}_{2} \mathrm{O}$.

$\begin{array}{rllllll}\text { II. } 0,1383 \mathrm{~g} & " & 0,3746 & \mathrm{CO}_{2} & & 0,1538 & \mathrm{H}_{2} \mathrm{O} . \\ \text { III. } 0,1056 \mathrm{~g} & " & 0,2799 & \mathrm{CO}_{2} & \# & 0,1172 & \mathrm{H}_{2} \mathrm{O} . \\ \text { IV. } 0,2381 \mathrm{~g} & " & 0,6486 & \mathrm{CO}_{2} & " & 0,2674 & \mathrm{H}_{2} \mathrm{O} \text {. } \\ \text { V. } 0,1506 \mathrm{~g} & " & 0,4073 & \mathrm{CO}_{2} & " & 0,1677 & \mathrm{H}_{2} \mathrm{O} .\end{array}$

\begin{tabular}{ccccccc} 
& Ber. für & & \multicolumn{5}{c}{ Gef. } \\
& $\mathrm{C}_{\mathbf{1 4}} \mathrm{H}_{23} \mathrm{O}_{2}$ & I & II & III & IV & V \\
$\mathrm{C}$ & $\mathbf{7 3 , 6 1}$ & $\mathbf{7 4 , 2 9}$ & $\mathbf{7 3 , 8 7}$ & $\mathbf{7 3 , 9 7}$ & $\mathbf{7 4 , 2 9}$ & $\mathbf{7 3 , 7 7}$ \\
$\mathrm{H}$ & 12,37 & $\mathbf{1 2 , 7 8}$ & $1 \mathbf{2 , 4 2}$ & 12,70 & $\mathbf{1 2 , 5 7}$ & $\mathbf{1 2 , 4 6}$
\end{tabular}

Die Analysenwerte würden nicht entscheiden zwischen der Säure $\mathrm{C}_{14} \mathrm{H}_{28} \mathrm{O}_{2}$ und dem Homologen $\mathrm{C}_{15} \mathrm{H}_{30} \mathrm{O}_{2}$, für welches berechnet ist $\mathrm{C} 74,31, \mathrm{H} \mathrm{12,49}$. Aber die $\mathrm{Zu}$ sammensetzung des aus den Fraktionen für die Analysen II, IV und V dargestellten Silbersalzes war für die Identität der Säure mit 14 Kohlenstoffatomen beweisend.

I. $0,1769 \mathrm{~g}$ gaben $0,3320 \mathrm{CO}_{2}$ und $0,1324 \mathrm{H}_{3} \mathrm{O}$.

II. $0,1645 \mathrm{~g}, 0,0531 \mathrm{Ag}$.

III. $0,1594 \mathrm{~g} \quad " \quad 0,0507 \mathrm{Ag}$.

IV. $0,3209 \mathrm{~g}, 0,1047 \mathrm{Ag}$. 


\begin{tabular}{lccccc} 
& Ber. für & \multicolumn{4}{c}{ Gef. } \\
& $\mathrm{C}_{\mathbf{1 4}} \mathrm{H}_{\mathbf{2 7}} \mathrm{O}_{2} \mathrm{Ag}$ & I & II & III & IV \\
$\mathrm{C}$ & $\mathbf{5 0 , 1 4}$ & 49,64 & - & - & - \\
$\mathrm{H}$ & $\mathbf{8 , 1 2}$ & $\mathbf{8 , 3 7}$ & - & - & - \\
$\mathrm{Ag}$ & $\mathbf{3 2 , 1 9}$ & - & 32,27 & 31,80 & 32,62
\end{tabular}

\section{Beschreibung.}

Die Säure $\mathrm{C}_{14} \mathrm{H}_{28} \mathrm{O}_{2}$ stellt in reinem Zustand ein farbloses, ziemlich dickes Öl dar. Sie siedet unter 8 bis $9 \mathrm{~mm}$ Druck bei $186-188^{\circ} ; \mathrm{d}_{4}^{0}=0,887, \mathrm{~d}_{4}^{20}=0,870$. Mit Holzgeist, Eisessig, Petroläther und anderen organischen Solvenzien ist sie mischbar. Die Säure ist gegen Permanganat in Eisessig momentan beständig, aber sie reduziert es allmählich, gegen Brom erweist sie sich ganz gesättigt. Von Chromtrioxyd in Eisessig-Schwefelsäure wird sie träge oxydiert zum Keton $\mathrm{C}_{13} \mathrm{H}_{26} \mathrm{O}$ und der nachstehenden Säure mit 12 Kohlenstoffatomen.

Das Silbersalz fällt aus der neutralisierten alkoholischen Lösung der Säure auf Zusatz von alkoholischem Silbernitrat krystallinisch aus. Es ist in den Alkoholen und Petroläther nicht löslich und nur spurenweise löslich in Äther. Erwärmt man ein wenig von dem Silbersalz mit Benzol, so löst es sich mit etwas bräunlicher Farbe, aber bei weiterem Erhitzen scheidet es sich als Gallerte wieder vollständig aus. Das Salz schmilzt unter Braunfärbung unscharf bei $186-188^{\circ}$.

\section{Säuren $\mathrm{C}_{13} \mathrm{H}_{28} \mathrm{O}_{2}$ (?) nnd $\mathrm{C}_{12} \mathrm{H}_{24} \mathrm{O}_{2}$.}

Bei dem Abbau des Phytols sind wir auBer den zwei reinen Säuren $\mathrm{C}_{14} \mathrm{H}_{28} \mathrm{O}_{2}$ und $\mathrm{C}_{10} \mathrm{H}_{20} \mathrm{O}_{2}$ anch nicht homogenen sauren Ölen von der Zusammensetzung $\mathrm{C}_{13} \mathrm{H}_{28} \mathrm{O}_{2}$ bis $\mathrm{C}_{11} \mathrm{H}_{22} \mathrm{O}_{2}$ begegnet. Obwohl nur Nebenprodukte, sind sie von Interesse für den Nachweis, daß unserer Reihe von Methylketonen analog eine Reihe homologer Säuren von sehr ähnlichen Eigenschaften auftritt. Die Säure $\mathrm{C}_{12} \mathrm{H}_{24} \mathrm{O}_{2}$ ist das $\mathrm{zu}$ erwartende Zwischenglied für die zwei genau untersuchten Säureu mit 14 und 10 Kohlenstoffatomen, die Säure $\mathrm{C}_{13} \mathrm{H}_{26} \mathrm{O}_{2}$ hingegen kann aus den 
Methylketonen $\mathrm{C}_{15} \mathrm{H}_{30} \mathrm{O}$ und der Sänre $\mathrm{C}_{14} \mathrm{H}_{28} \mathrm{O}_{2}$ nur hervorgehen durch intermediäre Bildung einer Malonsäure nach dem Schema:

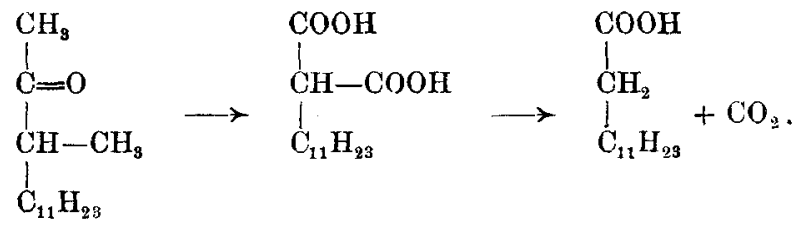

Beim Verkochen des Peroxyds aus $15 \mathrm{~g}$ Keton $\mathrm{C}_{15} \mathrm{H}_{30} \mathrm{O}$ erhielten wir $1,1 \mathrm{~g}$ Säure vom Siedep. $182-183^{\circ}$ $(9 \mathrm{~mm})$. Gleichriel ob die Behandlung mit Ozon mehr oder weniger lang ausgeführt worden, entsprach die $\mathrm{Zu}$ sammensetzung

$$
\text { C 72,75, 72,62 H } 12,21,12,31
$$

der Formel $\mathrm{C}_{13} \mathrm{H}_{26} \mathrm{O}_{2}$, für die sich berechnet $\mathrm{C} 72,82$, H 12,24. Nach der Untersuchung des Silbersalzes war diese Säure nicht einheitlich.

Ein ebenso zusammengesetztes Produkt (C 72,69 und H 12,21) lieferte die Oxydation von Phytansäure. Wir oxydierten 1,8 $\mathrm{g}$ in Eisessig-Schwefelsäure mit 1,55 g Chromtrioxyd obne zu erhitzen. Die gebildete Säure $(1,14 \mathrm{~g})$ destillierte bei etwa $176^{\circ}(9 \mathrm{~mm})$.

Aus der Säure $\mathrm{C}_{14} \mathrm{H}_{28} \mathrm{O}_{2}(5,1 \mathrm{~g})$ entstand bei derselben Behandlung mit Chromsäure und zwar bei zweimaliger Oxydation die Säure $\mathrm{C}_{12} \mathrm{H}_{24} \mathrm{O}_{2}(2,5 \mathrm{~g})$, welcher wahrscheinlich noch etwas unveränderte Ausgangssäure beigemischt war. Das Produkt destillierte unter $9 \mathrm{~mm}$ Druck bei $186-189^{\circ}$ als dickes, mit den üblichen Lösungsmitteln mischbares Öl, das gegen Permanganat die gleiche Beständigkeit zeigte wie Phytansäure. Das Silbersalz stimmte in seiner Löslichkeit mit dem Salz $\mathrm{C}_{14} \mathrm{H}_{27} \mathrm{O}_{2} \mathrm{Ag}$ überein.

$0,1477 \mathrm{~g}$ gaben $0,3900 \mathrm{CO}_{2}$ und $0,1600 \mathrm{H}_{2} \mathrm{O}$.

$\begin{array}{ccc} & \text { Ber. für } \mathrm{C}_{12} \mathrm{H}_{24} \mathrm{O}_{2} & \text { Gef. } \\ \mathrm{C} & \mathbf{7 1 , 9 3} & \mathbf{7 2 , 0 1} \\ \mathrm{H} & 12,09 & 12,12\end{array}$


Silbersalz.

0,1415 g gaben $0,2489 \mathrm{CO}_{2}$ und $0,0996 \mathrm{H}_{2} \mathrm{O}$.

$0,2158 \mathrm{~g} \quad, \quad 0,0728 \mathrm{Ag}$.

$\begin{array}{lcr} & \text { Ber. für } \mathrm{C}_{12} \mathrm{H}_{29} \mathrm{O}_{2} \mathrm{Ag} & \text { Gef. } \\ \mathrm{C} & 46,90 & 47,97 \\ \mathrm{H} & \mathbf{7}, 55 & 7,87 \\ \mathrm{Ag} & \mathbf{3 5 , 1 3} & \mathbf{3 4 , 5 2}\end{array}$

Nach der entgegengesetzten Seite, also mit einer iedrigeren Säure, verunreinigt war das Produkt der Oxydation des Methylketons $\mathrm{C}_{13} \mathrm{H}_{26} \mathrm{O}$. Dieses lieferte zum Unterschied vom Keton $\mathrm{C}_{15} \mathrm{H}_{30} \mathrm{O}$ mit ChromsänreSchwefelsäure-Eisessig nicht die Säure $\mathrm{C}_{10} \mathrm{H}_{20} \mathrm{O}_{2}$, sondern ein bei etwa $175^{\circ}(11 \mathrm{~mm})$ destillierendes Öl, das annähernd gemäß der Formel $\mathrm{C}_{12} \mathrm{H}_{24} \mathrm{O}_{2}$ zusammengesetzt war.

$0,1769 \mathrm{~g}$ gaben $0,4620 \mathrm{CO}_{2}$ und $0,1880 \mathrm{H}_{2} \mathrm{O}$.

$\begin{array}{ccc} & \text { Ber. für } \mathrm{C}_{12} \mathrm{H}_{24} \mathrm{O}_{2} & \text { Gef. } \\ \mathrm{C} & 71,93 & 71,23 \\ \mathrm{H} & 12,09 & 11,99\end{array}$

\author{
Säure $\mathrm{C}_{10} \mathrm{H}_{20} \mathrm{O}_{2}$. \\ 1. Aus Keton $\mathrm{C}_{15} \mathrm{H}_{30} \mathrm{O}$.
}

Die Oxydation des Ketons $\mathrm{C}_{15} \mathrm{H}_{30} \mathrm{O}$ in Eisessig mit Chromtrioxyd-Schwefelsäure ist S. 129 als Methode für die Gewinnung des Ketons $\mathrm{C}_{13} \mathrm{H}_{26} \mathrm{O}$ beschrieben worden. Dabei entsteht die Säure $\mathrm{C}_{10} \mathrm{H}_{20} \mathrm{O}_{2}$ als Nebenprodukt, das durch Waschen mit sehr verdünnter Lauge der ätherischen Lösung des Ketons entzogen wird, und zwar beträgt die Ausbeute in rohem Zustand zwischen 20 und 25 Proz. vom angewandten Keton, d. i. 26-33 Proz. der Theorie. Bei drei Versuchen lag die Säure schon nach einmaligem Destillieren analysenrein vor.

I. $0,1251 \mathrm{~g}$ gaben $0,3210 \mathrm{CO}_{2}$ und $0,1305 \mathrm{H}_{2} \mathrm{O}$.

II. $0,1302 \mathrm{~g} \quad, \quad 0,3343 \quad \mathrm{CO}_{2} \quad, \quad 0,1338 \mathrm{H}_{2} \mathrm{O}$.

\begin{tabular}{cccc} 
& Ber. für & \multicolumn{2}{c}{ Gef. } \\
& $\mathrm{C}_{10} \mathrm{H}_{20} \mathrm{O}_{2}$ & I & II \\
$\mathrm{C}$ & 69,70 & 69,98 & $\mathbf{7 0 , 0 2}$ \\
$\mathrm{H}$ & $\mathbf{1 1 , 7 1}$ & 11,67 & 11,50 \\
en der Chemie 37. Band. & & \multicolumn{2}{c}{10}
\end{tabular}


Obwohl die Säure nur noch das halbe Kohlenstoffgerïst des Phytols enthält, erinnert sie in ihrem Habitus stark an das Phytol. Sie ist ein dickes, farbloses und geruchloses ÖI, das sich mit den üblichen organischen Lösungsmitteln in jedem Verhältnis mischt. Sie siedet unter $11 \mathrm{~mm}$ Druck bei 155-158 (Quecksilber im Dampf) und zeigt bei $722 \mathrm{~mm}$ Barometerstand nach Schleiermacher den Siedep. $261^{\circ}$.

$\mathrm{d}_{4}^{0}=0,956, \mathrm{~d}_{\ddagger}^{30}=0,936 ; \mathrm{n}_{\mathrm{D}}^{20}=1,45205$. Molrefr. gef. 49,55, ber. 49,84 .

In alkoholischer Lösung rötet die Säure Lackmus stark. Sie entfärbt Brom und ist gegen Permanganat in Eisessig kurze Zeit beständig, dann erfolgt langsam Farbenumschlag.

Silbersalz, $\mathrm{C}_{10} \mathrm{H}_{19} \mathrm{O}_{2} \mathrm{Ag}$. Das Natriumsalz gibt in alkoholischer Lösung mit Silbernitrat eine weiße krystallinische Fällung, die in den gebräuchlichen Lösungsmitteln unlöslich ist. Mit Benzol entsteht eine kolloidale Lösung, ebenso wie bei dem Salz der Säure $\mathrm{C}_{\mathbf{1 4}} \mathrm{H}_{28} \mathrm{O}_{2}$ Das Silbersalz besitzt keinen Schmelzpunkt, es verkohlt beim Erhitzen.

I. $0,1678 \mathrm{~g}$ gaben $0,2637 \mathrm{CO}_{2}$ und $0,0996 \mathrm{H}_{2} \mathrm{O}$.

II. $0,2008 \mathrm{~g}, \quad 0,0774 \mathrm{Ag}$.

\begin{tabular}{lccc} 
& Ber. für & \multicolumn{2}{c}{ Gef. } \\
& $\mathrm{C}_{10} \mathrm{H}_{19} \mathrm{O}_{2} \mathrm{Ag}$ & I & II \\
$\mathrm{C}$ & 43,01 & 42,86 & - \\
$\mathrm{H}$ & 6,86 & 6,64 & - \\
$\mathrm{Ag}$ & 38,6 & - & 38,55
\end{tabular}

\section{Leitfähigkeit.}

Die Untersuchung der Leitfähigkeit der hier beschriebenen Säuren wird erschwert durch ihre sehr geringe Löslichkeit.

Herr Professor Bredig hatte die Freundlichkeit, die Prïfung von Herrn Assistenten Dr. Braune ausführen zu lassen und uns die folgenden Angaben zur Verfïgung zu stellen. Wir danken beiden Herren bestens für die Ansführung der Untersuchung. 
Die Leitfähigkeiten lassen sich mit einfachen Mitteln nicht genauer als auf etwa 2 Proz. messen. Die spezifische Leitfähigkeit des Lösungsmittels betrug $0,5-1.10^{-6}$ und wurde nicht abgezogen. Der angegebene Prozentgehalt bedeutet Gewichtsprozente Alkohol.

Säure $\mathrm{C}_{10} \mathrm{H}_{20} \mathrm{O}_{2}$.

$0,1710 \mathrm{~g}$ gelöst in $50 \mathrm{cem}=45,48 \mathrm{~g}$ Alkohol von 50 Proz.

$\begin{array}{cc}v \text { in Literu } & A \\ 50,3 & 0,684 \\ 100,6 & 0,950 \\ 201,2 & 1,31\end{array}$

Die zwei Säuren mit 20 Kohlenstoffatomen lösten sich erst in einer Mischung von $100 \mathrm{ccm} 50$ prozentigen und $50 \mathrm{cem}$ absoluten Alkohols. Das Lösungsmittel bestand dann aus $84,90 \mathrm{~g}$ Alkohol und $45,43 \mathrm{~g}$ Wasser und war in bezug auf Alkohol 65,2 prozentig.

Phytansäure $\mathrm{O}_{20} \mathrm{H}_{40} \mathrm{O}_{2}$.

$0,4156 \mathrm{~g}$ gelöst in $150 \mathrm{ccm}$.

$\begin{array}{cc}v & A \\ 112 & 0,544 \\ 224 & 0,814 \\ \Delta^{2} \text {-Phytensäure } & \mathrm{C}_{30} \mathrm{H}_{38} \mathrm{O}_{2} .\end{array}$

$0,3040 \mathrm{~g}$ gelöst in $150 \mathrm{cem}$.

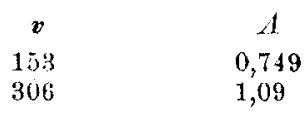

Essigsäure zum Vergleich.

$\begin{array}{rc}v & A \\ 50 & 0,452 \\ 100 & 0,708\end{array}$

Die $\Delta^{2}$-Säure übertrifft also, wie zu erwarten war, die Phytansäure in der Leittähigkeit.

2. Bildung aus dem Olefin $\mathrm{C}_{15} \mathrm{H}_{30}$.

Die Hydrolyse des Ozonids aus $\mathrm{C}_{15} \mathrm{H}_{30}$ lieferte neben der Säure $\mathrm{C}_{14} \mathrm{H}_{28} \mathrm{O}_{2}$ ein indifferentes Spaltungsprodukt (18 $\mathrm{g}$ aus $34 \mathrm{~g}$ Olefin), das keine Aldehyd- und Keton- 
reaktionen zeigte. Es destillierte zunächst in sehr weiten Grenzen, beim Fraktionieren haben wir von einem Kohlenwasserstoff, der im Vorlauf enthalten war, den Hauptbestandteil des indifferenten Produktes abgetrennt als ein ziemlich dünnflüssiges, geruchloses Öl, das sich mit den organischen Lösungsmitteln mischte; nach dem Destillieren war es hellgrünlich, beim Stehen entfärbte es sich. Die Analyse I ist mit einmal fraktionierter, unter $8 \mathrm{~mm}$ Druck zwischen $170-184^{\circ}$ übergegangener Substanz, die Bestimmungen II und III mit zweimal fraktioniertem Destillat vom Siedep. $175-176^{\circ}$ bei $11 \mathrm{~mm}$ Druck $\left(\mathrm{d}_{4}^{0}=0,889 ; \mathrm{d}_{4}^{\mathbf{2 0}}=0,808\right)$ und zwar aus zwei Darstellungen ausgeführt worden.

I. $0,1921 \mathrm{~g}$ gaben $0,5357 \mathrm{CO}_{2}$ und $0,2195 \mathrm{H}_{2} \mathrm{O}$.

II. $0,1651 \mathrm{~g}, \quad 0,4647 \mathrm{CO}_{2}, 0,1888 \mathrm{H}_{2} \mathrm{O}$.

III. $0,1969 \mathrm{~g} " 0,5515 \mathrm{CO}_{2} \# 0,2294 \mathrm{H}_{2} \mathrm{O}$.

\begin{tabular}{ccccc} 
& Ber. für & \multicolumn{3}{c}{ Gef. } \\
& $\mathrm{C}_{20} \mathrm{H}_{40} \mathrm{O}_{2}$ & I & II & III \\
$\mathrm{C}$ & $\mathbf{7 6 , 8 4}$ & 76,05 & $\mathbf{7 6 , 5 9}$ & $\mathbf{7 6 , 3 9}$ \\
H & $\mathbf{1 2 , 9 1}$ & $\mathbf{1 2 , 7 7}$ & $\mathbf{1 2 , 7 9}$ & $\mathbf{1 3 , 0 3}$
\end{tabular}

Die Substanz, die in ihren Eigenschaften an die Methylketone erinnert, besitzt hiernach die gleiche $\mathrm{Zu}-$ sammensetzung wie Phytansäure. Sie ist ein Säureester and wird beim Stehen mit konzentrierter methylalkoholischer Kalilauge in der Kälte verseift. Wir extrahierten, ohne mit Wasser zu verdünnen, aus dem Verseifungsprodukt den alkoholischen Bestandteil mit Äther und verjagten das Lösungsmittel quantitativ im Vakuum, um das gebildete indifferente Öl ohne weitere Reinigung zn analysieren. Es entsprach genau der Formel $\mathrm{C}_{10} \mathrm{H}_{22} \mathrm{O}$. $0,1198 \mathrm{~g}$ gaben $0,3317 \mathrm{CO}_{2}$ und $0,1487 \mathrm{H}_{2} \mathrm{O}$.

$\begin{array}{ccr} & \text { Ber. für } \mathrm{C}_{10} \mathrm{H}_{28} \mathrm{O} & \text { Gef. } \\ \mathrm{C} & 75,86 & \mathbf{7 5 , 5 1} \\ \mathrm{H} & \mathbf{1 4 , 0 2} & 13,89\end{array}$

Aus der Zusammensetzung des Esters und dieses Alkohols ergibt sich, daß auch die saure Komponente 10 Kohlenstoffatome enthält. Dieses hat sich bei der Analyse des durch Ansäuern und Ausäthern nach der 
Verseifung isolierten sauren Öles mit genügender Annäherung bestätigt.

$0,1298 \mathrm{~g}$ gaben $0,3289 \mathrm{CO}_{2}$ und $0,1405 \mathrm{H}_{2} \mathrm{O}$.

$\begin{array}{ccc} & \text { Ber. für } \mathrm{C}_{10} \mathrm{H}_{20} \mathrm{O}_{2} & \text { Gef. } \\ \mathrm{C} & 9,70 & 6 ! 1,10 \\ \mathrm{H} & 11,71 & 12,11\end{array}$

Der Ester ist also wahrscheinlich aus der beschriebenen Säure $\mathrm{C}_{10} \mathrm{H}_{20} \mathrm{O}_{2}$ mit dem entsprechenden primären Alkohol zusammengesetzt.

Anhang: Zur fraktionierten Destillation im Vakuum.

Bei der Fraktionierung im Vakuum arbeiteten wir lange mit einer Kombination von Wurtz- und Claisen-

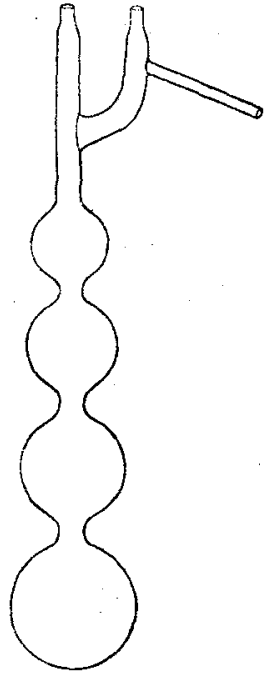

Fig. 1.

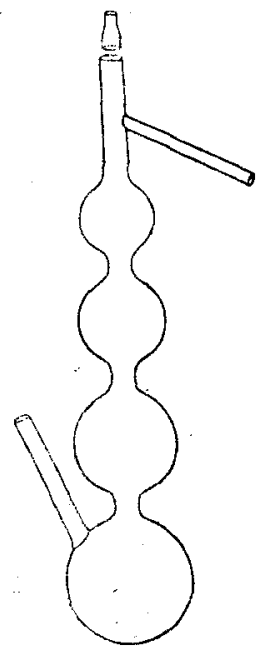

Fig. 2.

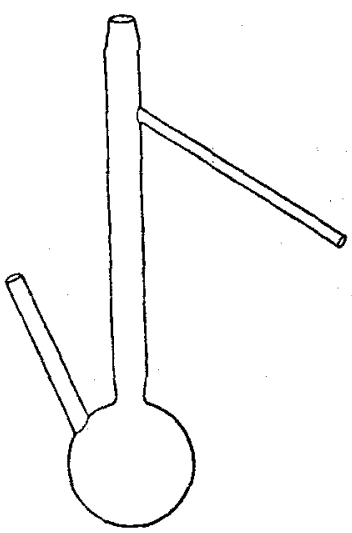

Fig. 3.

Kolben (Fig. 1), aber dann haben wir viel wirksamere Fraktionierkolben erprobt, welche die Besonderheiten des Wurtzschen Kugelaufsatzes und der Hempelschen Glasperlenkolonne vereinigen. Eine ähnliche Kombination hat bereits A. Michael ${ }^{1}$ ) empfohlen. Er verwendet

1) Ber. d. d. chem. Ges. 34, 4059 (1901). 
Wurtzsche Fraktionierkolben, anf deren Boden ein oben verjüngtes Glasrohr als Träger einer Hempelschen Säule steht. Die Kapillare wird in den Stopfen neben dem Thermometer eingesetzt und geht durch den Perlenaufsatz.

Wir ziehen eine abgeänderte Form von Destillationskolben vor (Fig. 2). Die Kapillare führen wir durch ein seitliches Ansatzrohr direkt in die unterste Kugel ein und ersetzen außerdem, um das Bespülen des Kautschuks zu verhïten, den Stopfen durch einen kleinen eingeschliffenen Helm. Die Perlen, oder besser die prismatischen Glasröhrchen schichten wir nicht auf eine Glasröhre als Unterlage, sondern wir machen noch von der Vorrichtung des Linnemannschen Aufsatzes Gebrauch and führen an die verjüngten Stellen, meistens zwei bis drei, je nach der Zahl der Kugeln, Netze von Platin-, Silberoder gewöhnlich Nickeldraht ein.

Wir finden diese Kolben namentlich für Substanzen geeignet, die nicht höher als etwa $170^{\circ} \mathrm{im}$ Vaknum sieden. Bei der Trennung von niedrig- und hochsiedenden Verbindungen unterbricht man zweckmäßig, sobald die letztere rein übergeht, die Destillation und spült den Rückstand in einen einfachen Kolben.

Ohne seitliches Einführungsrohr für die Kapillare verwenden wir die nämliche Fraktionierungsmethode für die Destillation unter gewöhnlichem Druck.

Die Anwendung der Kolben ist auf Substanzen beschränkt, die Überhitzen vertragen. Bei viseösen Stoffen staut sich die Flüssigkeit zuweilen in einer mittleren Kugel, so daß man das Erhitzen jeweils unterbrechen muß. Für solche Öle eignet sich ein Fraktionskolben mit Hempelscher Säule (Fig. 3); die Glasröhrchen liegen anf einem Netz, die Kapillare geht durch ein Ansatzrohr direkt in die Kugel.

Die Wirkung unserer Wurtz-Hempel-Kolben, die sehr leicht verstärkt oder vermindert werden kann, ist schon bei einmaliger Destillation ausgezeichnet, wie die folgenden Beispiele zeigen. 
1. Benzoesäureester (Siedep. $88,5-89,5^{\circ}$ unter $10 \mathrm{~mm}$ Druck) and Phthalsäureester (Siedep. $157^{\circ}$ unter $10 \mathrm{~mm}$ Druck) (Fig. 4).

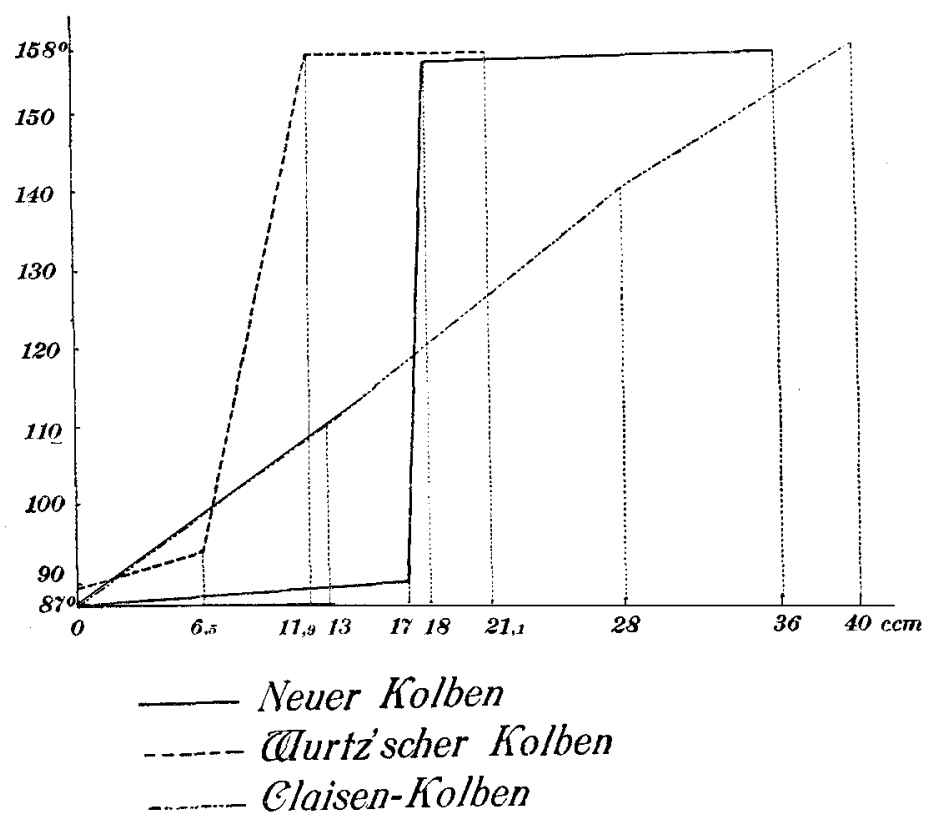

Fig. 4.

a) Claisen-Kolben (Ablaufrohr mittelhoch).

Je $20 \mathrm{ccm}$ Ester. Druck $11,5 \mathrm{~mm}$. Dauer 1 Stunde.

$\begin{array}{rrr}\text { Bad } 110-135^{\circ} & \text { Siedep. } 87-110^{\circ} & 13 \mathrm{ccm} \\ 135-160^{\circ} & 110-140^{\circ} & 15 " \\ 160-20^{\circ} & 140-158^{\circ} & 12 "\end{array}$

b) Wurtz-Kolben mit vier Kugeln.

Je $11 \mathrm{ccm}$ Ester. Druck $10 \mathrm{~mm}$. Dauer $1 \% / 4$ Stunden.
Bad $130-148^{\circ}$ Siedep. $89-94^{\circ} \quad 6,5 \mathrm{ccm}$

\begin{tabular}{|c|c|}
\hline $148-208^{\circ}$ & $94-157^{\circ}$ \\
\hline über $208^{\circ}$ & $157^{\circ}$ \\
\hline
\end{tabular}

c) Der neue Kolben, vier Kugeln mit Glasprismen.

Je $18 \mathrm{ccm}$ Ester. Druck $10 \mathrm{~mm}$. Dauer $2^{3 / 4}$ Stunden.

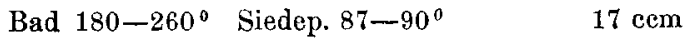

$$
\begin{aligned}
& 260-310^{\circ} \quad 90-156,5^{\circ} \quad 1 \text { " } \\
& 157^{\circ} \quad 18 "
\end{aligned}
$$

(Die letzte Fraktion ans gewöhnlichem Kolben) 
152 Willstätter, Mayer und Hüni, Uber Phytol.

2. Zimtsäureester (Siedep. $138,5^{\circ}$ unter $10 \mathrm{~mm}$ Drnck) und Phthalsäareester.

Der neue Kolben mit Glasprismen.

Je $20 \mathrm{~g}$ Ester. Druek $10 \mathrm{~mm}$. Dauer $2 \%$ Stunden.

\begin{tabular}{|c|}
\hline Siedep. $136-140^{\circ}$ \\
\hline $140-154^{0}$ \\
\hline über $154^{\circ}$ \\
\hline
\end{tabular}

3. Cetylalkohol (Siedep. $174-175^{\circ}$ unter $10 \mathrm{~mm}$ Druck) und Ölsäureester (Siedep. $191,5^{\circ}$ unter $10 \mathrm{~mm}$ Druck). Der neue Kolben, drei Kugeln mit Glasprismen.

Je $20 \mathrm{~g}$ Substanz. Druck $10 \mathrm{~mm}$. Dauer 3 Stunden.

Bad $220-240^{\circ}$ Siedep. $173-177^{\circ} \quad 14 \mathrm{~g}$

$\begin{array}{lll}240-260^{\circ} & 177-190^{\circ} & 15 \mathrm{~g} \\ 260-330^{\circ} & 190-192^{\circ} & 11 \mathrm{~g}\end{array}$

(Geschlossen den 11. Dezember 1910.) 